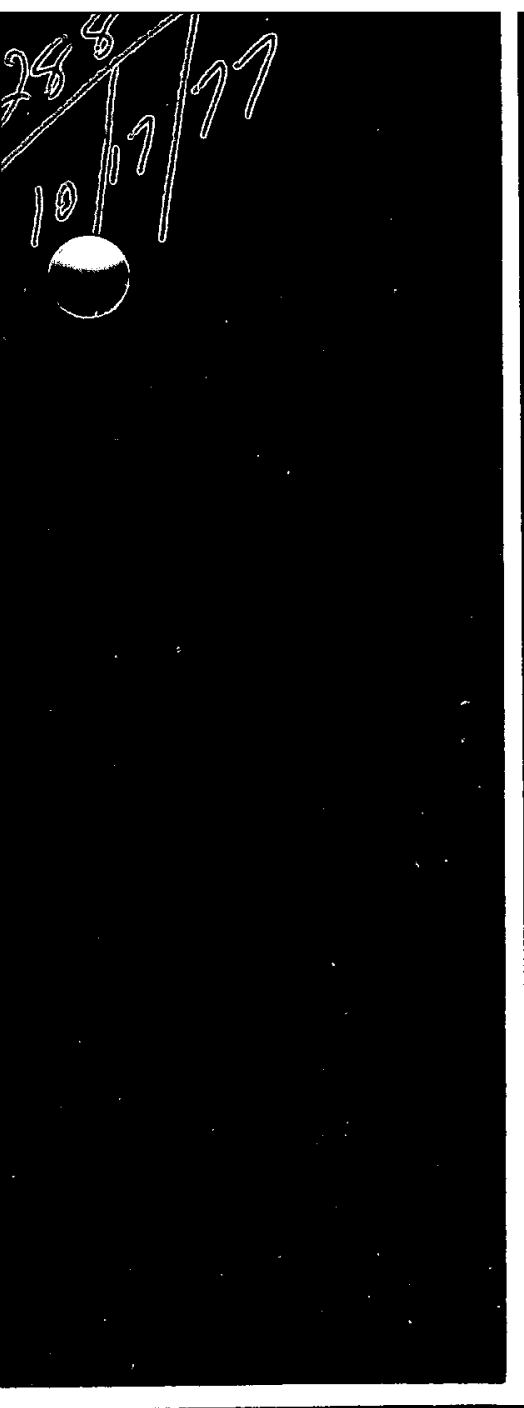

\title{
Storage and Release of Radiation Energy in Salt in Radioactive Waste Repositories
}
G. H. Jenks
C. D. Bopp

MASTER

\section{OAK RIDGE NATIONAL LABORATORY} OPERATED BY UNION CARBIDE CORPORATION FOR THE ENERGY RESEARCH AND DEVELOPMENT ADMINISTRATION 


\section{DISCLAIMER}

This report was prepared as an account of work sponsored by an agency of the United States Government. Neither the United States Government nor any agency Thereof, nor any of their employees, makes any warranty, express or implied, or assumes any legal liability or responsibility for the accuracy, completeness, or usefulness of any information, apparatus, product, or process disclosed, or represents that its use would not infringe privately owned rights. Reference herein to any specific commercial product, process, or service by trade name, trademark, manufacturer, or otherwise does not necessarily constitute or imply its endorsement, recommendation, or favoring by the United States Government or any agency thereof. The views and opinions of authors expressed herein do not necessarily state or reflect those of the United States Government or any agency thereof. 


\section{DISCLAIMER}

Portions of this document may be illegible in electronic image products. Images are produced from the best available original document. 


\begin{tabular}{c} 
Printed in the United States of America. Available from \\
National Technical Information Service \\
U.S. Department of Commerce \\
5285 Port Royal Road, Springfield, Virginia 22161 \\
Price: Printed Copy $\$ 5.50$, Microfiche $\$ 3.00$ \\
\hline
\end{tabular}

This report was prepared as an account of work sponsored by the United States Government. Neither the United States nor the Energy Research and Development Administration/United States Nuclear Regulatory Commission, nor any of their employees, nor any of their contractors, subcontractors, or their employees, makes any warranty, express or implied, or assumes any legal liabitity or responsibility for the accuracy, completeness or usefulness of any information, apparatus, product or process disclosed, or represents that its use would not infringe privately owned rights. 
ORNL-5058

Distribution Category UC-70

Contract No. W-7405-eng-26

CHEMICAL TECHNOLOGY DIVISION

STORAGE AND RELEASE OF RADIATION ENERGY

IN SALT IN RADIOACTIVE WASTE REPOSITORIES

G. H. Jenks and C. D. Bopp

Date Published: October 1977

This report was prepared as an account of work
sponsored by the United Sat

sponsored by the United States Government. Neither

Research and Development Administation, Energy

their employees, nor any of their, controstors

subcontractors, of their employees, makes any

warranty, express or implied, or assumes any legal

or usefulness of any information, apparatus, product or

infringe privately owned rights.

Oak Ridge National Laboratory

Oak Ridge, Tennessee 37830

operated by

UNION CARBIDE CORPORATION

for the

ENERGY RESEARCH AND DEVELOPMENT ADMINISTRATION 
$\ominus$

$\theta$ 
Abstract ....................... 1

1. Introduction ........................ 2

2. Anticipated Exposure Conditions of Salt in a Salt Mine Waste Repository ................. 3

3. Exposure Conditions Employed in Our Experimental Studies .... 4

4. Experimental .................. 6

4.1 Methods of Measuring Radiation Damage to Salt. . . . . . 6

4.2 Gamma Irradiations . . . . . . . . . . 7

5. Theoretical Aspects of the Formation and Accumulation of Stored Energy in Salt............... . . 7

6. Results of Our Irradiation Experiments and Correlation and Interpretation of These Results . . . . . . . . . . 11

6.1 Exposure Temperature Range $95-144^{\circ} \mathrm{C} . . . . . . . .11$

6.1.1. Stored energy vs dose in Harshaw salt irradiated at $126^{\circ} \mathrm{C}$ and 10 megarads/hr (drop calorimeter and $\mathrm{OCl}^{-}$ measurements) . . . . . . . . . .

6.1.2. Stored energy in Harshaw salt irradiated at $126^{\circ} \mathrm{C}$ and 1.6 megarads $/ \mathrm{hr}$........... . . 19

6.1.3. Stored energy vs dose in Harshaw salt irradiated at $95^{\circ} \mathrm{C}$ and 10 megarads/hr (drop calorimeter, heat of solution, $\mathrm{H}_{2}$, and $\mathrm{OCl}^{-}$measurements).....

6.1.4. Stored energy vs dose and dose rate in Lyons and Harshaw salt irradiated at $144^{\circ} \mathrm{C}$ and at 40 and 77 megarads/hr (drop calorimeter measurements). . .

6.1.5. Stored energy in Harshaw salt vs dose in HFIR- $\gamma$ exposures $7,8,9$, and $X$ at $130^{\circ} \mathrm{C}$ and at 51 to 74 megarads/hr (drop calorimeter measurements). . .

6.1.6. Stored energy in New Mexico and Lyons bedded salt vs dose in HFIR- $\gamma$ exposures $7,8,9$, and $X$ at $130^{\circ} \mathrm{C}$ and at 51 to 74 megarads/hr (drop calorimeter

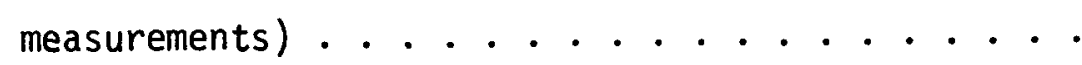


6.1.7. Stored energy in New Mexico bedded salt at $2.25 \times 10^{10}$ rads in HFIR- $\gamma$ exposures $11+12$ at $130^{\circ} \mathrm{C}$ and at 70 megarads (drop calorimeter measurements) . . . . . . . . . .

6.1.8. Comparisons between results of $\mathrm{H}_{2}$ evolution and drop calorimeter measurements on dome, bedded, and Harshaw salt irradiated at HFIR- $\gamma$ exposure 9 at $130^{\circ} \mathrm{C}, 51$ megarads $/ \mathrm{hr}$, and $9.8 \times 10^{9} \mathrm{rads} . . .22$

6.1.9. Stored energy in salt irradiated by gamma rays in situ in Project Salt Vault in the Lyons mine. .

6.2 Stored Energy in Harshaw Synthetic Crystals and in Lyons Bedded Salt After Gamma Irradiation at 10 Megarads/hr at 30 to $50^{\circ} \mathrm{C}$; Comparison with Results of Others for Salt Irradiated at Comparable Temperatures . . . . . . . . . .

6.3 Stored Energy in Harshaw and Lyons Salt Irradiated at 160 to $173^{\circ} \mathrm{C}$ and 1.6 to $66 \mathrm{Megarads} / \mathrm{hr}$ (Drop Calorimeter Measurements) . . . . . . . . . . . . . .

7. Results of Measurements of Postirradiation, Thermally Activated Annealing of Stored Energy . . . . . . . . . . . . . 29

8. Miscellaneous Observations ............... 31

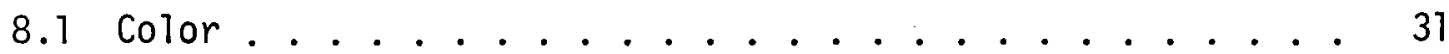

8.2 Chlorine Odor .................... 31

8.3 Cleaving. ..................... 32

8.4 The $\mathrm{pH}$ of Solutions of Irradiated, Unirradiated, and Annealed Salt............... 32

8.5 Loss of Water from Bedded Salt Specimens During Gamma Irradiation . . . . . . . . . . . . . . 34

8.6 Gases in Unirradiated and Irradiated Specimens of Bedded Salt ..................... 34

9. Summary and Discussion of Information on the Formation and Annealing of Stored Energy in Sodium Chloride . . . . . . . 35

9.1 Initial Rate of Formation of Stored Energy in $\mathrm{NaCl} \ldots 35$

9.2 Stabilization and Annealing of Stored Energy . . . . . . 36

10. Retention of Radiation Defects Within Sodium Chloride Crystals . 40

11. Comparisons Between Results of Our Experiments and Correlations to Those Reported Previously . . . . . . . . . . . . 
12. Predicted Amounts of Stored Energy in Salt in a Waste Repository

13. Conclusions Regarding Hazards Associated with the Storage of Radiation Energy in Salt in a Waste Repository . . . . . . . . . 44

14. Appendixes . . . . . . . . . . . . . . . . . . 49

14.1 Appendix I: Reference Concept for a High-Level Waste Repository in Salt. . . . . . . . . . . . . .

14.2 Appendix II: Temperatures in Salt Surrounding High-Leve1 Waste Packages. . . . . . . . . . . . . . 53

14.3 Appendix III: Gamma-Ray Dose Rates and Doses in Salt Around High-Level Waste Packages. . . . . . . . . . .

14.4 Appendix IV: Drop Calorimeter Measurements of Salt Specimens After Irradiation at $130^{\circ} \mathrm{C} ; \gamma$-Exposures 7 , $8,9, x$ and $11+12$............. 64

14.4.1 Equipment and procedure .......... . 64

14.4.2 Effects from the release of the occluded connate brine ................ 67

14.4.3 Surface-sorbed moisture . . . . . . . . . 67

14.4.4 Accuracy of measurements. . . . . . . . . . 68

14.5 Appendix $\mathrm{V}$ : Results of $\mathrm{H}_{2}$ and $\mathrm{OCl}^{-}$Measurements on Specimens of Harshaw Salt Irradiated at 95 and $126^{\circ} \mathrm{C} . .970$

14.6 Appendix VI: Hydrogen Evolution Measurements on Specimens of Harshaw and Natural Salt Irradiated at $130^{\circ} \mathrm{C} \mathrm{.} \mathrm{.} \mathrm{.} \mathrm{.} \mathrm{.} 73$

14.7 Appendix VII: Results of Measurements of Postirradiation Thermally Activated Annealing of Stored Energy. . . . . . 78

14.7.1 The effects of time at a given temperature on the amount of annealing - kinetic order of the annealing process.............

14.7.2 The effects of temperature on the amount of annealing - activation energy for the annealing

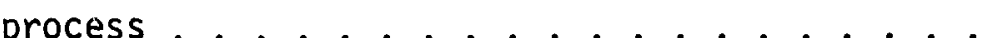

14.8 Appendix VIII: Loss of Water from Bedded Salt Specimens During Gamma Irradiation.

14.9 Appendix IX: Gases in Unirradiated and Irradiated Specimens of Bedded Salt. . . . . . . . . . . . .

14.10 Appendix X: Procedure for Estimating Mechanical Energy Released Upon the Abrupt Release of Stored Energy in Salt 91

References. . . . . . . . . . . . . . . . . . 95 


STORAGE AND RELEASE OF RADIATION ENERGY
IN SALT IN RADIOACTIVE WASTE REPOSITORIES

G. H. Jenks and C. D. Bopp

ABSTRACT

A variety of different geologic formations are being evaluated as possible sites for the permanent disposal of high-level radioactive wastes. One of the questions that can be raised regarding the suitability of a given geologic formation is whether the amount of stored gamma-radiation energy that would accumulate in rock immediately adjacent to the buried waste and the characteristics of the release of this stored energy could create excessive temperatures in the rock around the waste and/or could release mechanical energy in amounts capable of rupturing the surrounding rock. There may also be questions regarding the physical and chemical stability of the rock under irradiation. We have made experimental studies of the amounts of gamma-ray energy that are stored in salt under a variety of exposure conditions. We have also investigated the thermal annealing characteristics of the stored energy in salt, the chemical reactions that radiation defects in the salt undergo upon aqueous dissolution of the salt, and the retention of the radiation defects within the salt crystals. Our objective in this work was to obtain information which would enable us to predict the amounts and release characteristics of stored gamma-ray energy in the salt of a salt mine waste repository and thus provide a basis for determining whether any hazards would be associated with this type of energy storage. The results of this work, including portions which were reported previousiy, are reviewed and discussed in this report.

The results of our work showed that appreciable amounts of gammaradiation energy can be stored under certain exposure conditions. The results also showed that thermally activated annealing takes place at elevated temperatures and that the rates of this annealing at temperatures above about $150^{\circ} \mathrm{C}$ are such that negligible amounts of energy will be stored in salt in a repository where the salt is at temperatures above about $150^{\circ} \mathrm{C}$.

We are not able to show that thermally activated annealing takes place in rock salt at temperatures below about $150^{\circ} \mathrm{C}$, al though it may do so. There may also be some radiation-induced annealing. The results of our measurements of energy stored at irradiation temperatures between 30 and $150^{\circ} \mathrm{C}$, together with results of theoretical considerations, showed that the maximum stored energy that would be formed in salt in a repository with no annealing whatever would be about $50 \mathrm{cal} / \mathrm{g}$. We did not conceive a means by which the stored energy could be released abruptly, nor was any significant hazard believed to be possible from the release if it should occur abruptly by some unforeseen mechanism. In practice, salt temperatures below about $150^{\circ} \mathrm{C}$ will occur only with isolated or 
semi-isolated canisters in a repository, or with most canisters, after very long times during which the gamma-dose rate will have dropped off markedly.

Available evidence from thermal annealing observations and from calorimetric and dissolution measurements indicated that there were no significant losses of either chlorine or sodium during or after irradiation.

One effect of the stored energy which must be accounted for in a safety analysis is the generation of $\mathrm{H}_{2}$, which takes place upon aqueous dissolution of radiation-damaged salt; about $0.1 \mathrm{~cm}^{3}$ of $\mathrm{H}_{2}$ is generated per calorie of stored energy. However, we have not recognized any problems arising from this effect which cannot be counteracted by appropriate design and operation of the repository.

\section{INTRODUCTION}

A variety of different geologic formations are being evaluated as possible sites for the permanent disposal of high-level radioactive wastes. One of the questions that can be raised regarding the suitability of a given geologic formation is whether the amount of stored gamma-radiation energy that would accumulate in rock immediately adjacent to the buried waste and the characteristics of the release of this stored energy could create excessive temperatures in the rock around the waste and/or could release mechanical energy in amounts capable of rupturing the surrounding rock. There may also be questions regarding the physical and chemical stability of the rock under irradiation.

We have made experimental studies of the amounts of gamma-ray energy that are stored in salt under a variety of exposure conditions. We have also investigated the thermal annealing characteristics of the stored energy in salt, the chemical reactions that radiation defects in the salt undergo upon aqueous dissolution of the salt, and the retention of the radiation defects within the salt crystals. Our objective in this work was to obtain information which would enable us to predict the amounts and release characteristics of stored gamma-ray energy in the salt of a salt mine waste repository and thus provide a basis for determining whether any hazards would be associated with this type of energy storage. The results of this work and the predictions for a waste repository are reviewed and discussed in this report. Some portions of the reviewed work were reported previously. ${ }^{1,2}$ 
E. Sonder of the ORNL Solid State Division collaborated with us in some of the experimental work. S. Lindenbaum of the University of Kansas also collaborated in some of the work that will be mentioned.

\section{ANTICIPATED EXPOSURE CONDITIONS OF SALT IN A SALT MINE WASTE REPOSITORY*}

The disposal concept that will most likely be used with any future salt mine repository for high-level waste is one in which the solidified wastes are sealed within metal canisters, and the sealed canisters are lowered into vertical holes beneath the floors of rooms within a salt formation. The salt immediately adjacent to a waste canister will generally have a maximum temperature greater than $\sim 250^{\circ} \mathrm{C}$, and this will occur during the first 10 to 20 years following burial of 5- to 10-yearold wastes from $\mathrm{UO}_{2}$-fueled LWRs. The temperature at this location will then decrease to about $150^{\circ} \mathrm{C}$ after 70 to 80 years and to essentially normal geothermal temperatures after several hundred years. ${ }^{+}$Some canisters on the periphery of the repository will have salt temperatures lower than those in a more central location of the burial area because of their semi-isolation from the thermal effects of other packages within the repository. A rare canister may be isolated from the thermal effects of other packages and, accordingly, have still lower temperatures.

The gamma-ray dose of salt adjacent to a canister will depend on the specific fission product activity, the age of the waste within the canister, and the proximity of the salt to the surface of the canister. The maximum gamma-ray dose in salt at the canister surface will be

*Detailed information on the probable temperatures, doses, and dose rates of the salt adjacent to a waste canister is presented in Appendixes II and III. The reference concept for a salt mine high-level waste repository is described in Appendix I.

the salt around high-level wastes that contain larger amounts of actinides than those from $\mathrm{UO}_{2}$-fueled LWRs may cool at lower rates. However, detailed calculations are not available for the time-temperature characteristics in salt around high actinide wastes. 
$\sim 2.8 \times 10^{10}$ rads, $3.1 \times 10^{10}$ rads, and $4.3 \times 10^{10}$ rads after the burial of 5-year-01d waste for 100, 1000, and 10 million years, respectively. The maximum gamma dose rate at burial of the 5-year-aged waste will be 20.2 megarad/hr. The contribution of neutrons to the dose in the salt will be negligible.

\section{EXPOSURE CONDITIONS EMPLOYED IN OUR EXPERIMENTAL STUDIES}

The sample materials, gamma doses and dose rates, and exposure temperatures $<150^{\circ} \mathrm{C}$ which were investigated in our irradiation experiments are listed in Table 1. Other irradiation experiments, not 1isted, were conducted at exposure temperatures between 160 and $173^{\circ} \mathrm{C}$. Harshaw and Lyons bedded salt were studied in these higher-temperature experiments, and both the cobalt and HFIR- $\gamma$ radiation sources were employed. The Lyons salt was from the Carey mine at Lyons, Kansas (Empson-core No. 2, 90 in. below floor). The New Mexico bedded salt was from the Los Medaños area (AEC-core No. 7, primary, $2732 \mathrm{ft}$ ). The samples of dome salt were obtained from T. F. Lomenick. ${ }^{3}$

The thermal annealing characteristics of the stored energy in salt were investigated by subjecting portions of some of the irradiated specimens to high temperatures prior to measuring the stored energy.

The gamma doses employed in these experiments ranged up to amounts exceeding the actual maximum doses which will prevail in salt in a waste repository (Sect. 2). The dose rates were generally higher than those in the waste repository, and they were varied as much as possible so that evaluations of the effects of this parameter on the accumulation of stored energy could be made. Bedded and dome salt samples from a variety of sources were investigated in order to evaluate energy storage differences among salts from numerous sites.

The Hawshaw salt samples served as a reference material in these studies. The Harshaw synthetic crystals were composed of pure $\mathrm{NaCl}$, and the crystals were formed from the melt and cooled very slowly to avoid thermal stresses. Most of the previous experimental work of others on the radiation effects in salt has been done with synthetic crystals of 
Table 1. Salt samples, radiation exposure conditions, and methods of stored energy measurement in experimental studies employing salt temperatures less than $150^{\circ} \mathrm{C}$ during irradiation

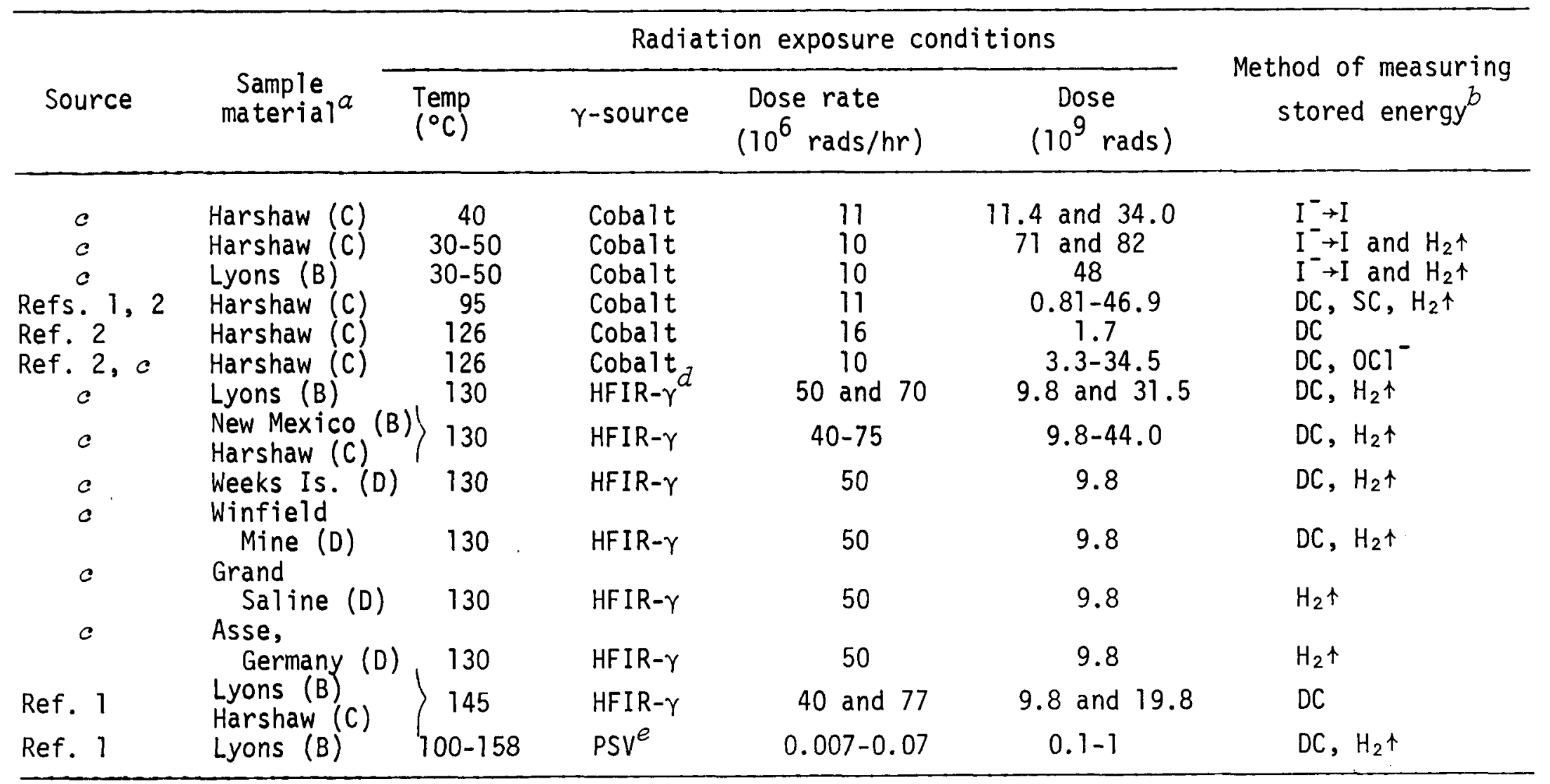

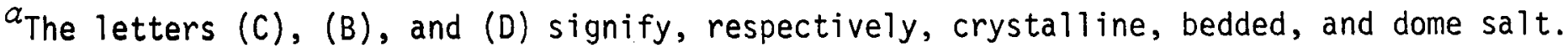

$b_{D C}$ and SC signify drop calorimeter and heat of solution calorimeter, respectively.

Work reported for the first time in this paper.

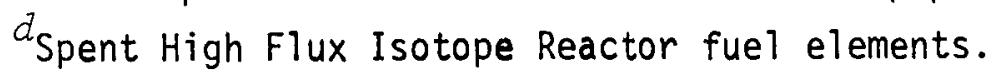

eproject Salt Vault. 
pure salt. An added incentive for the inclusion of the Harshaw salt in our studies was the fact that the drop calorimeter measurements of the stored radiation energy were less troublesome and more reliable with the Hawshaw salt than they were with the rock salts.

\section{EXPERIMENTAL}

\subsection{Methods of Measuring Radiation Damage to Salt}

Several methods of measuring the concentration of defects, or stored energy, in irradiated crystals were used: (1) a calorimetric method in which a Roux-type, reverse-drop calorimeter was employed to measure the heat released upon thermal annealing of the stored energy (ref. 1 and Appendix IV); (2) a calorimetric method that measured the difference between the heats of solution of irradiated and unirradiated salt; ${ }^{2}, *(3)$ a chemical method in which measurements were made, using a mass spectrometer, of the amount of $\mathrm{H}_{2}$ formed upon the aqueous dissolution of an irradiated sample; ${ }^{2}, \dagger(4)$ a method analogous to No. 3 that used a different method for collecting the $\mathrm{H}_{2}$ and measuring the volume; ${ }^{\S}$ (5) a chemical method in which measurements were made, with an absorption spectrophotometer, of the amount of $\mathrm{OCl}^{-}$formed upon the aqueous dissolution of an irradiated sample; ${ }^{2}, \pi$ and (6) a chemical method that measured the amount of $\mathrm{I}^{-}$oxidation that took place upon the dissolution of a sample in an aqueous solution containing $\mathrm{I}^{-}$."

* Heat of solution measurements were made by $S$. Lindenbaum of the University of Kansas, Lawrence, Kansas.

These measurements were made by J. R. Walton, ORNL Analytical Chemistry Division.

${ }^{\mathrm{H}_{2}}$ measurements made in ORNL Analytical Chemistry Division by dissolving $20.15 \mathrm{~g}$ of sample in $1 \mathrm{ml}$ of boiled water in a 16-ml, rubber stopper vial, collecting an aliquot of the gas using a syringe and needle, and then measuring the amount of $\mathrm{H}_{2}$ in the aliquot using gas chromptography with an argon carrier gas.

"These measurements were made by $E$. Sonder of the ORNL Solid State Division.

\#Oxidation measurement made in ORNL Analytical Chemistry Division by dissolving $20.10 \mathrm{~g}$ of sample in $3 \mathrm{ml}$ of solution $(0.1 \mathrm{~N} \mathrm{HCl}, \sim 0.2 \mathrm{~N} \mathrm{KI})$ and titrating with $0.1 \mathrm{~N} \mathrm{~S}_{2} \mathrm{O}_{3}{ }^{2}$ to the starch endpoint. 
The drop calorimeter method (No. 1) was the standard method, and most of the samples were analyzed by this method. Methods 1, 2, 3, and 5 were employed with sets of samples irradiated at 95 and $126^{\circ} \mathrm{C}$ (Table 1) as part of a study ${ }^{2}$ aimed at explaining the observed difference of a factor of $\sim 2$ between the amounts of heat released by heating and by dissolving irradiated salt. This difference was explained quantitatively in terms of the formation of $\mathrm{H}_{2}$ and $\mathrm{HOCl}+\mathrm{OCl}^{-}$, and possibly $\mathrm{H}_{2} \mathrm{O}_{2}$, in addition to $\mathrm{Na}^{+}$and $\mathrm{Cl}^{-}$during dissolution. ${ }^{2}$ This study confirmed our correct interpretation of the results of the drop calorimeter measurements. It also provided a basis for interpreting the results of chemical measurements in terms of stored energy.

The results of measurements made by methods 4 and 6 were less reliable than those obtained by the other methods (Appendix VI). However, the results of $\mathrm{H}_{2}$-evolution measurements by method 4 were useful for determining the relative amounts of stored energy among the sample sets exposed to about $10^{10}$ rads at $130^{\circ} \mathrm{C}$. Also, methods 4 and 6 were the only methods that were conveniently available for measuring the several samples that were irradiated at temperatures in the range of 30 to $50^{\circ} \mathrm{C}$.

\subsection{Gamma Irradiations}

Gamma-ray irradiations were made using either a cobalt source or a HFIR spent fuel element. The equipment, methods, and procedures for conducting the irradiations were described previously. ${ }^{1}$,*

\section{THEORETICAL ASPECTS OF THE FORMATION AND ACCUMULATION OF STORED ENERGY IN SALT}

Charged energetic particles bring about changes, or damage, in an insulating crystal by several different processes, including the displacement of atoms from their normal lattice positions. In most

${ }^{*}$ All cobalt source irradiations were conducted by $E$. Sonder of the ORNL Solid State Division. 
materials, this displacement of atoms results primarily from the transfer of energy between nuclear particles and atoms by elastic collisions between the particles and the atoms. ${ }^{4}, 5$ For example, a collision between a particle and an atom in the structure in Fig. 1 might transfer a sufficient amount of energy to move the atom into an interstitial position.

The amount of energy transfer required for this displacement depends somewhat on the irradiated material. Generally, the energy is believed to be in the range 25 to $50 \mathrm{eV} .{ }^{4}$ The amount of energy which can be transferred from an energetic particle to an atom depends upon the relative masses of the particle and the atom and upon the energy of the particle. Gamma rays of the maximum energies and maximum doses that would be present in a repository would cause very few elastic-collision displacements.

A different process of displacement takes place in sodium chloride and in other alkali halides. ${ }^{4,5}$ In these materials, the displacement of an anion results from the radiationless recombination of an electron and an electron vacancy on an anion in the lattice. An electron vacancy or hole on the chlorine is produced when the electron is excited into the conduction band through the electronic interaction between a charged nuclear particle and the bound electron on the chlorine. The chlorine species within the lattice that is produced in this process moves closer to and becomes bound with an adjacent chloride ion to form what is called a self-trapped hole $\left(\mathrm{Cl}_{2}{ }^{-}\right) *$ (Fig. 1). A subsequent radiationless recombination of an electron and the hole causes the chlorines in the $\mathrm{Cl}_{2}{ }^{-}$center to move apart and also releases energy to the center. These effects cause the initiation and propagation of a replacement chain in the chlorine ions along a closed-packed (110) direction and form an interstitial chlorine atom and an $\mathrm{F}$ center ${ }^{\dagger}$ as the immediate products.

Since the electron-hole pairs are formed by the ionizing action of the radiations, all types of radiations, including gamma rays, cause

${ }^{*} A$ self-trapped hole may also be called a $V_{K}$ center. ${ }^{4,5}$

${ }^{\dagger} \mathrm{F}$ center is an anion vacancy containing a trapped electron. 
ORNL DWG 75-5169R1

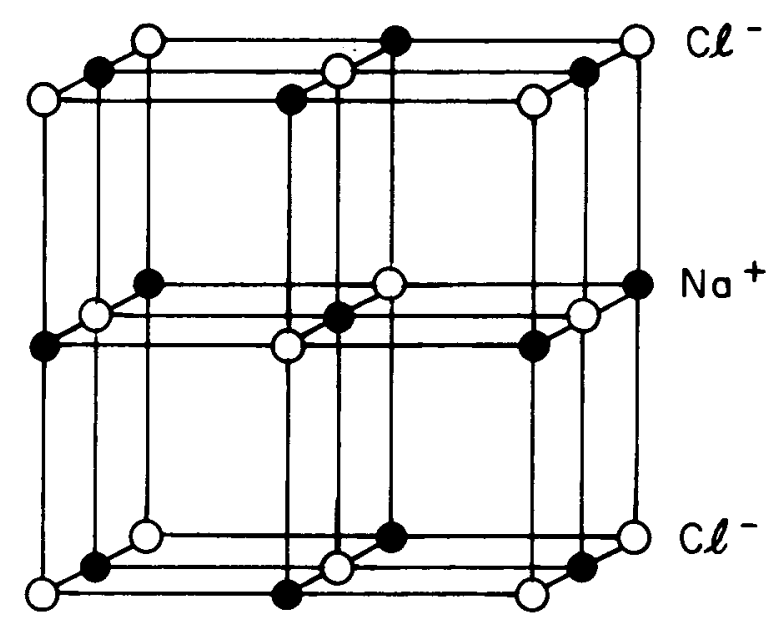

NaCI STRUCTURE

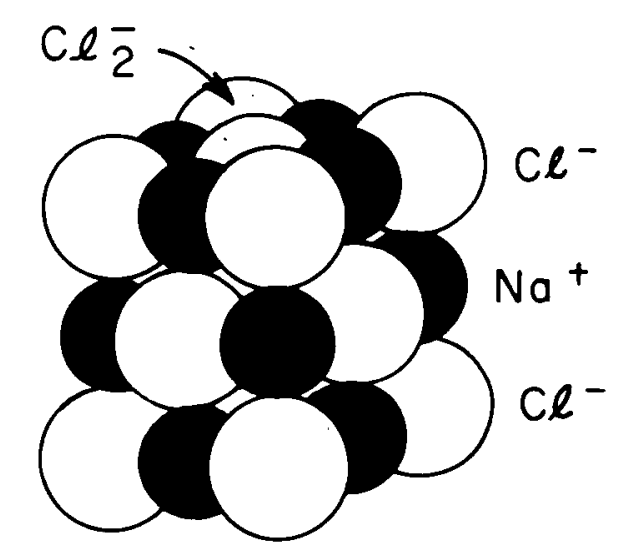

ATOMIC MODEL

OF NOCI STRUCTURE

Fig. 1. Models of the sodium chloride structure. 
the displacement of anions in alkali halides. Gamma rays are included since these radiations interact with matter by processes that produce energetic electrons, that is, by Compton scattering of electrons, by the formation of photoelectrons, and by the formation of positron-electron pairs.

The above discussion applies to the mechanism for the primary process of defect production. The net rate of formation and the accumulation of defects in the salt depends upon the recombination and the stabilization reactions of the defects.

The interstitial atoms are mobile at room temperature, and they rapidly aggregate into clusters. ${ }^{4,6}$ This clustering apparently stabilizes the interstitials against back reactions with the $F$ centers. Presumably, this clustering occurs also at higher temperatures.

The $F$ center is not mobile at room temperature, ${ }^{5}$ but the vacancy without the trapped electron is mobile. ${ }^{4,5}$ Aggregates of two or more $F$ centers are formed under certain conditions, and the required vacancy motion is ascribed to the charged vacancies. Under some conditions, colloidal sodium is formed from the coalescence of $F$ centers. This formation of colloidal sodium is enhanced by raising the temperature above room temperature ${ }^{7,8}$ and by extending the time available for diffusion of vacancies into aggregates. ${ }^{9}$ The formation of colloidal aggregates of sodium apparently confers additional stability to radiation defects in sodium chloride. ${ }^{8}$

Exposure variables that are known to affect the net rate of formation and/or the numbers of accumulated $F$ centers during the late stages* of the irradiation of a salt specimen include: temperature, irradiation intensity (dose rate), divalent cation impurities, and plastic strain. ${ }^{5}$

*An early stage coloration occurs in which a relatively rapid accumulation of $F$ centers takes place. Saturation of this stage occurs at about $10^{17}$ centers $/ \mathrm{cm}^{3}$, corresponding to about $0.008 \mathrm{cal} / \mathrm{g}$ at 5 $\mathrm{eV} /$ center. This stage is thought to result from the conversion of other defects, already present, into $F$ centers. The amount of early stage coloration in $\mathrm{NaCl}$ is affected by several factors including temperature, impurities in the salt, and prior plastic strain in the salt. ${ }^{5}$ 
The effects of these variables have been qualitatively explained in terms of their effects on the stabilization reactions, that is, upon the mobility, trapping, and clustering of defects. ${ }^{5}$ However, some of these variables also affect the initial rate of defect production by altering the fraction of electron-hole pairs that recombine at impurity sites and lose recombination energy with no defect production.

\section{RESULTS OF OUR IRRADIATION EXPERIMENTS AND CORRELATION AND INTERPRETATION OF THESE RESULTS}

We found that significant amounts of energy were stored in the salt under most of the exposure conditions which we tested and that the amount which accumulated depended primarily upon the temperature, the gamma-ray dose, and whether the sample was Harshaw or natural rock salt. At exposure temperatures $\geq 160^{\circ} \mathrm{C}$, the amount accumulated at a given dose also depended strongly upon the gamma-ray dose rate.

The results for the three ranges of exposure temperatures 30 to 50 , 95 to 144 , and 160 to $173^{\circ} \mathrm{C}$ are presented in separate sections.

\subsection{Exposure Temperature Range $95-144^{\circ} \mathrm{C}$}

Many of the experimental data for stored energy (E) vs dose (D) in this temperature range could be correlated using the rate equation,

$$
d E / d t=K_{1} I-K_{2} I E,
$$

and its integral,

$$
E=\frac{K_{1}}{K_{2}}\left(1-\exp -K_{2} D\right)+E_{0} \exp -K_{2} D,
$$

where $I$ is the dose rate and is invariant with time, $E_{0}$ is the stored energy at zero time, and $K_{1}$ and $K_{2}$ are formation and annealing constants, respectively, for a given set of exposure conditions. Curves are drawn through the stored energy vs dose data in Figs. 2 through 6, using Eq. (2). An explanation of each of these curves follows in Sects. 6.1.1 
through 6.1.6. The value of $K_{1}$ is $1.4 \times 10^{-9} \mathrm{cal} \mathrm{g}^{-1} \mathrm{rad}^{-1}$ for each of these curves. The value of $K_{2}$ increases with increasing temperatures and, at a given temperature, is higher for Harshaw than for natural rock salt. The stored energy values obtained for the high dose specimens in the radiation exposures at 126 and $130^{\circ} \mathrm{C}$ (Figs. 2, 5, and 6) deviate from those predicted by extrapolation from the curves using the lower dose values, and it appears that some change in the rate of formation or annealing of the stored energy took place when the stored energy exceeded about $20 \mathrm{cal} / \mathrm{g}$. The results of the data correlations in this temperature range are summarized in Table 2.

The general form of the rate expression, Eq. (1), is semi-theoretical. The formation term, $K_{1} I$, can be explained on the basis of the defectformation mechanism described in Sect. 5. The form of the annealing term can be explained by assuming that: (1) a fraction of the freshly formed defects reacts during formation with defects of opposite sign already present to reform sodium chloride in the lattice and (2) the value of this fraction is directly proportional to the number of defects already present. ${ }^{1}$

6.1.1. Stored energy vs dose in Harshaw salt irradiated at $126^{\circ} \mathrm{C}$ and 10 megarads/hr (drop calorimeter and $\mathrm{OCl}^{-}$measurements) Stored energy data obtained with Harshaw synthetic crystals of pure $\mathrm{NaCl}$ that were irradiated in a cobalt source are plotted vs dose in Fig. 2. The circles show the stored energy measured with the drop calorimeter. The triangles represent the results of measurements of the amount of $\mathrm{OCl}^{-}$ formed upon the aqueous dissolution of a specimen and a subsequent increase in the $\mathrm{pH}$ of the solution (method 5). The stored energy corresponding to the amount of $\mathrm{OCl}^{-}$was calculated by assuming that (1) all of the trapped hole defects react to form $\mathrm{HOCl}+\mathrm{OCl}^{-}$upon dissolution according to the reaction shown in Fig. 2 and that (2) the energy associated with a trapped electron-trapped hole defect pair within the irradiated crystal is equal to $4.25 \mathrm{eV}$.*

*We previously reported ${ }^{2}$ that the experimental data indicated a value of $4.6 \mathrm{eV}$ for this quantity. The plotted points in Fig. 2 show that a better correlation between $\mathrm{OCl}^{-}$and drop calorimeter data results when the lower value is used. 


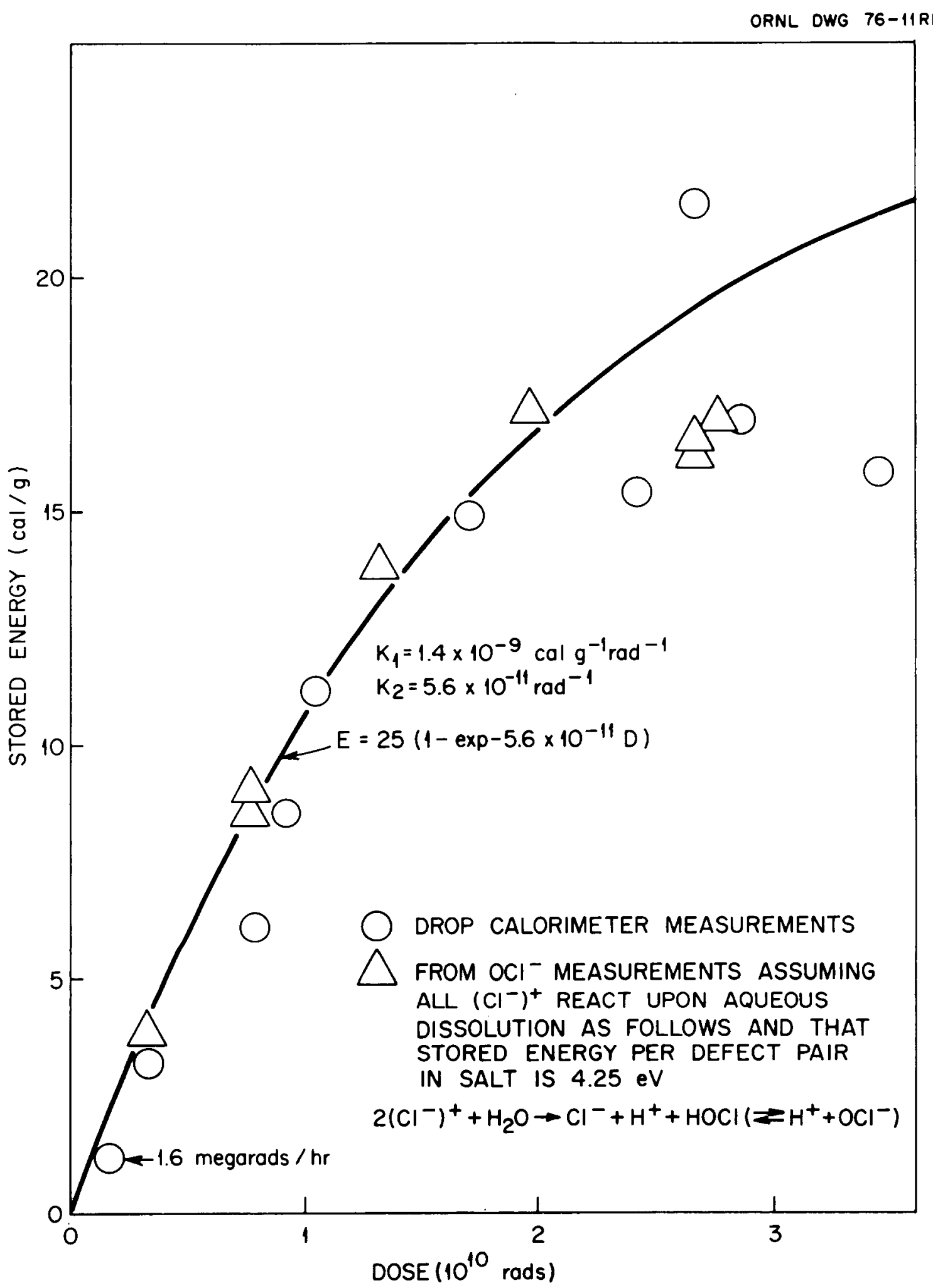

Fig. 2. Stored energy vs dose in Harshaw salt irradiated in a cobalt source at $126^{\circ} \mathrm{C}$ and 10 megarads/hr (drop calorimeter and $\mathrm{OCl}^{-}$measurements). 
ORNL DWG. 75-5170R2

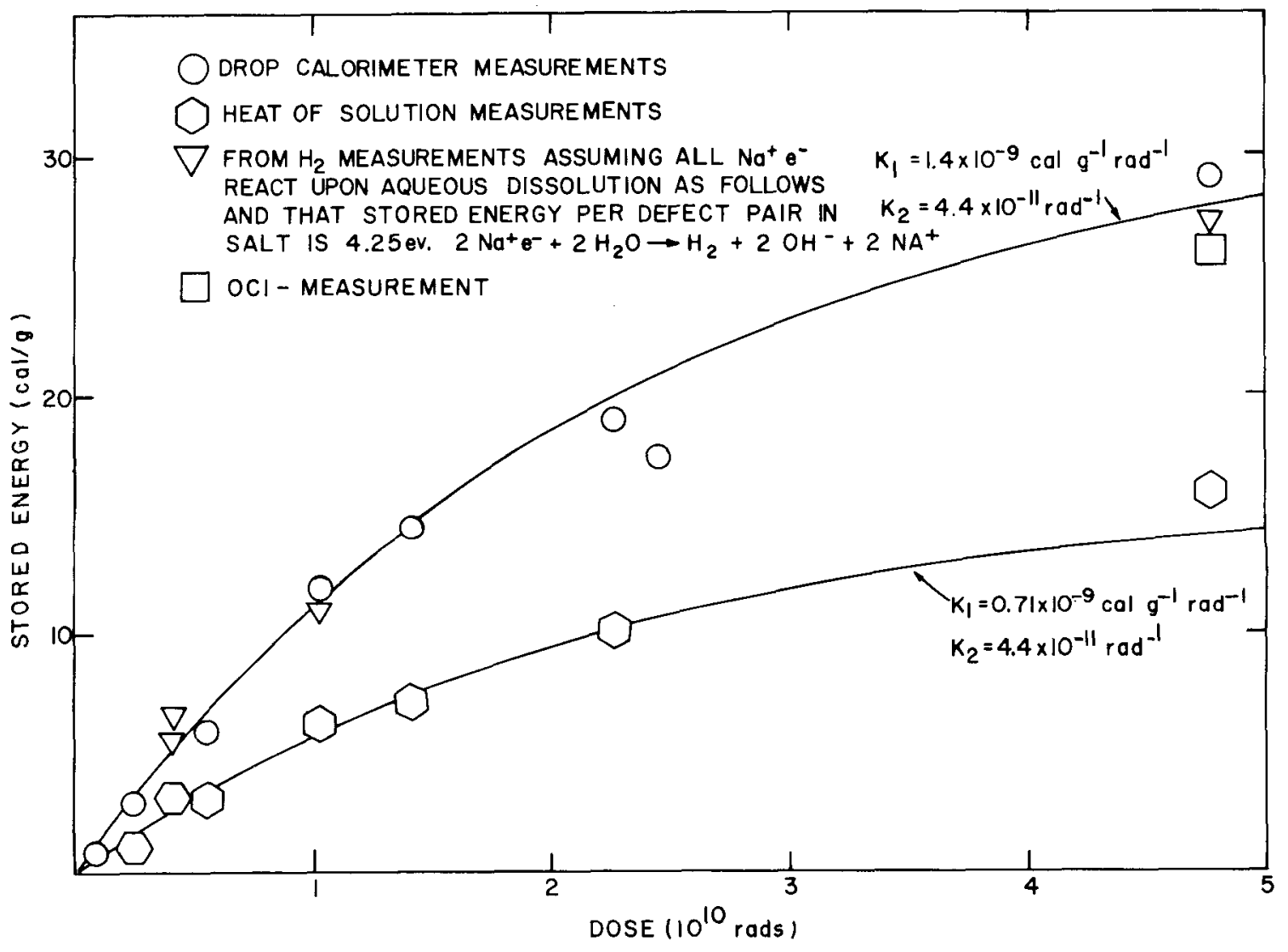

Fig. 3. Stored energy vs dose in Harshaw salt irradiated at $95^{\circ} \mathrm{C}$ and 10 megarads/hr (drop calorimeter, heat of solution, $\mathrm{H}_{2}$ and $\mathrm{OCl}^{-}$measurements). 


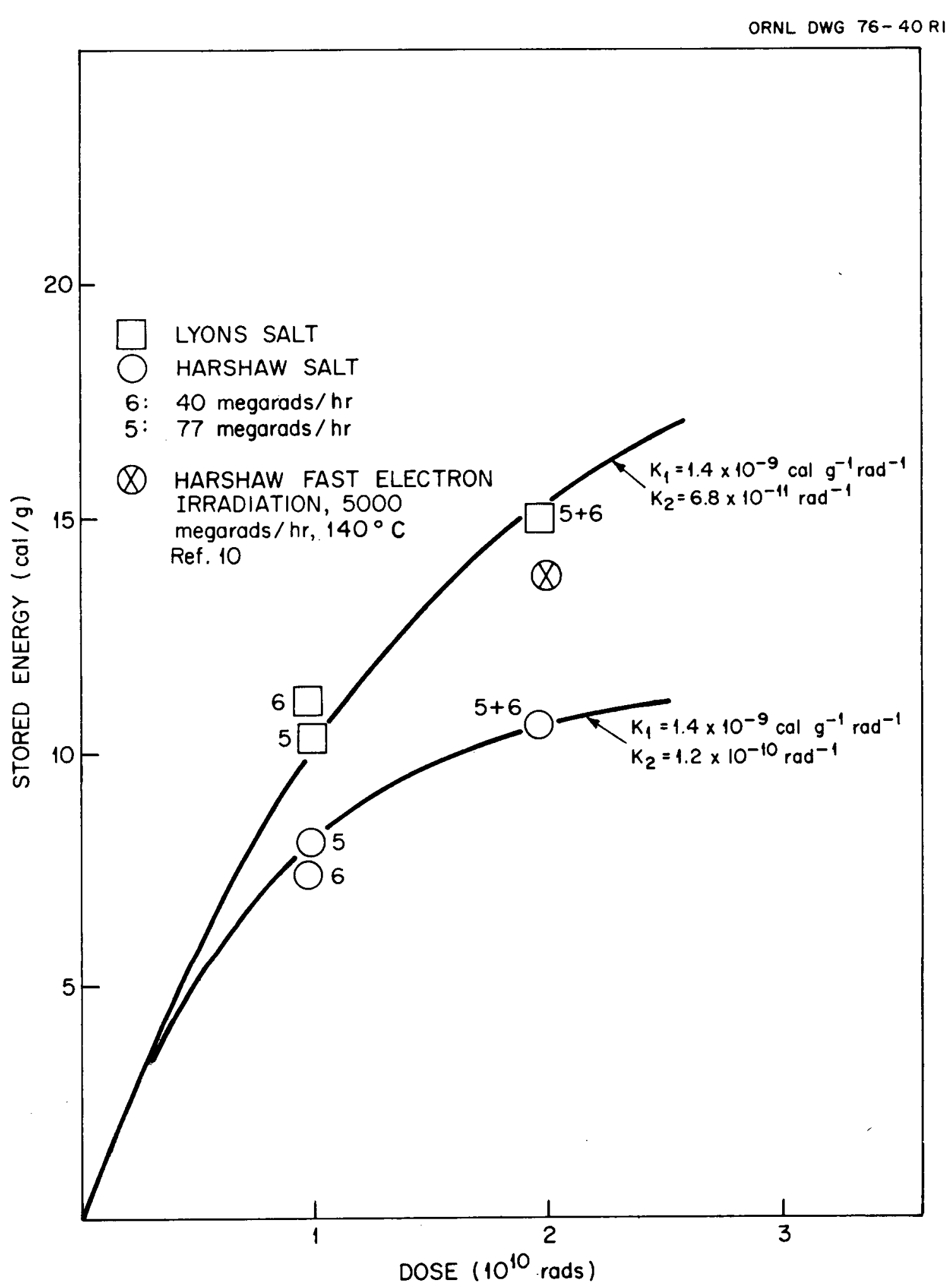

Fig. 4. Stored energy vs dose and dose rate in Lyons and Harshaw salt irradiated at $144^{\circ} \mathrm{C}$ and at 40 and 77 megarads/hr (drop calorimeter measurements). 


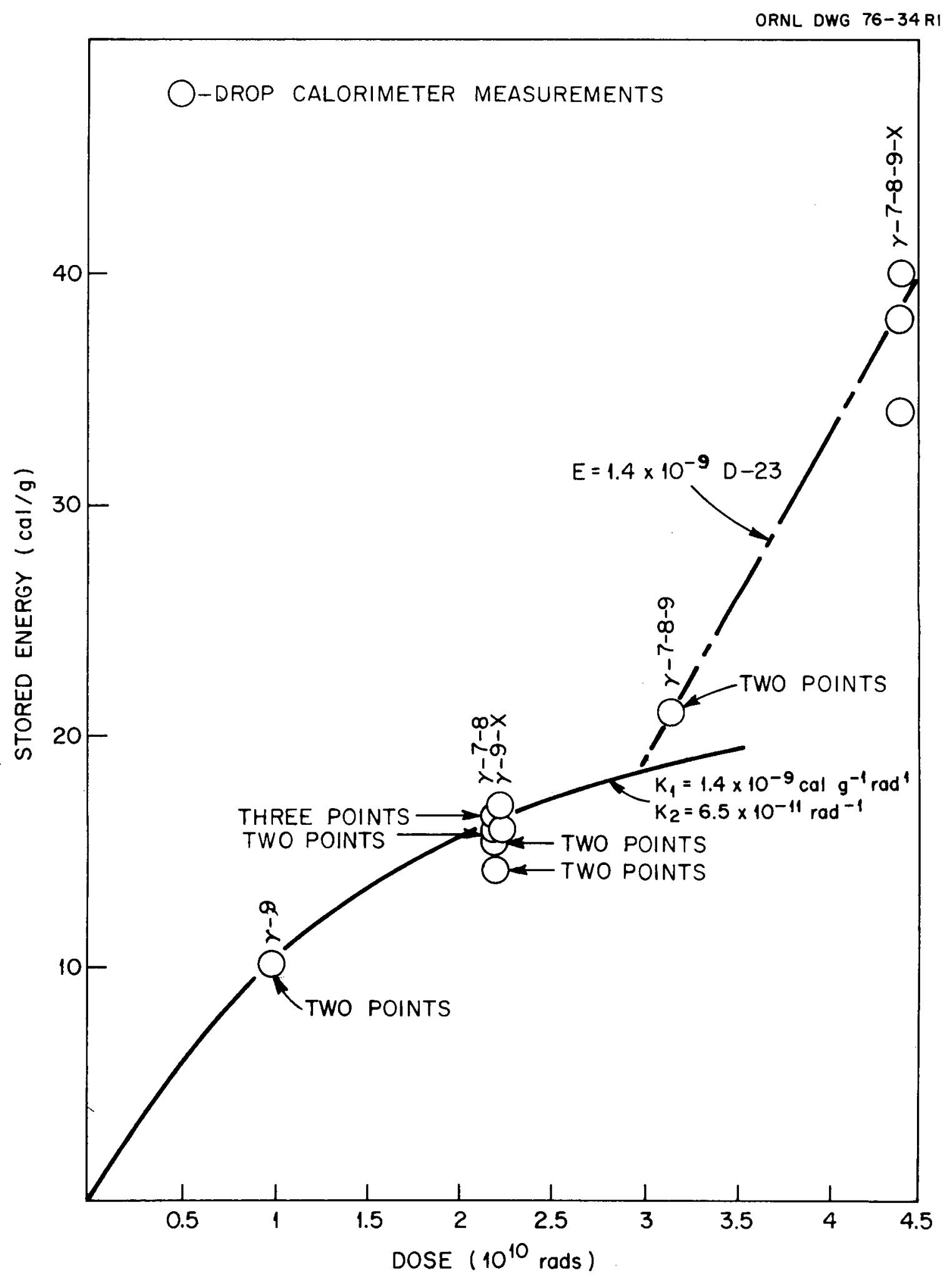

Fig. 5. Stored energy in Harshaw salt vs dose in HFIR- $\gamma$ exposures 7, 8, 9, and $X$ at $130^{\circ} \mathrm{C}$ and at 51 to 74 megarads/hr (drop calorimeter measurements). 
ORNL DWG $76-44$ RI

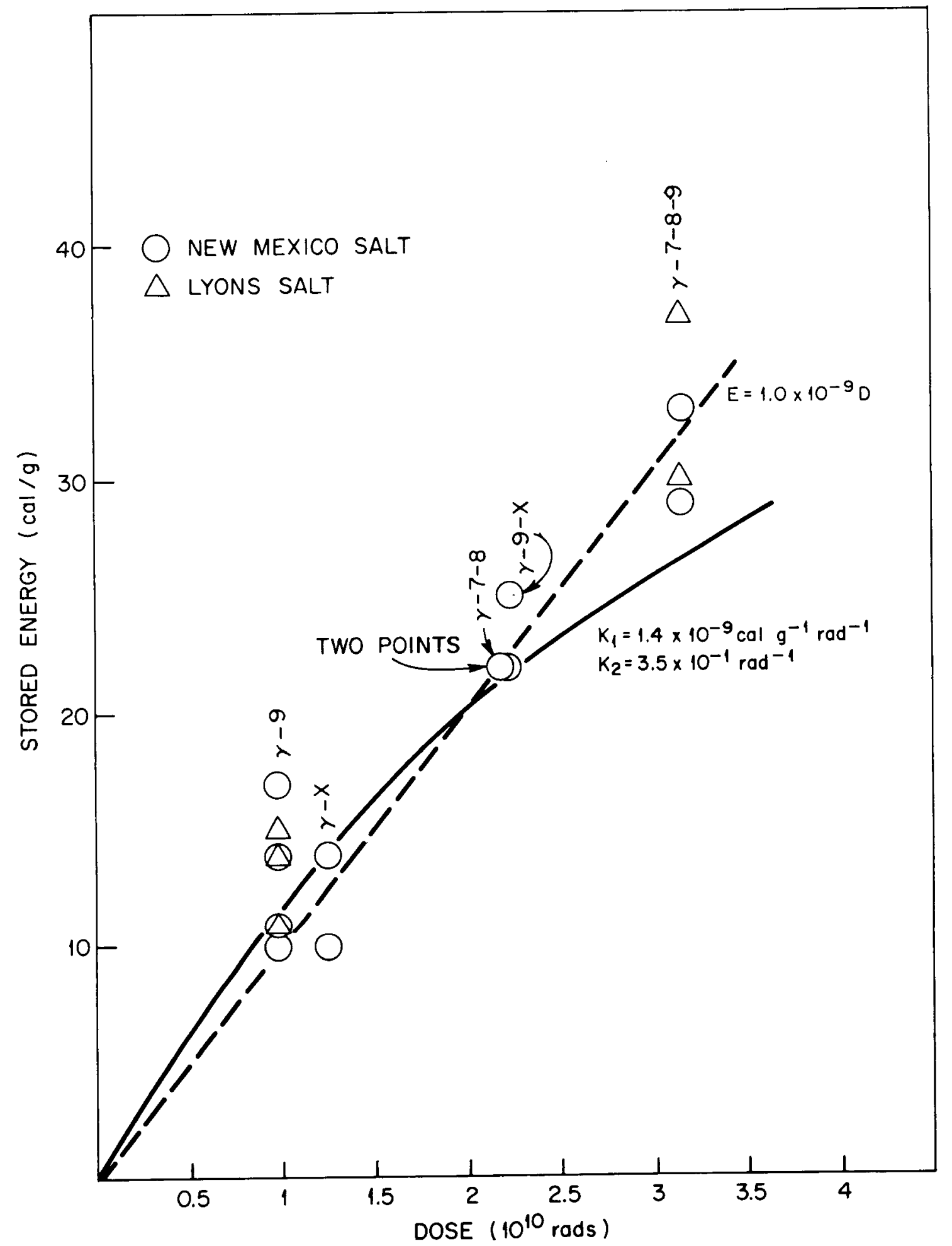

Fig. 6. Stored energy in New Mexico and Lyons bedded salt vs dose in HFIR- $\gamma$ exposures $7,8,9$, and $X$ at $130^{\circ} \mathrm{C}$ and at 51 to 74 megarads/hr (drop calorimeter measurements). 
Table 2. Results of correlations of experimental stored-energy data for values of $E$ less than about $20 \mathrm{cal} / \mathrm{g}^{a}$

\begin{tabular}{|c|c|c|c|}
\hline Salt & $\begin{array}{l}\text { Temperature during } \\
\text { irradiation } \\
\left({ }^{\circ} \mathrm{C}\right)\end{array}$ & $\begin{array}{c}\mathrm{K}_{2} \\
\left(10^{-11} \mathrm{rad}^{-1}\right)\end{array}$ & $\begin{array}{l}K_{1} / K_{2} \\
(\text { cal } / g)\end{array}$ \\
\hline \multirow[t]{6}{*}{ Harshaw } & 95 & 4.4 & 31.8 \\
\hline & 126 & 5.6 & 25.0 \\
\hline & 130 & 6.5 & 21.5 \\
\hline & 144 & 12.0 & 11.7 \\
\hline & $30-55^{b}$ & 70 & \\
\hline & & $(F=0.021)$ & \\
\hline \multirow[t]{3}{*}{ Bedded } & 130 & 3.5 & 40.0 \\
\hline & 144 & 6.8 & 20.6 \\
\hline & $115-155(P S V)^{C}$ & & \\
\hline Dome & 130 & & \\
\hline All Salts & $\geq 150$ & \multicolumn{2}{|c|}{$\begin{array}{l}\text { Negligible stored energy when } \\
\mathrm{I} \leq 10^{5} \mathrm{rads} / \mathrm{hr}\end{array}$} \\
\hline
\end{tabular}

${ }^{a}$ Correlation equation and its integral:

$$
\begin{aligned}
& d D / d t=K_{1} I-K_{2} I E, \\
& E=\frac{K_{1}}{K_{2}}\left(1-\exp -K_{2} D\right) .
\end{aligned}
$$

$b_{A}$ modified correlation equation applies to these data (see Sect. 6.2 and Eqs. 4 to 6).

${ }^{C}$ Project Salt Vault. 
It can be noted that the $4.25 \mathrm{eV}$ per defect pair is the same as the value for the heat of formation of crystalline sodium chloride from the elements. The energy per defect pair cannot be appreciably higher than this since we have assumed that all of the pairs form $\mathrm{HOCl}$ and $\mathrm{OCl}^{-}$upon dissolution.* The energy per pair could be less than this value if it is assumed that the fraction of defect pairs which form $\mathrm{HOCl}+\mathrm{OCl}^{-}$is $<1$ and that this fraction is the same for all of these specimens. Additional information on this point in Sect. 6.1.3 and in Fig. 3 supports the idea that all of the defect pairs form $\mathrm{HOCl}+\mathrm{OCl}^{-}$upon dissolution of the salt under the dissolution conditions employed (Appendix V).

6.1.2. Stored energy in Harshaw salt irradiated at $126^{\circ} \mathrm{C}$ and 1.6 megarads/hr The drop calorimeter result obtained with the one sample that was irradiated under these conditions is included in the plot in Fig. 2. There was no difference between this result and the result expected at the higher dose rate of 10 megarads $/ \mathrm{hr}$. This indicates that the value of $K_{1}$ is independent of the dose rate in this range of dose rates.

6.1.3. Stored energy vs dose in Harshaw salt irradiated at $95^{\circ} \mathrm{C}$ and 10 megarads $/ \mathrm{hr}$ (drop calorimeter, heat of solution, $\mathrm{H}_{2}$, and $\mathrm{OCl}^{-}$measurements) The results of several types of measurements on Harshaw salt irradiated at about 10 megarads $/ \mathrm{hr}$ and at $95^{\circ} \mathrm{C}$ are shown in Fig. 3. The circled points along the upper curve represent drop calorimeter data, and the triangles represent the results of hydrogen evolution measurements by Method 3 (see page 4). An $\mathrm{OCl}^{-}$measurement on a portion of the highest dose specimen is represented by the square. The results of the heat of solution measurements are shown by the hexagons along the bottom curve.

The stored energies corresponding to the amount of evolved $\mathrm{H}_{2}$ were calculated assuming that all of the trapped electron defects react upon dissolution to form $\mathrm{H}_{2}$, as shown in Fig. 3 , and that the stored energy per defect pair is $4.25 \mathrm{eV}$. These assumptions are analogous to those made for the $\mathrm{OCl}^{-}$measurement shown here and for those described above

*We previously reported ${ }^{2}$ that the experimental data indicated a value of $4.6 \mathrm{eV}$ for this quantity. The plotted points in Fig. 2 show that a better correlation between $\mathrm{OCl}^{-}$and drop calorimeter data results when the lower value is used. 
in Sect. 6.1.1 and Fig. 2. The difference of $49 \%$ between the results of the drop calorimeter and the heat of solution measurements are quantitatively explained by the same assumptions, that is, by assuming that (1) all of the radiation defect pairs form $\mathrm{H}_{2}$ and $\mathrm{HOCl}+\mathrm{OCl}^{-}$in addition to $\mathrm{Na}^{+}$and $\mathrm{Cl}^{-}$upon dissolution of the sample under the conditions present in the heat-of-solution calorimeter and that (2) the stored energy in the salt per defect pair is $4.25 \mathrm{eV}^{2}$

As stated above, these results, together with those described in Sect. 6.1.1, supported our belief that the results of our drop calorimeter measurements were interpreted correcty. They also provided a basis for the interpretation, in terms of stored energy, of the results of the chemical measurements. ${ }^{2}$

6.1.4. Stored energy vs dose and dose rate in Lyons and Harshaw salt irradiated at $144^{\circ} \mathrm{C}$ and at 40 and 77 megarads/hr (drop calorimeter measurements) The results of these measurements are plotted in Fig. 4. The gamma irradiations were conducted using HFIR spent fuel elements (exposures $\gamma-5$ and $\gamma-6$ ). ${ }^{1}$ Specimens from $\gamma-5$ were subsequently irradiated an additional amount in $\gamma-6$ to obtain the higher dose specimens ( 5 $+6)$.

The result of a very high dose-rate experiment reported by Sonder and Lindenbaum ${ }^{30}$ is included in Fig. 4 . We doubled their reported value for the difference between the heat of solution of the irradiated and unirradiated salt to obtain the plotted value. ${ }^{2}$

The results showed that changing the dose rate had no significant effects on the amounts of stored energy accumulated in either Harshaw or bedded salt. However, the amounts of stored energy in the bedded salt were substantially greater than those in the Harshaw salt at the test doses. As shown, this difference can be expressed formally as a difference between the $K_{2}$ values, in Eq. (2), for the two data curves. 6.1.5. Stored energy in Harshaw salt vs dose in HFIR- $\gamma$ exposures $7,8,9$, and $X$ at $130^{\circ} \mathrm{C}$ and at 51 to 74 megarads $/ \mathrm{hr}$ (drop calorimeter measurements) The results of these measurements are plotted in Fig. 5. As indicated in the figure, the dose that accumulated during each 
exposure was $210^{10}$ rads. Higher doses for a given specimen were obtained by irradiating the specimen with two or more exposures.

The data points at $2.2 \times 10^{10}$ rads and below were fitted with a curve which obeys Eq. (2), where $K_{1}$ was equal to its usual value and $K_{2}$, as expected, had a value somewhat greater than its $126^{\circ} \mathrm{C}$ value and less than its $144^{\circ} \mathrm{C}$ value (see Figs. 2 and ${ }_{r}$ ). These findings gave additional evidence that there was no significant dose-rate effect on the accumulation of stored energy in our experiments in the temperature range be iow $145^{\circ} \mathrm{C}$ and in the dose range of 210 to 100 megarads $/ \mathrm{hr}$.

The stored energy values at 3.2 and $4.4 \times 10^{10}$ rads were higher than those predicted by extrapolation from the values at lower doses. The value at $4.4 \times 10^{10}$ rads was very much higher (by a factor of $\sim 2$ ), and it appeared that some change in the rates of formation and/or the annealing rates of the radiation defects took place when the stored energy exceeded $\sim 20 \mathrm{cal} / \mathrm{g}$.

6.1.6. Stored energy in New Mexico and Lyons bedded salt vs dose in HFIR- $Y$ exposures $7,8,9$, and $X$ at $130^{\circ} \mathrm{C}$ and at 51 to 74 megarads $/ \mathrm{hr}$ (drop calorimeter measurements) The results of these measurements are plotted in Fig. 6. There was appreciable scatter among the data obtained at a given dose, and the $E$ vs $D$ relationship was poorly defined. $A$ straight line passing through the origin can be drawn through the data. However, a curve which obeys Eq. (2), with the values of $K_{1}$ and $K_{2}$ given in Fig. 6, fits the data at stored energies of $22 \mathrm{cal} / \mathrm{g}$ and below equally well. The deviations from the curve above about $20 \mathrm{cal} / \mathrm{g}$ do not cxcoed those noted for Harshaw salt in the same stored energy range. The ratio of the $K_{2}$ value in Fig. $6\left(3.5 \times 10^{-11} \mathrm{rad}^{-1}\right)$ to the $K_{2}$ value for bedded salt at $144^{\circ} \mathrm{C}\left[6.8 \times 10^{-11} \mathrm{rad}^{-1}\right.$ (see $\mathrm{Fig}$. 4) $]$ is approximately the same as the ratio of the $K_{2}$ value for Harshaw salt at $130^{\circ} \mathrm{C}$ to the $K_{2}$ value at $144^{\circ} \mathrm{C}$ (see Figs. 4 and 5 ).

There were no significant differences between stored energy in the bedded salt from Lyons and from New Mexico, as indicated by the results in Fig. 5 and the results of $\mathrm{H}_{2}$ measurements (see Sect. 6.1.8). 
6.1.7. Stored energy in New Mexico bedded salt at $2.25 \times 10^{10}$ rads in HFIR- $\gamma$ exposures $11+12$ at $130^{\circ} \mathrm{C}$ and at 70 megarads (drop calorimeter measurements) The results of three measurements taken on this sample are: 12,14 , and $16 \mathrm{cal} / \mathrm{g}$. These values are below those found with $\gamma-7-8$ and $\gamma-9-X$ samples [22 to $24 \mathrm{cal} / \mathrm{g}$ (see Fig. 6)], and they are near those found with Harshaw salt, which was irradiated under comparable conditions (see Fig. 5). There is no apparent explanation for the lower values for these particular samples. A conceivable explanation is that the salt used for the $\gamma-11+12$ sample approximated the Harshaw salt in those properties which may affect the value of $K_{2}$, for example, purity, crystal strain (see Sect. 5).

6.1.8. Comparisons between results of $\mathrm{H}_{2}$ evolution and drop calorimeter measurements on dome, bedded, and Harshaw salt irradiated at HFIR- $\gamma$ exposure 9 at $130^{\circ} \mathrm{C}, 51 \mathrm{megarads} / \mathrm{hr}$, and $9.8 \times 10^{9} \mathrm{rads}$ The results of these measurements are presented in Table 3. The drop calorimeter results for bedded and Harshaw salt were presented graphically in previous sections (see Figs. 5 and 6). They are included in Table 3 for convenience in making intercomparisons between the results for the salt samples from the several different sources and for making comparisons between the relative amounts of stored energy indicated by the drop calorimeter and $\mathrm{H}_{2}$ measurements.

The results of the calorimetric measurements indicate that, on the average, the amount of stored energy in the dome salt was less than that in the bedded salt by about $16 \%$ but was slightly greater than the stored energy in the Harshaw salt. On the other hand, the results of the $\mathrm{H}_{2}$ measurements indicate that there was no significant difference between the amounts of stored energy in the samples of bedded salt and the amounts in three of the four dome salt samples. They also indicate that the stored energy in the Harshaw salt was a few percent higher than the stored energy in the bedded and dome salt.

These differences between the relative results of the two types of measurements might have resulted from variations among the portions of 
Table 3. Comparisons between the results of $\mathrm{H}_{2}$ evolution and drop calorimeter measurements on dome, bedded, and Harshaw salt samples irradiated in HFIR- $\gamma$ exposure 9 at $130^{\circ} \mathrm{C}, 9.8 \times 10^{9} \mathrm{rads}$, and 51 megarads $/ \mathrm{hr}$

\begin{tabular}{|c|c|c|c|c|c|c|}
\hline \multirow{2}{*}{$\begin{array}{c}\text { Sample } \\
\text { material }\end{array}$} & \multicolumn{3}{|c|}{$\begin{array}{l}\text { Stored energy } \\
\text { determined by } \\
\text { drop calorimetry }\end{array}$} & \multicolumn{3}{|c|}{ Observed amount of $\mathrm{H}_{2}{ }^{a}$} \\
\hline & & $\begin{array}{l}\text { Value } \\
\text { (cal/g) }\end{array}$ & Relative value & & $\begin{array}{l}\text { Value } \\
\text { liter } / g \text { ) }\end{array}$ & Relative value \\
\hline \multirow[t]{2}{*}{$\begin{array}{l}\text { Harshaw } \\
\text { (Crystalline) }\end{array}$} & & $\begin{array}{l}10.1_{b}^{b} \\
10.3^{b}\end{array}$ & & & $\begin{array}{r}970 \\
1000 \\
\end{array}$ & \\
\hline & av & 10.2 & 0.89 & av & 985 & 1.08 \\
\hline \multirow[t]{2}{*}{$\begin{array}{l}\text { New Mexico } \\
\text { (Bedded) }\end{array}$} & & $\begin{array}{l}10^{c} \\
11^{c} \\
14^{c} \\
17^{c}\end{array}$ & & & $\begin{array}{l}900 \\
910\end{array}$ & \\
\hline & av & 13.0 & 1.16 & av & 905 & 0.99 \\
\hline \multirow[t]{2}{*}{$\begin{array}{l}\text { Lyons } \\
\quad \text { (Bedded) }\end{array}$} & & $\begin{array}{l}11^{c} \\
14^{c} \\
15^{c}\end{array}$ & & & $\begin{array}{l}890 \\
960\end{array}$ & \\
\hline & av & 13.3 & 1.1 .6 & av & 925 & 1.01 \\
\hline \multirow{2}{*}{$\begin{array}{l}\text { Winfield } \\
\text { Mine } \\
\text { (Dome) }\end{array}$} & & $\begin{array}{l}10 \\
13 \\
\end{array}$ & & & $\begin{array}{l}870 \\
960 \\
\end{array}$ & \\
\hline & av & 11.5 & 1.0 & av & 915 & 1.0 \\
\hline \multirow[t]{2}{*}{$\begin{array}{l}\text { Weeks } \\
\text { Is land } \\
\text { (Dome) }\end{array}$} & & $\begin{array}{l}11 \\
10.8 \\
10.7 \\
\end{array}$ & & & $\begin{array}{l}1020 \\
1100\end{array}$ & \\
\hline & av & 10.8 & 0.94 & av & 1060 & 1.16 \\
\hline $\begin{array}{l}\text { Grand } \\
\text { Sal ine } \\
\text { (Dome) }\end{array}$ & & & & & 880 & 0.96 \\
\hline \multirow{2}{*}{$\begin{array}{l}\text { Asse, } \\
\text { Germany } \\
\text { (Dome) }\end{array}$} & & & & & $\begin{array}{l}900 \\
940 \\
\end{array}$ & \\
\hline & & & & av & 920 & 1.01 \\
\hline
\end{tabular}

$a_{\mathrm{H}_{2}}$ evolution measurements made by method 4 .

${ }^{b}$ These data plotted in Fig. 5.

${ }^{c}$ These data plotted in Fig. 6. 
the samples which were selected for measurement.* A relatively large sample, $2150 \mathrm{mg}$, was used for measuring $\mathrm{H}_{2}$ evolution. No specifications were made for the selection of salt from the bulk material other than to avoid any regions in the bedded salt with relatively large amounts of white material (probably gypsum). Much smaller samples, 20 to $40 \mathrm{mg}$, were used to make a calorimetric measurement (60 mg for Harshaw salt). Also, in the case of the bedded and dome salt, the bulk material was crushed, and clean pieces in the neighborhood of 0.05 to $0.07 \mathrm{~cm}$ (cubiform) were selected for the calorimetric sample. (With the Harshaw salt, the calorimeter sample was not crushed. It was comprised of one or two pieces of the bulk sample. See Appendix IV.)

Regardless of the explanation for the apparent differences between relative measurements of drop calorimeter and $\mathrm{H}_{2}$-evolution, the results show that there was no substantial difference at the tested gamma dose between dome salt from different mines or between dome and bedded salt. The results also support the conclusion that there was no significant difference between bedded salt from the Lyons and New Mexico sites.

6.1.9. Stored energy in salt irradiated by gamma rays in situ in Project Salt Vault in the Lyons mine The exposure conditions for this salt and the results of drop calorimeter and $\mathrm{H}_{2}$ measurements (method 3 ) were presented in detail in a previous report. ${ }^{1}$ our interpretations of the results were also discussed.

We concluded that the stored energy results were consistent with a model in which radiation defects were formed at a rate proportional to the dose rate (i.e., at a rate equal to $\mathrm{K}_{I} \mathrm{I}^{\dagger}$ ) and underwent thermally acti-

* We have no reason to question the reliability of the results for the relative amounts of $\mathrm{H}_{2}$ evolved by the different samples. The $\mathrm{H}_{2}$ measurements were all made on the same day, December 12, 1974. Also, the amounts of $\mathrm{H}_{2}$ that were evolved during a measurement did not differ appreciably from one salt sample to another (see Appendix VI).

tIt was previously assumed that $K_{1}$ was equal to $1.66 \times 10^{-9} \mathrm{cal} \mathrm{g}^{-1}$ $\mathrm{rad}^{-1}$ in these exposures. ${ }^{1}$ The conclusions are not changed if $K_{1}$ is assumed equal to $1.4 \times 10^{-9} \mathrm{cal} \mathrm{g}^{-1} \mathrm{rad}^{-1}$. The dose received by the PSV salt was $<10^{9}$ rads; so the annealing term, $-K_{2} I E$, was negligible. 
vated annealing of stored energy at temperatures $\geq 150^{\circ} \mathrm{C}$ at rates predicted by the extrapolation of results of our annealing experiments, which were conducted at somewhat higher temperatures $\left(\geq 185^{\circ} \mathrm{C}\right)$ (see Sect. 7).

\subsection{Stored Energy in Harshaw Synthetic Crystals and in Lyons Bedded Salt After Gamma Irradiation at \\ 10 Megarads $/ \mathrm{hr}$ at 30 to $50^{\circ} \mathrm{C}$; Comparison with Results of Others for Salt Irradiated at Comparable Temperatures}

High-dose, cobalt-gamma irradiations were conducted on several samples of Harshaw synthetic crystals and on one sample of Lyons bedded salt at salt temperatures in the range of 30 to $50^{\circ} \mathrm{C}$ during irradiation. ${ }^{11}$ These samples were analyzed for stored energy by methods 4 and 6 , that is, by the $\mathrm{H}_{2}$-evolution and $\mathrm{I}^{-}$oxidation methods.* The results are listed in Table 4, together with information on the temperature, gamma dose, and analytical methods. The results obtained by the two methods were in near agreement, and the corrected $E$ values for samples No. 126 and $126 \mathrm{efg}$ are probably accurate within 10 to $15 \%$. The results for samples No. $125 \mathrm{a}$ and $125 \mathrm{k}$ were less precise than results for the other samples because there were no $\mathrm{H}_{2}$-evolution measurements. The values at the upper ends of the ranges for 125a and 125k are in nearest agreement with those reported by others for comparable exposure temperatures and doses and are probably most nearly correct.

The data for Harshaw salt in Table 4 are plotted vs dose in Fig. 7 together with stored energy values obtained from previously reported results of others for salt irradiated at comparable temperatures but at different dose rates. Sonder and Lindenbaum ${ }^{10}$ reported the difference between the heats of solution of irradiated and unirradiated salt. We doubled their reported values to obtain the actual stored energy. Kubota ${ }^{13}$

*The drop calorimeter method was not reliable because the samples could not be preheated at a high temperature to remove sorbed water without possibly annealing some of the stored energy. 
Table 4. Stored energy in Harshaw snythetic crystals and in Lyons bedded salt after gamma radiation at 10 megarads $/ \mathrm{hr}$ and at temperatures in the range of 30 to $50^{\circ} \mathrm{C}$

\begin{tabular}{llcccc}
\hline Salt & $\begin{array}{c}\text { Sample } \\
\text { No. }\end{array}$ & $\begin{array}{c}\text { Temperature } \\
\text { during } \\
\text { irradiation } \\
\left({ }^{\circ} \mathrm{C}\right)\end{array}$ & $\begin{array}{c}\text { Dose } \\
\left(10^{10} \text { rads }\right)\end{array}$ & $\begin{array}{c}\mathrm{I}^{-} \rightarrow \mathrm{I}^{a} \\
(\mathrm{cal} / \mathrm{g})\end{array}$ & $\begin{array}{c}\mathrm{H}_{2}^{b} \\
(\mathrm{ca}) / \mathrm{g})\end{array}$ \\
\hline Harshaw & $125 \mathrm{a}$ & 40 & 1.1 & $0.7-2.4^{c}$ & \\
Harshaw & $125 \mathrm{k}$ & 40 & 3.4 & $1.2-2.9^{c}$ & \\
Harshaw & 126 & $30-50$ & $7.1 \pm 10 \%$ & $3.6-4.3^{d}$ & 4.2 \\
Harshaw & $125 \mathrm{efg}$ & $30-50$ & $8.2 \pm 10 \%$ & $4.0-4.7^{d}$ & 4.0 \\
Lyons & $\mathrm{k} 127$ & $30-50$ & $4.8 \pm 10 \%$ & $0-0.5^{d}$ & 0.1 \\
\hline
\end{tabular}

${ }^{\alpha}$ Stored energy calculated from results of $\mathrm{I}^{-}$oxidation measurements, assuming $4.25 \mathrm{eV}$ for each $\mathrm{I}^{-}$oxidized (method 6).

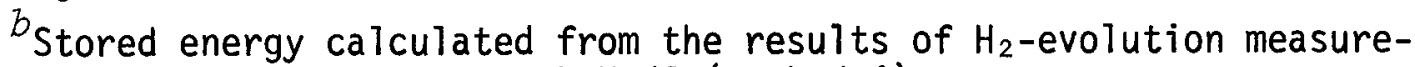
ments, assuming $4.25 \mathrm{eV}$ for each $\mathrm{H}_{2} / 2$ (method 4).

${ }^{c}$ Control measurements on unirradiated salt showed the oxidation of $\mathrm{I}^{-}$in amounts equivalent to 0.8 to $1.7 \mathrm{cal} / \mathrm{g}$. The upper values here are those calculated with no correction for background oxidation. The lower values are those obtained after subtracting an assumed background value equivalent to $1.7 \mathrm{cal} / \mathrm{g}$.

$d_{\text {Control measurements on unirradiated salt showed the oxidation of }}$ $\mathrm{I}^{-}$in amounts equivalent to $0.7 \mathrm{cal} / \mathrm{g}$. The upper values here are those calculated with no correction for background oxidation. The lower values are those obtained after subtracting an assumed background value of $0.7 \mathrm{cal} / \mathrm{g}$. 


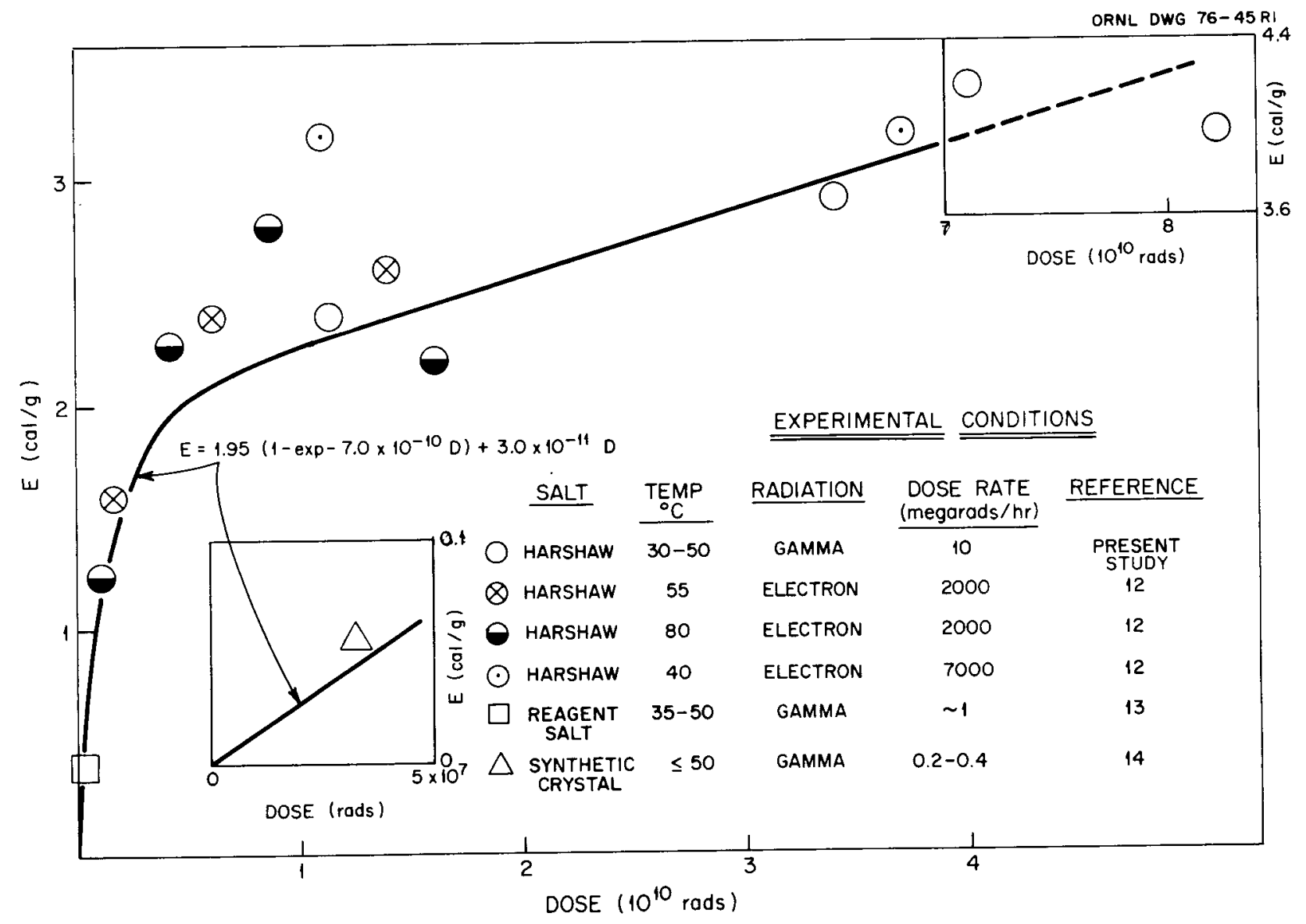

Fig. 7. Stored energy in gamma or electron irradiated salt at 0.2 to 7000 megarads $/ \mathrm{hr}$. and at temperatures in the range of 30 to $80^{\circ} \mathrm{C}$. 
reported the amount of oxidation of o-tolidine. Epstein ${ }^{14}$ reported the amounts of oxidation of $\mathrm{I}^{-}$or o-tolidine which occurred upon dissolution of irradiated specimens. We calculated the amounts of stored energy corresponding to their reported values using $4.25 \mathrm{eV}$ per defect pair in the salt.

The results show that stored energy accumulation in the Lyons bedded salt was negligible at these low temperatures. The stored energy in the Harshaw salt increased slowly after an initial period of more rapid growth. The E vS D relationship for these Harshaw data (using the higher values of $E$ for $125 \mathrm{a}$ and $125 \mathrm{k}$ ) and for the previously reported lower dose data of others can be expressed,

$$
E=1.95\left(1-\exp -K_{2} D\right)+3.0 \times 10^{-11} D,
$$

where the value of $K_{2}$ is $7.0 \times 10^{-10} \mathrm{rad}^{-1}$. The general form of Eq. (3) can be explained by assuming that a small fraction, $F$, of the generated defects assume forms in the salt that are stable against annealing, while the remaining, major fraction is formed and annealed, as expressed by Eq. (1). With this interpretation, the rate expressions corresponding to Eq. (3) are:

$$
\begin{aligned}
& E=E^{\prime}+E^{\prime \prime}, \\
& d E^{\prime \prime} / d D=F K_{1},
\end{aligned}
$$

and

$$
\frac{d E^{\prime}}{d D}=(1-F) K_{1}-K_{2} E^{\prime} .
$$

The value of $K_{1}$ is about the same as its value at higher temperatures, that is, $1.4 \times 10^{-9} \mathrm{cal} \mathrm{g}^{-1} \mathrm{rad}^{-1}$, and the value of $\mathrm{F}$ is 0.0214 . The amounts of stored energy shown by the data in Table 4 and by Eq. (3) are much less than those found at higher exposure temperatures $\left(95^{\circ} \leq\right.$ temp $\leq 144^{\circ} \mathrm{C}$ ) apparently because the back reaction (annealing) is relatively more important at the low temperature. 
6.3. Stored Energy in Harshaw and Lyons Salt Irradiated at 160 to $173^{\circ} \mathrm{C}$ and 1.6 to 66 Megarads/hr

(Drop Calorimeter Measurements)

The exposure conditions employed in these experiments, the results of the calorimetric measurements, and the interpretation of the results were described and/or discussed previously. ${ }^{1}$ It was concluded that the value of $K_{1}$ for these exposures was probably the same or lower than its value at lower temperatures. However, additional annealing processes, including thermally activated annealing, came into play during exposures at these higher temperatures, and, as a result of these processes, the stored energy accumulated during a given dose was dependent on the dose rate during the exposure. The data obtained at these exposure temperatures, together with other data relevant to the rates of the thermally activated annealing process (see Sect. 7), indicated that thermally activated annealing would be sufficient to make the accumulation of stored energy negligible at salt temperatures $>150^{\circ} \mathrm{C}$ at the relatively low dose rates prevailing in salt in a waste repository.

\section{RESULTS OF MEASUREMENTS OF POSTIRRADIATION, THERMALLY ACTIVATED ANNEALING OF STORED ENERGY}

Thermally activated annealing characteristics were investigated by exposing portions of some irradiated samples to elevated temperatures prior to measuring the stored energy. This work was presented and discussed in a previous report; most of this previous presentation is included in Appendix VII. A brief summary is given below.

The Harshaw salt that had been irradiated at $95^{\circ} \mathrm{C}$ showed rapid annealing to a maximum value in the range of 2 to $3 \mathrm{cal} / \mathrm{g}$ in the temperature range of 115 to $120^{\circ} \mathrm{C}$. The remainder annealed at measurable rates only at temperatures above $\sim 180^{\circ} \mathrm{C}$. Most of our quantitative measurements dealt with the higher temperature stage of the annealing. Specimens that had been irradiated at temperatures $\geq 126^{\circ} \mathrm{C}$ exhibited only the higher temperature stage. 
The results of annealing experiments in the temperature range of 195 to $230^{\circ} \mathrm{C}$, which were designed to determine the effects of time at a constant temperature and the effects of the amount of stored energy in a specimen on the rate of annealing, showed that the annealing process is of zero-kinetic order:

$$
\mathrm{dE} / \mathrm{dt}=\mathrm{K} .
$$

That is, the rate of annealing is independent of the amount of stored energy in a specimen. This is a very rare type of rate process, but it can be explained by assuming that a rapid equilibrium exists between different types of defects in which the types that are reacting to produce the annealing remain at, essentially, a constant concentration throughout the annealing period. It is known that an equilibrium exists between $\mathrm{F}$ centers and colloidal sodium in $\mathrm{NaCl}$ and that the concentration of $F$ centers in this equilibrium depends upon temperature but is independent of the amount of colloidal sodium in the salt crystal. ${ }^{15,16}$ It can be speculated that this or a comparable equilibrium accounts for the zero-order kinetics.

The results of other annealing experiments in the temperature range of 185 to $260^{\circ} \mathrm{C}$ showed that the temperature dependence of the zero-order rate constant can be expressed by an Arrhenius-type relationship, although the pre-exponential factor may depend upon the exposure history of a specimen and upon the type of salt, that is, Harshaw or bedded. Equation (8) shows the most conservative relationship between the rate constant and the temperature for Lyons salt which was indicated by our data:

$$
\mathrm{K}=1.92 \times 10^{16} \exp -1.96 \times 10^{4} / \mathrm{T} \text { cal } \mathrm{g}^{-1} \mathrm{hr}^{-1} \text {. }
$$

Values of $K$ in the temperature range of 158 to $170^{\circ} \mathrm{C}$, which are found from this equation, are in near agreement with those deduced from information we obtained with samples of Lyons salt which were irradiated in 
situ in PSV at $2158^{\circ} \mathrm{C}$ (maximum) and those irradiated in the range of 160 to $173^{\circ} \mathrm{C}$ in our laboratory experiments (see Sects. 6.1.9 and 6.2).

The relationship between the rate constant and the temperature for Harshaw salt that was indicated by the annealing experiments was:

$$
K=4.97 \times 10^{16} \exp -1.96 \times 10^{4} / \mathrm{T} \text { cal } \mathrm{g}^{-1} \mathrm{hr}^{-1} \text {. }
$$

The value of the pre-exponential factor in Eq. (9) is $2 \frac{1}{2}$ times greater than that given for the Lyons salt by Eq. (8).

\section{MISCELLANEOUS OBSERVATIONS}

\subsection{Color}

Most of the irradiated specimens were very black. Some specimens of bedded salt contained white specks which showed clearly against the black background. The specimen of New Mexico salt which was used in HFIR exposure No. $X$ had the largest amount of this white material; visual inspection indicated that 1 or $2 \%$ of the sample was white. The white material was probably gypsum.

Upon thermal annealing of irradiated specimens in the drop calorimeter, the black color disappeared, and the specimens became more or less clear. Specimens that had the largest amount of stored energy became cloudy, whereas specimens with the smaller amounts of stored energy became clear. Additional high-temperature measurements of the cloudy specimens showed negligible amounts of stored energy associated with this appearance.

Numerous small negative crystals could be seen in the heavily irradiated Harshaw salt after annealing.

\subsection{Chlorine Odor}

An odor of chlorine was emitted during the cleaving or crushing of samples of heavily irradiated salt. The source of this odor may have 
been the aggregates of trapped holes $\left(\mathrm{Cl}_{2}{ }^{-}\right)$on the grain boundaries which were exposed to air by the cleaving or crushing.

\subsection{Cleaving}

Salt with large amounts of stored energy, 10 to $20 \mathrm{cal} / \mathrm{g}$, was difficult to cleave.

\subsection{The pH of Solutions of Irradiated, Unirradiated, and Annealed Salt}

A few measurements of the pH of solutions of different salt samples were made. The results of the most careful measurements are given in Table 5.

The set of measurements on the Harshaw salt showed that the pH of the solution of the irradiated salt was substantially greater than the $\mathrm{pH}$ of the unirradiated and thermally annealed salt solutions. However, the $\mathrm{pH}$ of the irradiated salt was significantly less than that predicted ${ }^{2}$ by calculation, assuming equal numbers of trapped electron and trapped hole defects were undergoing the dissolution reactions,

$$
\mathrm{Na}^{+} \mathrm{e}^{-}+\mathrm{H}_{2} \mathrm{O} \rightarrow \frac{1}{2} \mathrm{H}_{2}+\mathrm{Na}^{+}+\mathrm{OH}^{-},
$$

and

$$
\begin{aligned}
& \left(\mathrm{Cl}^{-}\right)^{+}+\frac{1}{2} \mathrm{H}_{2} \mathrm{O} \rightarrow \frac{1}{2} \mathrm{Cl}^{-}+\frac{1}{2} \mathrm{H}^{+}+\frac{1}{2} \mathrm{HOCl}, \\
& \mathrm{HOCl} \stackrel{\leftrightarrow}{\rightarrow} \mathrm{H}^{+}+\mathrm{OCl}^{-} \quad\left(\mathrm{K}=3 \times 10^{-8}\right) .
\end{aligned}
$$

Several other $\mathrm{pH}$ measurements, not shown, on samples of Harshaw salt, also irradiated at $95^{\circ} \mathrm{C}$ and at 11 megarads $/ \mathrm{hr}$, showed comparable differences between observed and predicted values of the $\mathrm{pH}$.

The difference between the observed and predicted values indicates that about $10 \%$ of the trapped electron defects $\left(\mathrm{Na}^{+} \mathrm{e}^{-}\right)$did not contribute an $\mathrm{OH}^{-}$to the solution during dissolution. Several different explanations can be postulated: (1) the salt may have absorbed some nitrogen acid or some carbonic acid during the cobalt irradiations (the specimens were 
Table 5. The pH of solutions of irradiated, unirradiated, and annealed salt

\begin{tabular}{|c|c|c|c|c|}
\hline \multirow[t]{2}{*}{$\begin{array}{l}\text { Sample } \\
\text { description }\end{array}$} & \multirow{2}{*}{$\begin{array}{l}\text { Sample weight } \\
(g)\end{array}$} & \multirow{2}{*}{$\begin{array}{l}\text { Solution } \\
\text { volume } \\
\left(\mathrm{cm}^{3}\right)\end{array}$} & \multicolumn{2}{|c|}{$\begin{array}{l}\mathrm{pH} \text { of } \\
\text { solution }\end{array}$} \\
\hline & & & Observed & Predicted \\
\hline Harshaw unirradiated & $\begin{array}{l}0.003 \\
0.03 \\
0.15 \\
0.30\end{array}$ & 5.0 & $6.25 \pm 0.05^{b}$ & \\
\hline $\begin{array}{l}\text { Harshaw irradiated } \\
\text { sample } \mathrm{C}-2 \text {, exposed } \\
\text { at } 95^{\circ} \mathrm{C} \text { and } 11 \\
\text { megarads/hr; } \mathrm{H}_{2} \\
\text { evolution measured } \\
\text { by method } 3 \text { was } 31.5 \\
\mu \text { mole/g }\end{array}$ & 0.0425 & 5.0 & $8.05^{b}$ & 8.96 \\
\hline $\begin{array}{l}\text { Harshaw irradiated } \\
\text { sample C-2 after } \\
\text { thermal annealing } \\
\text { at } 500^{\circ} \mathrm{C} \text {; clear } \\
\text { specimen }\end{array}$ & 0.1011 & 5.0 & $5.90^{b}$ & \\
\hline $\begin{array}{l}\text { Core from Project } \\
\text { Salt Vault Hole } 6\end{array}$ & & & & \\
\hline $\begin{array}{l}\text { Unirradiated } \\
\text { sample }\end{array}$ & 0.351 & 10 & $5.40^{c}$ & \\
\hline $\begin{array}{l}\text { Sample from highest } \\
\text { dose region after } \\
\text { thermal annealing } \\
\text { for } 5 \text { min at } 450^{\circ} \mathrm{C} \text {; } \\
\text { clear specimen }\end{array}$ & 0.131 & 10 & $5.60^{c}$ & \\
\hline $\begin{array}{l}\text { Sample located } 16 \text { in. } \\
\text { from tip of core } \\
\text { annealed at } 250^{\circ} \mathrm{C} \\
\text { for } 1 \mathrm{hr} \text {; clear } \\
\text { specimen }\end{array}$ & 0.076 & 10 & $5.59^{c}$ & \\
\hline $\begin{array}{l}\text { Sample taken from } \\
\text { highest dose region; } \mathrm{H}_{2} \\
\text { evolution measured by } \\
\text { method } 3 \text { was } 4.8 \mu \mathrm{mole} / \mathrm{g}\end{array}$ & 0.300 & 5.0 & $7.80^{\circ}$ & 8.99 \\
\hline
\end{tabular}

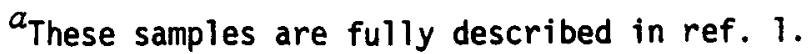

${ }^{b}$ Solvent was demineralized and boiled in water in an open beaker. A glass electrode was used for the measurement.

${ }^{c}$ The solvent was demineralized water. The $\mathrm{pH}$ was equal to 6.0 with reagent salt added. A glass electrode in an open beaker was used for the $\mathrm{pH}$ measurement. 
wrapped in aluminum foil but were not completely sealed during irradiation); (2) the solution formed by dissolving the salt may have absorbed $\mathrm{CO}_{2}$ very rapidly from the air during the dissolution and measurement steps to neutralize some of the $\mathrm{OH}^{-}$; (3) part of the trapped electron defects may have undergone some unrecognized reaction with water or $\mathrm{HOCl}-\mathrm{OCl}^{-}$during dissolution in which either $\mathrm{OH}^{-}$was not produced or $\mathrm{H}^{+}$ was not consumed. We believe that the first and second of the above explanations are more likely than the third.

The results for the bedded salt specimens from Project Salt Vault again showed that the $\mathrm{pH}$ of the solution of irradiated salt was less than the value predicted, assuming Eqs. (10) and (11). However, in this case, the difference was explained by the acid properties shown by the unirradiated and the annealed bedded salt. These acid reactions probably resulted from the presence of traces of hydrolyzable impurity cation in the bedded salt.

\subsection{Loss of Water from Bedded Salt Specimens During Gamma Irradiation}

Several specimens of bedded salt from the Lyons mine and one Harshaw salt specimen, which were irradiated in previous HFIR- $\gamma$ exposures 2 and 3 , were examined for changes in weight that took place during the radiation exposures. The measurements and the results are presented and discussed in Appendix VIII.

\subsection{Gases in Unirradiated and Irradiated Specimens of Bedded Salt}

Two samples of Lyons bedded salt which had been gamma irradiated and one that had not been irradiated were analyzed for contained amounts of $\mathrm{H}_{2}, \mathrm{O}_{2}$, and $\mathrm{N}_{2}+\mathrm{CO}$. The measurements and the results are described and discussed in Appendix IX. 
9. SUMMARY AND DISCUSSION OF INFORMATION ON THE FORMATION AND ANNEALING OF STORED ENERGY IN SODIUM CHLORIDE

9.1. Initial Rate of Formation of Stored Energy in $\mathrm{NaCl}^{*}$

Our experimental data for irradiation temperatures $<145^{\circ} \mathrm{C}$ (30 to $144^{\circ} \mathrm{C}$ ) showed that the rate of formation of stored radiation energy in $\mathrm{NaCl}$ could be expressed:

$$
\mathrm{dE} / \mathrm{dt}=\mathrm{K}_{1} \mathrm{I},
$$

with $K_{1}=1.4 \times 10^{-9} \mathrm{cal} / \mathrm{g}^{-1} \mathrm{rad}^{-1}$. The dose rate had no effect on the value of $K_{1}$ in the range investigated [1.6 to $\sim 100$ megarads/hr in laboratory experiments and 0.007 to 0.07 megarads $/ \mathrm{hr}$ in salt irradiated in Project Salt Vault (see Table 1)]. We also deduced the same value of $K_{1}$ from the reported results of others for dose rates in the range of 0.2 to 2000 megarads $/ \mathrm{hr}$ (see Sects, 6.2 and 10). The source of the salt had no effect on the $K_{1}$ value. The value of $K_{1}$ at temperatures $>145^{\circ} \mathrm{C}(160$ to $173^{\circ} \mathrm{C}$ ) was about the same or slightly less than its value at the lower temperatures (see Sect. 6.3).

Our considerations of theory, our experimental results, and the reported experimental results of others led us to conclude that the plastic strain in the salt has no significant effects on the value of $K_{1}$ at the temperatures, dose rates, and doses of interest in a high-level waste repository. These considerations are summarized in the following:

1. Theory - As discussed in Sect. 5, any effects of plastic strain on the late-stage accumulation of radiation defects in alkali halides probably results from the effects of the strain on the defect reactions which take place after the defects are formed.

*The defect concentrations in our samples and in the samples of others which we consider here were generally greater than $210^{18} / \mathrm{cm}^{3}$ $\left(10^{18} / \mathrm{cm}^{3}\right.$ corresponds to $20.08 \mathrm{cal} / \mathrm{g}$ in salt at $4.25 \mathrm{eV}$ per defect pair). Accordingly, we were generally dealing with late-stage radiation effects (see Sect. 5). 
2. Our indirect experimental evidence - Harshaw synthetic crystals are quite free from strain, as indicated by the low yield stress (less than $\left.15 \mathrm{~kg} / \mathrm{cm}^{2}\right) .{ }^{17,18}$ Bedded and dome salt have usually undergone considerable deformation in situ (tectonic deformation) and during mining, and it is likely that our samples of natural salt retained some of the effects of this strain. ${ }^{18, *}$ That is, it is likely that removal by the recrystallization of all dislocations, etc., that were produced during the straining was incomplete. Also, those sample of bedded salt which were exposed at temperatures greater than $2130^{\circ} \mathrm{C}$ probably underwent some plastic strain as a result of the thermal expansion of brine inclusions within the salt. ${ }^{20}$ Despite these probable differences in the residual effects of plastic strain, there were no differences between the values of $K_{1}$ for the different salt samples.

3. Experimental results of others - Nowick ${ }^{21}$ reported that both the early- and late-stage coloration (F-center formation) in Harshaw crystals under gamma irradiation at room temperature were increased by prior plastic strain. Later workers ${ }^{5}$ suggested that Nowick's apparent late stage was, in fact, part of the early stage (Nowick's maximum Fcenter concentration was $2.5 \times 10^{17} \mathrm{~cm}^{-3}$ ) and that most of the evidence indicates no significant effects of prior strain on late-stage coloration. In any case, the F-center formation rate for Nowick's 4.3 and $8.5 \%$ strained specimens in his later stages was somewhat less than the rate that corresponds to our $K_{1}$ value $\left(1.4 \times 10^{-9} \mathrm{cal} \mathrm{g}^{-1} \mathrm{rad}^{-1}\right)$ with our value of $4.25 \mathrm{eV}$ per defect pair in the salt.

\subsection{Stabilization and Annealing of Stored Energy}

Most of our experimental results showed that an annealing (or effective annealing) of the radiation defects was taking place during irradiation.

*Bulk samples of bedded and dome salt are usually comprised of aggregates of small irregularly shaped crystals. The yield stress of unannealed samples of these aggregates ranges from about 150 to 200 $\mathrm{kg} / \mathrm{cm}^{2} .18,19$ We do not have yield stress information for annealed samples of the aggregates. 
For the temperature range of 30 to $144^{\circ} \mathrm{C}$ during irradiation, and for stored energies less than $20 \mathrm{cal} / \mathrm{g}$, the appropriate kinetic expression for the formation and annealing of stored energy was:*

$$
d E / d t=K_{1} I-K_{2} I E \text {. }
$$

The form of the annealing term, $-K_{2} I E$, can be explained by assuming that a fraction of the radiation defects produced in the primary process react, during formation, with existing defects to reform undamaged $\mathrm{NaCl}$ and that the fraction which reacts is proportional to the number of defects already in the crystal, as given by $E$.

A 1 ist of values of $K_{2}$ determined from our experimental data for this temperature range is included in Table 2 . In the temperature range of 126 to $144^{\circ} \mathrm{C}$, the value of $K_{2}$ for the Harshaw salt increased with increasing temperature, and this increase corresponds to an activation energy of $14.0 \mathrm{kcal} / \mathrm{mole}$. However, the $\mathrm{K}_{2}$ value for $95^{\circ} \mathrm{C}$ is triple that predicted by extrapolation of the 126 to $144^{\circ} \mathrm{C}$ values, and the value for the temperature range of 30 to $55^{\circ} \mathrm{C}$ is several hundred times the extrapolated value. The $K_{2}$ 's for the bedded salt evaluated at 130 and $144^{\circ} \mathrm{C}$ were less than those for Harshaw salt by $\sim 45 \%$. Above $\sim 20 \mathrm{cal} / \mathrm{g}$ at 126 and $130^{\circ} \mathrm{C}$, the amounts of stored energy deviated from those predicted by extrapolation from the lower $\mathrm{E}$ values at these temperatures. Presumably, these deviations resulted from alterations in the rates of annealing when the stored energy in a sample exceeded certain amounts.

The effects of temperature on the values of the annealing constant, $K_{2}$, were qualtitatively explained by assuming: ' (1) that the probability of back reaction between freshly formed defects and those already present depended upon the states of aggregation of the defects already present and (2) that the states of aggregation for exposures in the temperature

*At 30 to $55^{\circ} \mathrm{C}$, the expression differed slightly from this [see Eqs. (3) to (6), Sect. 6.2]. The rate of formation in the primary process is given by $K_{1} I$, as discussed above in Sect. 8.1. 
range above $2125^{\circ} \mathrm{C}$ differed from those for the temperature range of 30 to $50^{\circ}$ and, to a lesser degree, from those for the $95^{\circ} \mathrm{C}$ exposures.* Both of these assumptions are consistent with the available experimental and theoretical information (see Sect. 5). This information suggests that most of the anion vacancy defects may be present as aggregates of colloidal sodium during irradiation in the higher temperature range but that they may be present as individual $F$ centers and in clusters of a few $F$ centers at the lower temperatures. This difference could result from differences between the mobility of the $\mathrm{F}$ and/or $\mathrm{F}^{+}$centers in the two temperature ranges. The trapped hole defects would probably be present as aggregates (probably as $\mathrm{Cl}_{2}{ }^{-}$) in both temperature ranges. The differences between the values of $K_{2}$ for the two different temperature ranges would then be a result of differences between the reactivity of aggregates of colloidal sodium and of the smaller cluster of anion vacancy defects with newly formed defects. The increase in the value of $\mathrm{K}_{2}$ with temperature above $\sim 125^{\circ} \mathrm{C}$ could be a result of the increase with temperature of the concentration of $F$ centers that are in equilibrium with colloidal sodium in $\mathrm{NaCl}$.

The differences between the values of $K_{2}$ for Harshaw and bedded salt and the changes in the apparent value of $K_{2}$ at stored energies above $20 \mathrm{cal} / \mathrm{g}$ at 126 and $130^{\circ} \mathrm{C}$ can be qualitatively explained on the basis of assumptions similar to those described above. For example, the agglomerates of colloidal sodium and of $\mathrm{Cl}_{2}{ }^{-}$presumably form on grain boundaries, dislocations, and other crystal defects, and it is very likely that the numbers and types of these agglomerates are different for the two types of salt. Accordingly, the distribution and sizes of the agglomerates and their reactivities could be different for the two types of salt. Similarly, the very accumulation of large numbers of radiation defects within a crystal could lead to the formation of

*The occurrence of two-stage, thermally activated annealing for the specimens irradiated at $95^{\circ} \mathrm{C}$ (see Sect. 7) supports the idea that defects were present in two different states of aggregation during the $95^{\circ} \mathrm{C}$ exposure. 
additional crystal defects (e.g., plastic strain dislocations) that would provide new trapping and agglomeration sites and thus alter the overall reactivities between freshly formed and accumulated defects.

The difference between the stored energy results for the $95^{\circ} \mathrm{C}$ exposures at 10 megarads $/ \mathrm{hr}$ and those for the $80^{\circ} \mathrm{C}$ exposures at 2000 megarads/hr (see Sect. 6.2) can also be explained along lines similar to those described above. Thus, at the high dose rate used in the $80^{\circ} \mathrm{C}$ exposures and at the possible low mobility of the anion vacancy defects in this range of temperatures, it can be assumed that most of these defects remained as $F$ centers and clusters of a few $F$ centers, so that the value of $K_{2}$ was approximately the same as its value for the exposures in the temperature range of 30 to $55^{\circ} \mathrm{C}$. On the other hand, at the much lower dose rate used with $95^{\circ} \mathrm{C}$ exposures and at the correspondingly longer exposure times, most of the anion vacancy defects were probably able to move into aggregates of colloidal sodium. At higher temperatures, where the movement of anion vacancy is more rapid, there would be less likelihood of a dose rate effect on $K_{2}$. The datum of Sonder and Lindenbaum ${ }^{10}$ for an exposure at $140^{\circ} \mathrm{C}$ and 5000 megarads $/ \mathrm{hr}$ included in Fig. 4 confirms this expectation.

For the temperature range above $2750^{\circ} \mathrm{C}$ and at low dose rates such as those found in a repository ( $20.1 \mathrm{megarad} / \mathrm{hr}$, maximum), the appropriate kinetic expression is:

$$
d D / d t=K_{1} I-K_{2} I E-K,
$$

where $K$ is the rate of thermally activated annealing and is given conservatively by:

$$
K=1.92 \times 10^{16} \exp -1.96 \times 10^{4} / \mathrm{T} \text { cal } \mathrm{g}^{-1} \mathrm{hr}^{-1} \text {. }
$$

The value of $K_{2}$ in this temperature range was not firmly established. However, this was unimportant from the practical standpoint of predicting the amounts of stored energy in salt in a waste repository since the 
predicted $K$ value at temperatures $\geq 150^{\circ} \mathrm{C}$ exceeds the predicted value of $K_{1} I$ at the relatively low values of $I$ that will prevail in salt in a waste repository.

A possible explanation for the occurrence of zero-order kinetics in the thermally activated annealing process was described in Sect. 7.

\section{RETENTION OF RADIATION DEFECTS WITHIN SODIUM CHLORIDE CRYSTALS}

The fact that our irradiated crystals were entirely or essentially entirely bleached upon heating indicated that no trapped electron defects (i.e., colloidal sodium, $F$ centers, etc.) remained after annealing and thus indicated that no chlorine had escaped from the crystals during irradiation or during annealing. The possibility that some trapped electron defects (i.e., sodium) had escaped could not be ruled out by the bleaching results since we could not be sure that the excess chlorine defects would produce color centers in the annealed crystals. However, the results of $\mathrm{pH}$ measurement (Sect. 8.4) indicated that no significant amount of chlorine remained in crystals after thermal annealing.

\section{COMPARISONS BETWEEN RESULTS OF OUR EXPERIMENTS AND CORRELATIONS TO THOSE REPORTED PREVIOUSLY}

We previousty reported ${ }^{1}$ correlations of experimental data in which values of $K_{1}$ and $K_{2}$ at certain temperatures differed by small amounts from values in this report. The present values are based on correlations of additional experimental data and on additional theoretical considerations.

Earlier workers ${ }^{12}$ who used very high dose rates $\left(>10^{9} \mathrm{rads} / \mathrm{hr}\right)$ at exposure temperatures of $80^{\circ} \mathrm{C}$ and below reported saturation of stored energy in Harshaw salt at $\sim 1$ to $2 \mathrm{cal} / \mathrm{g}$. The results of this previous work are included in Sect. 6.2. As discussed in Sect. 9, the difference between our present results at $95^{\circ} \mathrm{C}$ and the previously reported data obtained at a higher dose rate and at temperatures of $80^{\circ} \mathrm{C}$ and below is 
probably associated with the effects of the dose rate on the fraction of the trapped-electron defects that diffuse into stable agglomerates before these defects react with trapped-hole defects in an annealing reaction. ${ }^{7}$

Some results obtained at high dose rates and high temperatures have been reported for Lyons salt, ${ }^{12}$ but the temperatures in that study were either poorly established or were greater than those used in our work. The maximum amount of stored energy found in the earlier work was $\sim 20$ $\mathrm{cal} / \mathrm{g}$.

Previous workers reported ${ }^{7}$ that colloids of sodium were formed from $\mathrm{F}$ centers upon heating previously irradiated $\mathrm{NaCl}$ in the temperature range of 150 to $200^{\circ} \mathrm{C}$. The colloids were thermally annealed during continued heating in this temperature range. Plots of the absorbance of the colloids vs heating time at $200^{\circ} \mathrm{C}$ were presented, but no comments were made concerning the kinetics or rate constants. However, we concluded from these plots that a straight-line relationship existed between the absorbance and time and that, therefore, the annealing process was zero order; this is in agreement with our findings.

Dreschhoff and Zeller reported ${ }^{22}$ measurements of stored energy in PSV specimens that were irradiated in salt mine locations in near proximity to our PSV specimens. They used a differential thermal analysis (DTA) device to measure the stored energy. Their values for stored energy at given doses (or locations) were greater than ours by amounts ranging up to factors of $\sim 4$. We do not have a firm explanation for this difference. However, we believe that we have established the accuracy of the results for our specimens, which had a stored energy of $\sim 1 \mathrm{cal} / \mathrm{g}$, by checking our $\mathrm{H}_{2}$ evolution measurements with our measurements of the amount of heat released in the drop calorimeter.

Dreschhoff and Zeller also reported ${ }^{22}$ that, in a plot of stored energy vs distance up the $45^{\circ} \mathrm{C}$ sample core, a discontinuity occurred at about 8 in. such that the amount of stored energy in the specimen at 8 in. was greater than that in the preceding specimen at 6 in. They suggested that stress within the in situ salt at this location may have caused this discontinuity. Our analysis of their data showed that specimens 
located at distances of $8 \mathrm{in}$. or more were exposed to temperatures of less than $2110^{\circ} \mathrm{C}$ for the first 400 days and temperatures less than $136^{\circ} \mathrm{C}$ for the final 80 days when the temperatures were at the maxima. Also, average dose rates $\left(<10^{4} \mathrm{rads} / \mathrm{hr}\right)$ and doses $\left(\leq 10^{8}\right.$ rads $)$ were very low at distances of $8 \mathrm{in}$. or more.

We previously suggested ${ }^{1}$ that the discontinuity and relatively higher amounts of stored energy at distances $\geq 8$ in. were associated with temperature and dose rate effects rather than with stress and that the value of $K_{1}$ at temperatures less than $\sim 120^{\circ} \mathrm{C}$ might be greater than the $K_{I}$ values at higher temperatures by a factor of $\sim 3$. We now agree that stress may have been a factor and that the discontinuity may have been a result of differences between plastic strain effects at the two locations. As discussed in Sect. 9, we found that the value of $K_{1}$ is independent of the several different exposure variables that were considered, including temperature and plastic strain. However, the accumulation of early stage-type radiation damage is affected by the plastic strain, and it is likely that the discontinuities observed by Dreschhoff and Zeller ${ }^{22}$ were part of early-stage effects.

Previous workers reported ${ }^{8}$ that $\mathrm{NaCl}$ which was exposed to high doses of fast electrons at either room or elevated temperatures was completely bleached upon heating to $250^{\circ} \mathrm{C}$ and that equal numbers of oxidizing and reducing species were observed during aqueous dissolution. These results are in agreement with our findings.

Various workers have reported sputtering of chlorine, sodium, and sodium chlorine from the surface of $\mathrm{NaCl}$ crystals during exposure to low-energy electrons in a highly evacuated environment. ${ }^{23,24}$ However, investigators who exposed $\mathrm{NaCl}$ to high doses of fast electrons or to gamma rays while the $\mathrm{NaCl}$ was sealed within evacuated ampoules could not detect chlorine by sensitive mass spectrometry upon opening the irradiated ampoules. ${ }^{25,26}$ No explanation has been offered for the apparent difference between the results of the two types of experiments. 
12. PREDICTED AMOUNTS OF STORED ENERGY

IN SALT IN A WASTE REPOSITORY

The experimental data and correlations showed that the maximum rate of formation of stored energy in salt in a waste repository will be $1.4 \times 10^{-9} \mathrm{cal} \mathrm{g}^{-1} \mathrm{rad}^{-1}$. This rate will be independent of temperature, dose rate $\left(\right.$ at $<10^{8} \mathrm{rads} / \mathrm{hr}$ ), dose, and the type of salt. Then, the maximum amount of stored energy that will accumulate in the salt adjacent to a waste canister is given by the product of the maximum formation rate, $1.4 \times 10^{-9} \mathrm{cal} \mathrm{g}^{-1} \mathrm{rad}^{-1}$, and the dose in the salt. As stated above, the maximum gamma dose in salt immediately adjacent to a waste canister will be $\sim 2.8 \times 10^{10}$ rads, $3.1 \times 10^{10}$ rads, and $4.3 \times 10^{10}$ rads after 90,1000 , and $10^{7}$ years of burial. The corresponding maximum values of stored energy are 39,43 , and $60 \mathrm{cal} / \mathrm{g}$, respectively.

Some annealing of the stored energy will take place during exposure in the repository, depending on the temperature and other factors. At temperatures $\geq 150^{\circ} \mathrm{C}$, thermally activated annealing will be the dominant process and will limit the accumulation of stored energy to negligible amounts. The rates of this thermally activated annealing increase with temperature but are independent of the amounts of stored energy in the irradiated salt. Illustrative values for the annealing rates indicated by the experimental data are $1.4 \times 10^{-4}$ to $9 \times 10^{-4}, 0.019$ to 0.12 , and 5.6 to $34 \mathrm{cal} \mathrm{g}^{-1} \mathrm{hr}^{-1}$ at 150,200 , and $275^{\circ} \mathrm{C}$, respectively.

The rates of thermally activated annealing or annealing by other processes at temperatures $\angle 150^{\circ} \mathrm{C}$ in a repository could not be predicted reliably from the results of the experimental studies. For the purposes of assessing hazards resulting from stored energy accumulations in the salt, it was assumed that the maximum amounts of stored energy at temperatures $<150^{\circ} \mathrm{C}$ will be those calculated from the maximum formation rates and the maximum gamma doses in the preceding paragraph.

The salt that is located within 6 to 7 in. of a waste canister and receives significant gamma-ray doses will normally have maximum temperatures $>200^{\circ} \mathrm{C}$, and the maxima will occur 10 to 20 years following the burial 
of 10-year-old-wastes. The temperatures will exceed $150^{\circ} \mathrm{C}$ after 1 to 2 years of burial and will remain above $150^{\circ} \mathrm{C}$ for more than 50 years. Accordingly, energy storage in salt in the normal burial area will be negligible for more than 50 years following the burial of 10year-old wastes.

Some canisters on the periphery of the repository will have salt temperatures less than those within the normal burial area because of their semi-isolation from thermal effects of other canisters. A rare canister may be isolated from the thermal effects of other canisters and, accordingly, have still lower temperatures. At times, significant concentrations of stored energy might accumulate in the salt around these canisters in less than 50 years following burial.

13. CONCLUSIONS REGARDING HAZARDS ASSOCIATED WITH THE STORAGE OF RADIATION ENERGY IN SALT IN A WASTE REPOSITORY

A principal concern of stored energy in the salt around a waste canister is the excessive temperatures and/or the release of hazardous amounts of mechanical energy that could result from the rapid release of very large amounts of the stored energy. No conditions that would promote a sudden release of stored energy in repository salt or in the contained waste are apparent other than rapid heating of the salt or waste to a $\Delta T$ of a few hundred degrees by a source other than the contained stored energy. No such source of external heat is known. However, if a sudden release of the entire amounts of stored energy in the waste within a canister and within the surrounding salt occurs in some unforeseen way, it is estimated that there would be no serious adverse effects on waste containment, and safe operation of the repository would result.

Thus, with a reference 12-in.-ID canister containing $3.65 \mathrm{~kW}$ of 5 year-old $\mathrm{UO}_{2}$-fueled PWR high-level waste at burial $(2.25 \mathrm{~kW}$ when aged 10 years), the maximum temperature rise from the release of stored energy after 55 years of burial in salt would be $\sim 130$ and $9^{\circ} \mathrm{C}$ near the edge of the canister and at 7 in. from the edge, respectively (Fig. 8). If the 


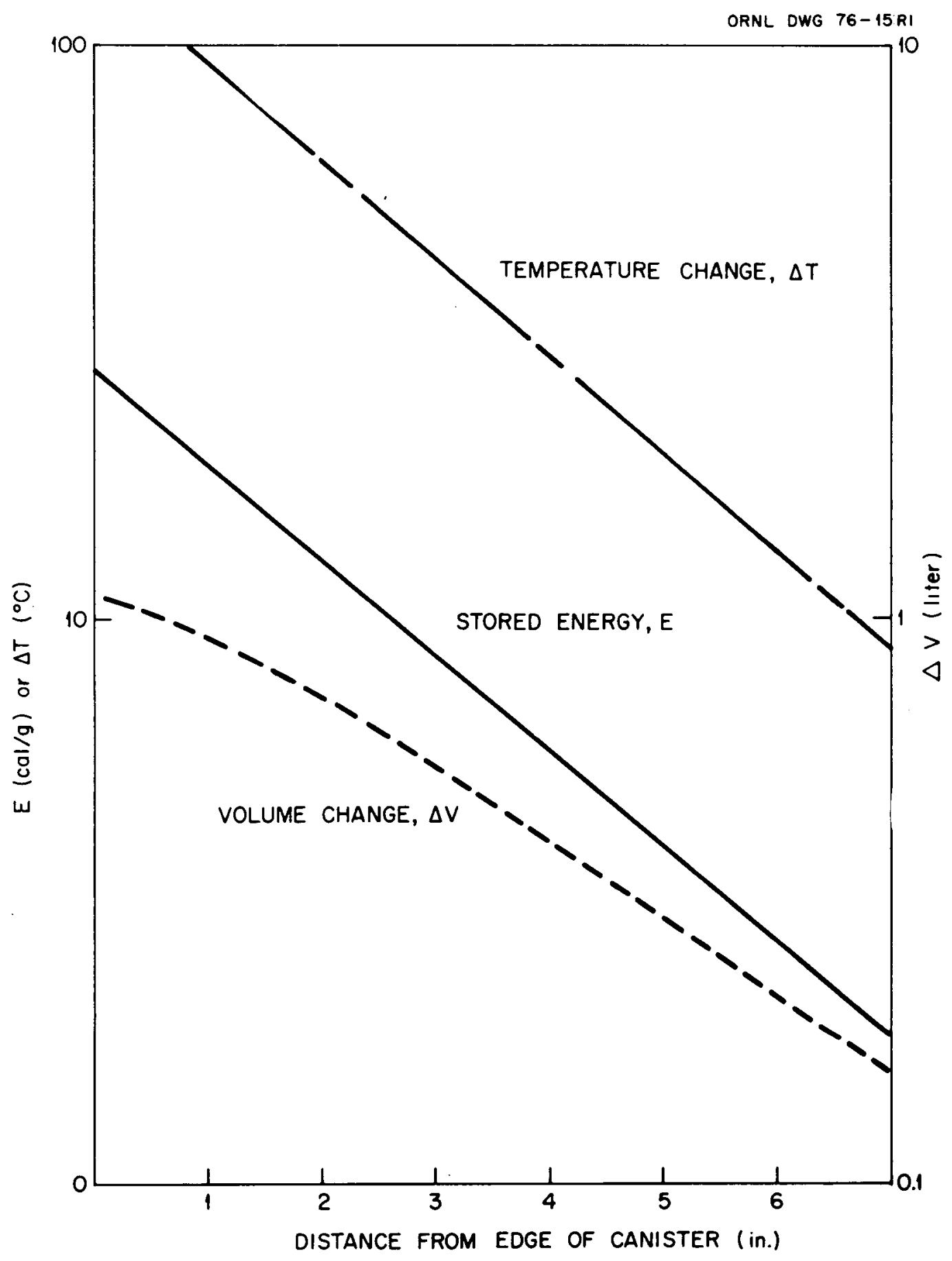

Fig. 8. Maximum stored energy in salt after 55 years of burial of 3.65 $\mathrm{KW}$ of 5-year-old $\mathrm{UO}_{2}$-fueled PWR waste in reference 12-in.-ID canister, temperature change upon the adiabatic release of stored energy; and volume change in salt and in brine inclusions (1 vol \%) accompanying change in temperature. 
salt column undergoing these $\Delta T \mathrm{~s}$ is $8 \mathrm{ft}$ high, the mechanical energy release ranges from $\sim 10^{4} \mathrm{cal}$, when the overburden pressure is $2000 \mathrm{psi}$, to $\sim 10^{5} \mathrm{cal}$, depending upon the rate of the release. For the maximum stored energy at 100 years, the respective values are $\sim 1.3 \times 10^{4} \mathrm{cal}$ and $2.4 \times 10^{5} \mathrm{cal}$. The larger amounts result when the temperature rise is so rapid that no immediate expansion of the salt takes place; instead, the local pressure increases by an amount determined by the compressibility of the salt (Appendix $X$ ). The explosive effects of the $1.3 \times 10^{5} \mathrm{cal}$ of mechanical energy would be practically negligible $\left(4.9 \times 10^{5} \mathrm{cal}\right.$ correspond to heat of detonation of $11 \mathrm{~b}$ of heavily confined TNT). The maximum amount of mechanical energy that would be released in the wastes within the 12-in.-ID canister as a result of the release of the saturation amount of stored energy $(\leq 50 \mathrm{cal} / \mathrm{g})$ would be $\sim 0.8 \times 10^{5} \mathrm{cal}$, assuming that the heat capacity and compressibility of the wastes are the same as those for Pyrex glass. ${ }^{27, *}$ The sum of the explosive energies from the mechanical energy released in the wastes and in the surrounding salt would also be practically negligible.

After 1000 years of burial of the above-described waste, the maximum stored energies in salt and the other salt-related variables considered would all be increased by a factor of 21.6 . The explosive energies from the assumed rapid release of the stored energies would remain negligible.

If appreciable thermal expansion of the salt accompanies the transient temperature rise resulting from the sudden release of stored energy, the contraction of the salt upon cooling to the pre-release temperature would leave some crevices and cracks in the temperature-affected salt, probably along crystal boundaries. These would disappear with time as the salt reconsolidates under the pressure of the overburden. Small amounts of brine, which might be located on the crystals' boundaries, would be free to move about through the temperature-affected region around the canister while the cracks remained open. The brine would be retrapped during the reconsolidation. It is conceivable, although unlikely, that the cracks would extend to the room above the canister and that some of the brine ( $<40$ liters) would escape into the room. An analysis of the fate of water within the room will be made by others

*The value of $1.7 \times 10^{5} \mathrm{cal}$ quoted in ref. 27 is too high by a factor of 2; see Appendix $X$. 
and will be reported elsewhere. The situation postulated above will be included in this anatysis.

Finally, $\mathrm{H}_{2}$ is generated upon aqueous dissolution of the irradiated salt. The experimental results showed that the amount of $\mathrm{H}_{2}$ is $5.2 \times 10^{-6}$ $\mathrm{mole} / \mathrm{cal}$. At $40 \mathrm{cal} / \mathrm{g}$, the salt that dissolves to saturation in $1 \mathrm{ml}$ of water would generate and release $1.7 \mathrm{~cm}^{3}$ of $\mathrm{H}_{2}$ at STP. It was also found that the irradiated salt may dissolve much more rapidly than unirradiated salt. Normally, there will be no occasion to introduce water into the spaces around a waste can, and there will be no $\mathrm{H}_{2}$ evolution hazard. If a need to bring water into contact with salt should arise during the development work in a repository, the possibility of an $\mathrm{H}_{2}$ hazard can be eliminated by using an air sweep or by using saturated brine rather than freshwater. 
14. APPENDIXES

0 


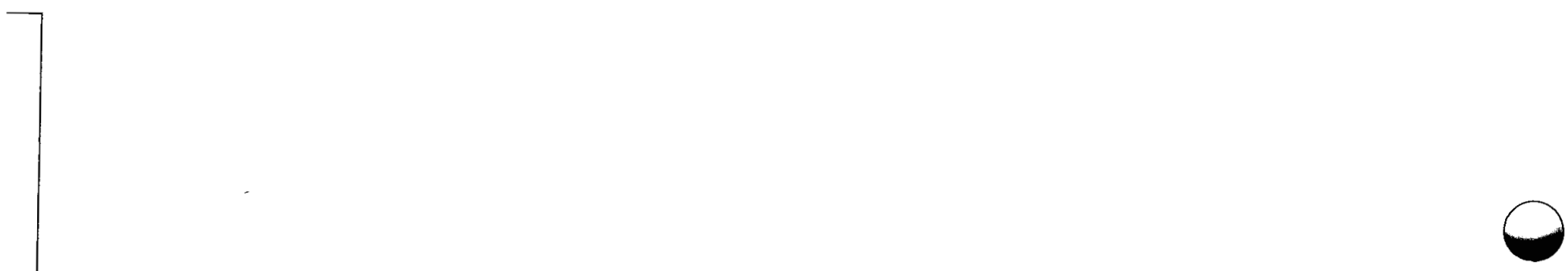

$\bullet$ 
14.1. Appendix I: Reference Concept for a High-Level Waste Repository in Salt

The final-phase concept that will most likely be used with any future salt mine repository for high-level waste was developed at ORNL and was tested in the Carey Salt Company Mine at Lyons, Kansas, in Project Salt Vault. In this concept, the solidified radioactive wastes are sealed within metal canisters, and the sealed canisters are lowered into vertical holes beneath the floors of rooms within a salt formation (Fig. 9). The space around each waste package is backfilled with crushed salt, and the room is also backfilled with crushed salt after the specified number of packages have been buried. Deformation of the solid salt throughout the burial area takes place as a result of overburden pressure and elevated temperatures, and this deformation causes the reconsolidation and recrystallization of the crushed salt backfills. After several decades, when this process is complete, the waste materials are contained within a solid-salt formation and are permanently isolated.

This final-phase disposal concept will be preceded by restricted operations (initial phase) during which the retrievability of the waste canisters and their contents will be maintained. This will entail the use of a sleeve or a large air gap between a canister and the salt formation. It may also include the enclosure of each canister within a second container (an overpack). The room will not be backfilled under the retrievability mode of operation.

The dimensions of the high-level waste canisters, rooms, etc., have not been firmly established. The canister reference dimensions that are presently in use are: ID, $12.0 \mathrm{in.;}$ OD, $12.75 \mathrm{in.}$; height, $10 \mathrm{ft}$; fill height, $8 \mathrm{ft}$; and waste volume, $6.3 \mathrm{ft}^{3}$. The reference room dimensions are $18 \mathrm{ft}$ by $18 \mathrm{ft}$. The hole in the floor would be $18 \mathrm{ft}$ deep, and the hole diameter would accommodate a waste package with $\sim 7$-in. radial clearance. Reference sleeves would have an OD of $\sim 19 \mathrm{in.}$ 


\section{2}

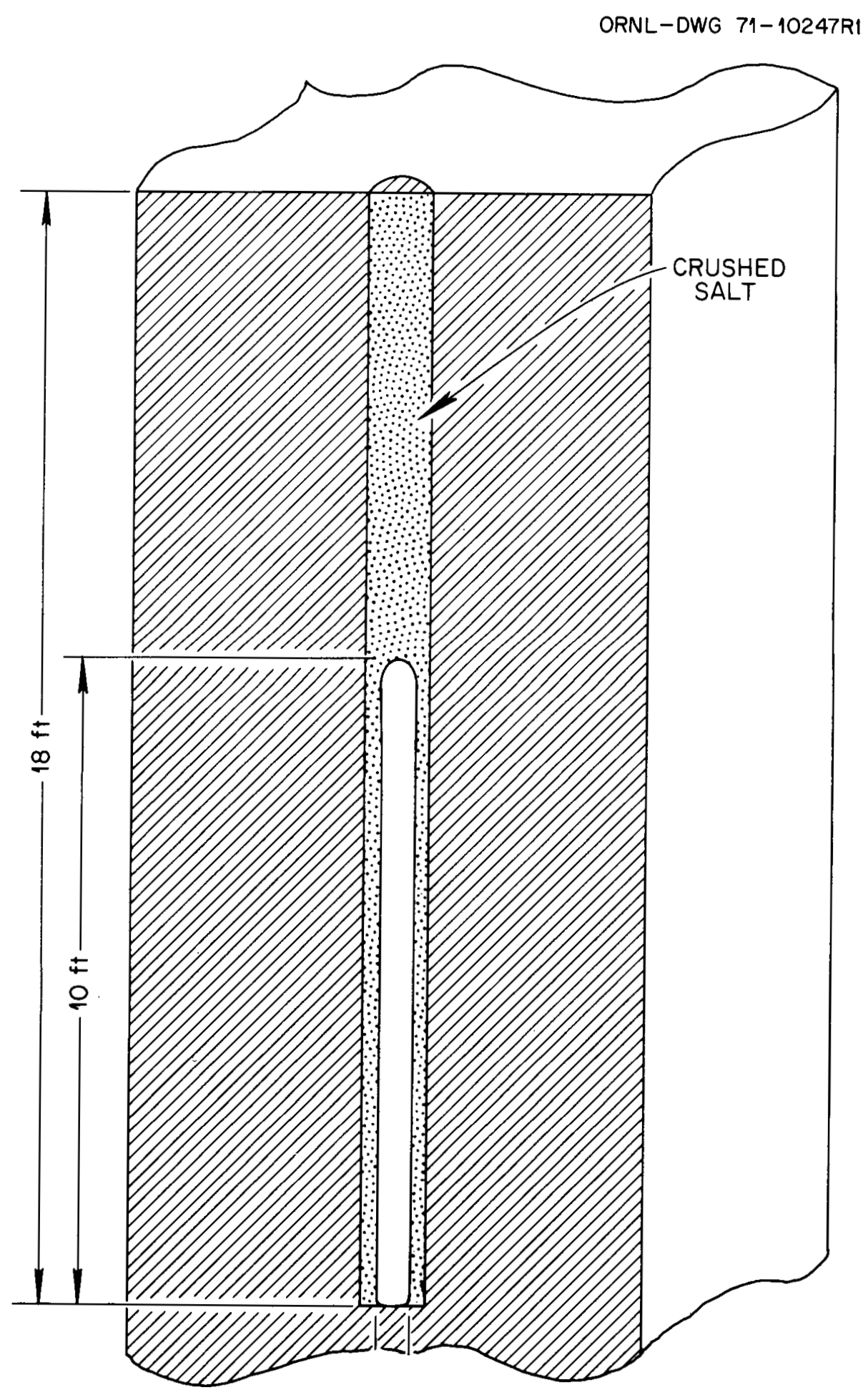

Fig. 9. Waste package in a backfilled hole. 
14.2. Appendix II: Temperatures in Salt Surrounding High-Level Waste Packages

In genera1, HLW waste packages in a repository will be spaced such that, regardless of the amount of waste in each, most of the salt in the vicinity of a package will reach peak temperatures $>200^{\circ} \mathrm{C}$. The salt that is immediately adjacent to a package may reach peak temperatures exceeding $250^{\circ} \mathrm{C}$ * ${ }^{*}$ of course, there will be exceptions in which lower temperatures will occur, for example, in the salt near isolated canisters and canisters containing very small amounts of waste. Also, the temperatures will approach the initial ambient temperatures after a burial period of a few hundred years.

Table 6 shows a list of some thermal-power characteristics of highlevel wastes generated in the reprocessing of spent fuel elements from a $\mathrm{UO}_{2}$-fueled pressurized water reactor (PWR). ${ }^{30}$ Relatively rapid decay of the heat generation rate occurs during the first 5 to 10 years after discharge from the reactor. A decay factor of $\sim 20$ in the first 10 years and a factor of 210 in the next 90 years are shown by these numbers. The volume of this PWR waste after solidification is expected to be $\sim 3$ $\mathrm{ft}^{3}$ per metric ton of heavy metal (MTHM). ${ }^{31,32}$ Accordingly, we will have $20.35 \mathrm{~kW} / \mathrm{ft}^{3}$ in the 10-year-old waste and $\sim 1.6$ times this in 5year-old waste. The high-level wastes that are placed in a repository will have been aged for 5 to 10 years. ${ }^{28,31}$

The 10-year-old waste from PWR mixed oxide ( $\mathrm{Pu}$ recycle) fuel will generate about four times more heat per MTHM than that from the enriched $\mathrm{UO}_{2}$ fuel because of the additional actinides in the mixed oxide (MOX) wastes. ${ }^{30}$ The MOX waste will be mixed with at least 2 parts $\mathrm{UO}_{2}$-fuel wastes during processing; ${ }^{33}$ so the maximum difference will be a factor of $\sim 2$ in 10-year-old waste (the maximum factor is 21.7 in 5-year-old waste).

*Design criteria that have been established state that less than $25 \%$ of the salt contained in a unit cell exceeds $200^{\circ} \mathrm{C}$ and less than $1 \%$ exceeds $250^{\circ} \mathrm{C} .^{28}$ These criteria limit the thermal-loading of 10-yearold waste to $\sim 180 \mathrm{~kW}$ per acre. ${ }^{28,29}$. 
Table 6. Thermal characteristics of high-level waste from the reprocessing of spent fuel elements from a $\mathrm{UO}_{2}$-fueled presurized water reactor (Power $=30 \mathrm{MW} / \mathrm{MTHM}$, Burnup $=33,000$ MWd $/$ MTHM).

\begin{tabular}{|c|c|c|c|c|}
\hline \multirow{2}{*}{$\begin{array}{l}\text { Time since } \\
\text { reprocessing } \\
\text { (years) }\end{array}$} & \multicolumn{3}{|c|}{$\begin{array}{c}\text { Power from waste from one metric ton } \\
\text { of uranium (kW) }\end{array}$} & \multirow{2}{*}{$\begin{array}{c}\text { Total } \\
\text { power per unit volume } \\
\text { of solidified } \\
\text { waste }\left(\mathrm{kW} / \mathrm{ft}^{3}\right)^{d}\end{array}$} \\
\hline & Fission products ${ }^{b}$ & Actinides $^{c}$ & Total & \\
\hline 0 & 19.2 & 0.72 & 19.9 & 6.6 \\
\hline 3 & 2.93 & 0.091 & 3.02 & 1.0 \\
\hline 5 & 1.68 & 0.080 & 1.76 & 0.59 \\
\hline 10 & 1.01 & 0.067 & 1.08 & 0.36 \\
\hline 100 & 0.105 & 0.0097 & 0.115 & 0.038 \\
\hline 1000 & $0.0255 \times 10^{-3}$ & 0.0022 & 0.0022 & 0.0007 \\
\hline
\end{tabular}

$a_{\text {Fuel }}$ is reprocessed 150 days after its discharge from the reactor.

$b_{\text {It }}$ is assumed that all of the tritium and noble gases and $99.9 \%$ of the halogen fission products in the spent fuel are separated from the high-level waste during reprocessing.

${ }^{C}$ All the actinides remaining after the removal of the $99.5 \%$ of the uranium and plutonium during reprocessing.

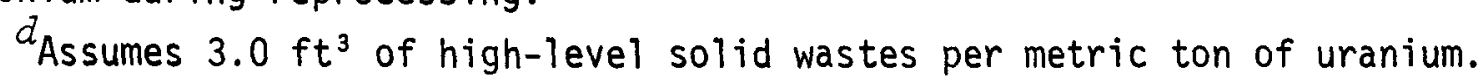


High-level wastes from $\mathrm{UO}_{2}$-fueled BWRs and from LMFBRs are expected to have thermal and radiation properties that are similar to, but somewhat below, those for PWRs. ${ }^{30,33}$

Temperatures that will prevail in a salt mine repository with highlevel waste are illustrated in the plots in Figs. 10 to 12. Calculated temperatures vs distance from the center of a $6-i n$. waste canister are plotted for several different times after burial of 10-year-old PWR waste. ${ }^{1,29,34}$ The height is the reference $(8 \mathrm{ft})$, and the thermal powers at burial are 0.95 and $3.2 \mathrm{~kW}$. Good thermal contact between the salt and the canister wall is assumed. It can be estimated that with packages of larger diameter and with the same total power, the temperatures at the canister-salt interface would be approximately equal to those in the salt, at the given radius, around the 6-in. canister. Thus, the temperatures at the surface of the 12-in. reference canister loaded with $3.2 \mathrm{~kW}$ of 10-year-old wastes from $\mathrm{UO}_{2}$-fueled LWRs would be near those at $0.5 \mathrm{ft}$ in the graph (Fig. 12). As indicated, the temperatures around this reference canister would rise rapidly to over $300^{\circ} \mathrm{F}$ and would reach a maximum of about $550^{\circ} \mathrm{F}\left(290^{\circ} \mathrm{C}\right)$ after about 20 years of burial. After 50 years, the temperatures would sti1l be above $200^{\circ} \mathrm{C}$ out to distances exceeding $1.5 \mathrm{ft}$ from the center of the canister. After 70 to 80 years, the temperatures probably would drop below about $150^{\circ} \mathrm{C} .{ }^{28}$ The temperature-time characteristics in the salt around a reference-size canister containing $0.96 \mathrm{~kW}$ of 10 -year-old waste from $\mathrm{UO}_{2}$-fueled LWRs are similar to those around the 3.2-kW canister. In particular, it is notable that the 50-year temperatures around the lower power canister would still be above $200^{\circ} \mathrm{C}$ at distances exceeding $1.5 \mathrm{ft}$ from the center of the canister.

The local temperatures are influenced by the presence of other strong heat sources in the repository. If a package is isolated from other packates (i.e., its temperature is not affected by the presence of other packages), the temperature of the salt adjacent to the isolated package will be much lower than that around packages within the main portion of the repository. Figure 13 shows plots of the calculated temperatures around a 12-in.-diam, i0-ft-high, isolated waste package. The package contains $5 \mathrm{~kW}$ of 10-year-old waste at burial. The temperatures 


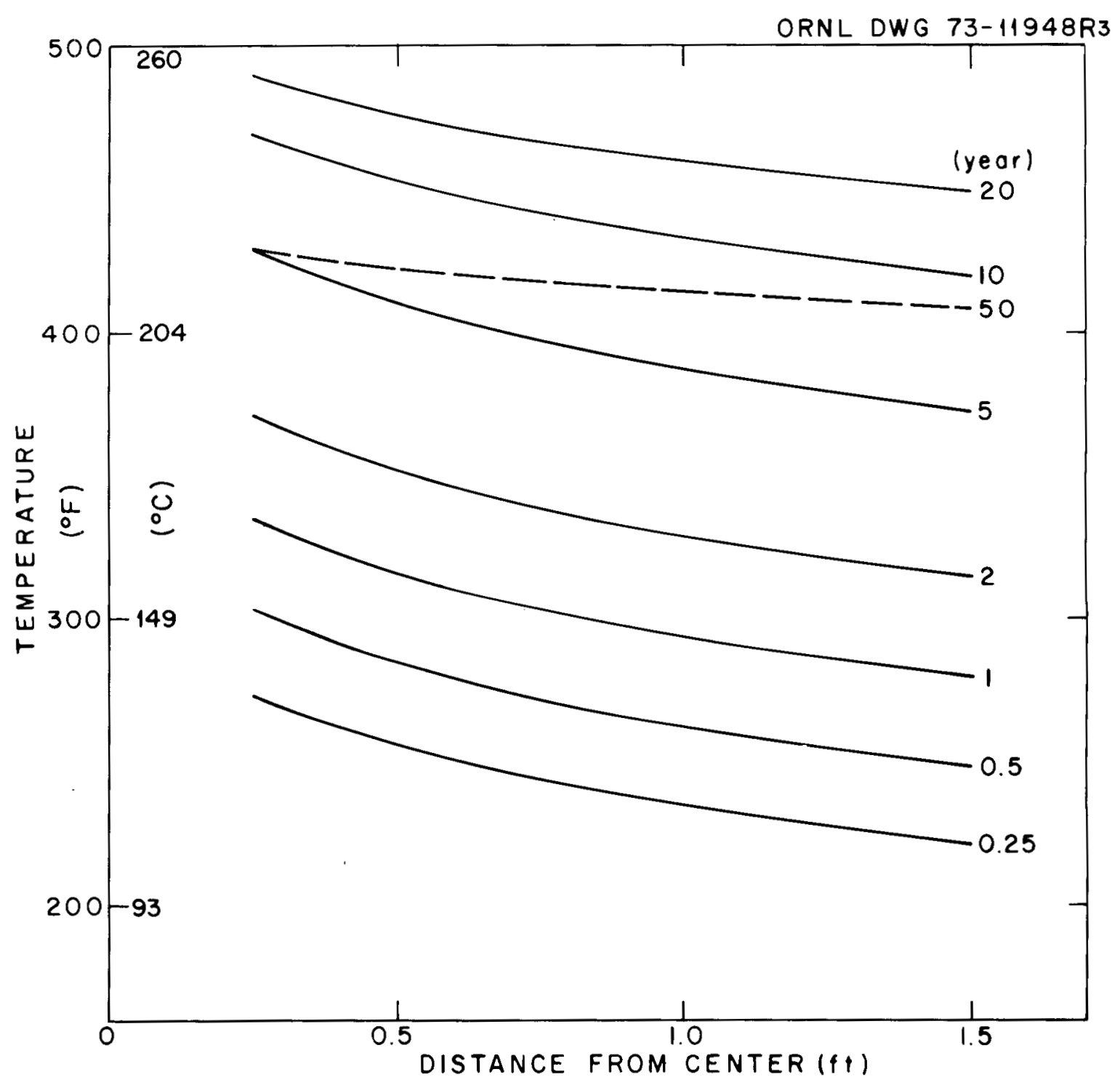

Fig. 10. Salt temperature vs distance from the center of a waste package for several different times after burial (midplane of canister). Canister dimensions: 6-in. ID, $8 \mathrm{ft}$ high; age of waste at buria 1: 10 years; radioactive decay heat: $0.96 \mathrm{~kW}\left(0.61 \mathrm{~kW} / \mathrm{ft}^{3}\right)$ at burial; conditions: 18-ft room, 3-ft pitch, $183 \mathrm{~kW} / \mathrm{acre}$, 2000-ft-deep mine, 60-ft pillars. 


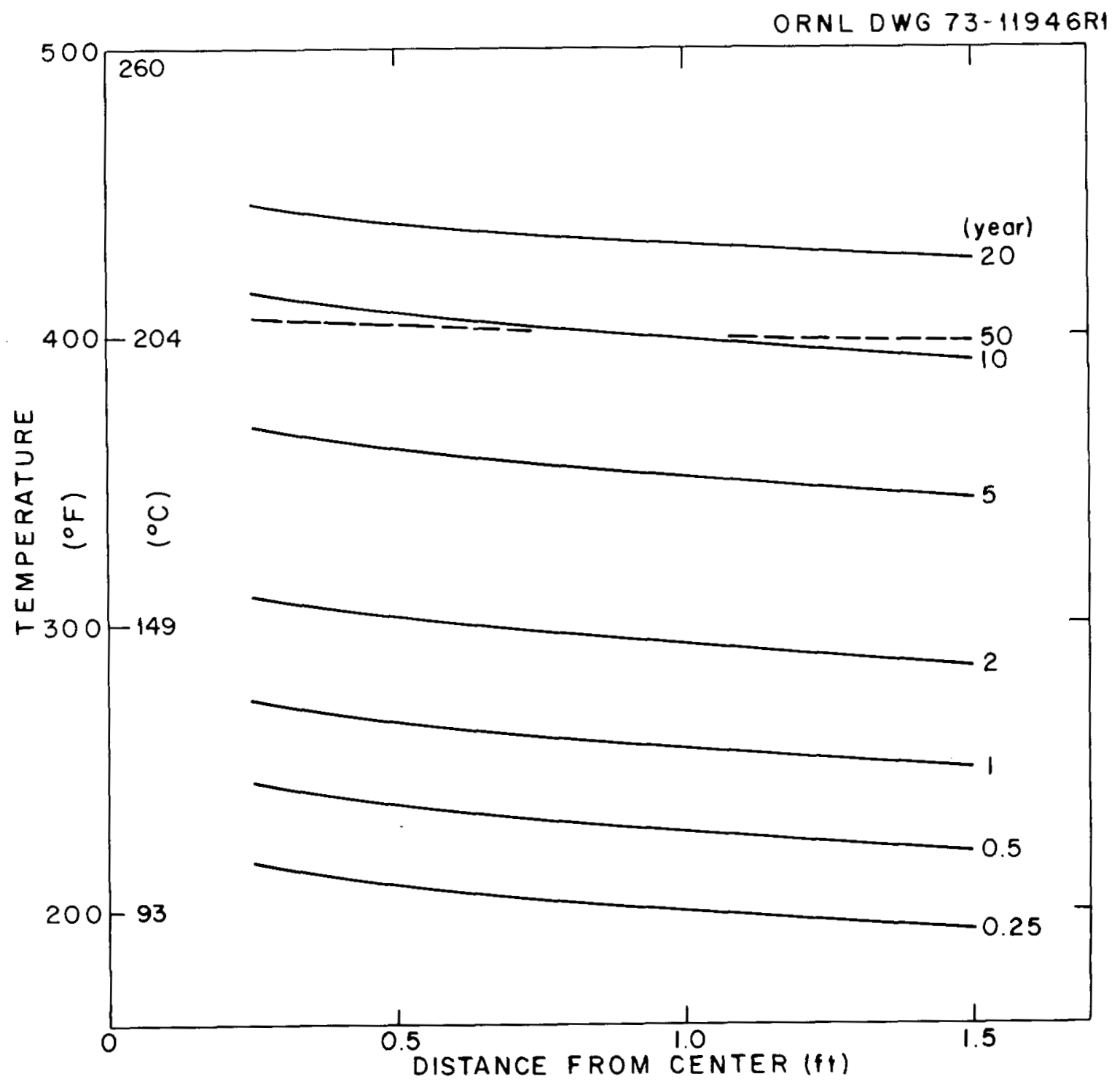

Fig. 11. Salt temperature vs distance from the center of a waste package for several different times after burial (top of canister). Canister dimensions: $6-i n$. ID, $8 \mathrm{ft}$ high; age of waste at burial: 10 years; radioactive decay heat: 0.96 $\mathrm{kW}\left(0.61 \mathrm{~kW} / \mathrm{ft}^{3}\right)$ at burial; conditions: $18-\mathrm{ft}$ room, $3-\mathrm{ft}$ pitch, $183 \mathrm{~kW} /$ acre, 2000-ft-deep mine, 60-ft pillars. 
ORNL DWG. $73-11944$

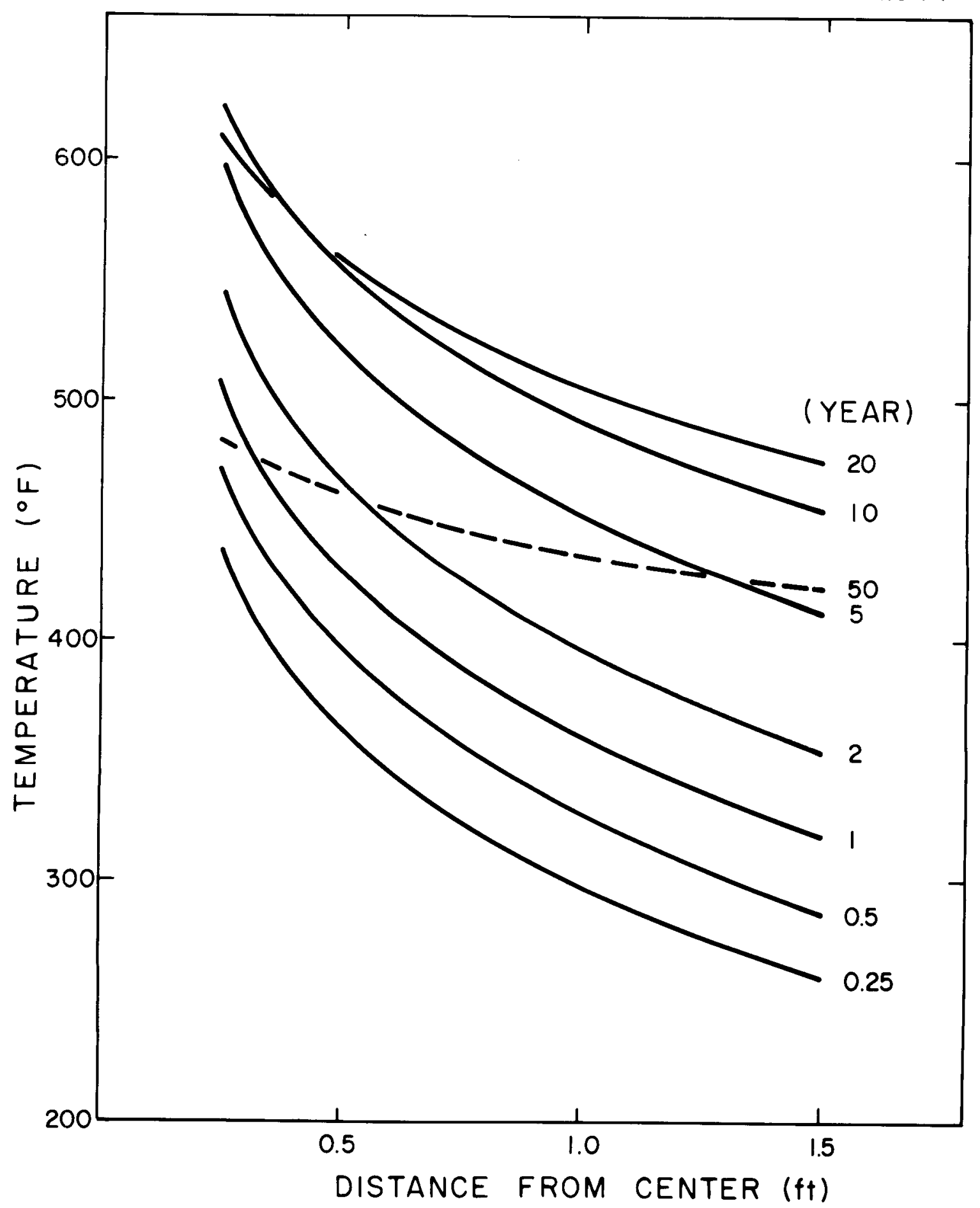

Fig. 12. Salt temperature vs distance from the center of a waste package for several different times after burial (midplane of canister). Canister dimensions: 6 -in. ID, $8 \mathrm{ft}$ high; age of waste at burial: 10 years; radioactive decay heat: $3.2 \mathrm{~kW}$ at burial; conditions: 18-ft room, 10-ft pitch, $183 \mathrm{~kW} / \mathrm{acre}, 2000-\mathrm{ft}-$ deep mine, 60-ft pillars. 
are those at the surface and at a radius of $1 \mathrm{ft}$ at the horizontal midplane and at a horizontal plane through the top of the package. The calculated temperature rise is nearly proportional to the heat output of the package (assuming that thermal conductivity of the salt is constant), and if, for example, this package contained $2 \mathrm{~kW}$ rather than $5 \mathrm{~kW}$ of 10 year-old waste at burial, the maximum temperature at the midplane surface would be $\sim 170^{\circ} \mathrm{F}$. The information plotted in Fig. 13 was obtained by Cheverton, 1,28,29 using two-dimensional calculations. 


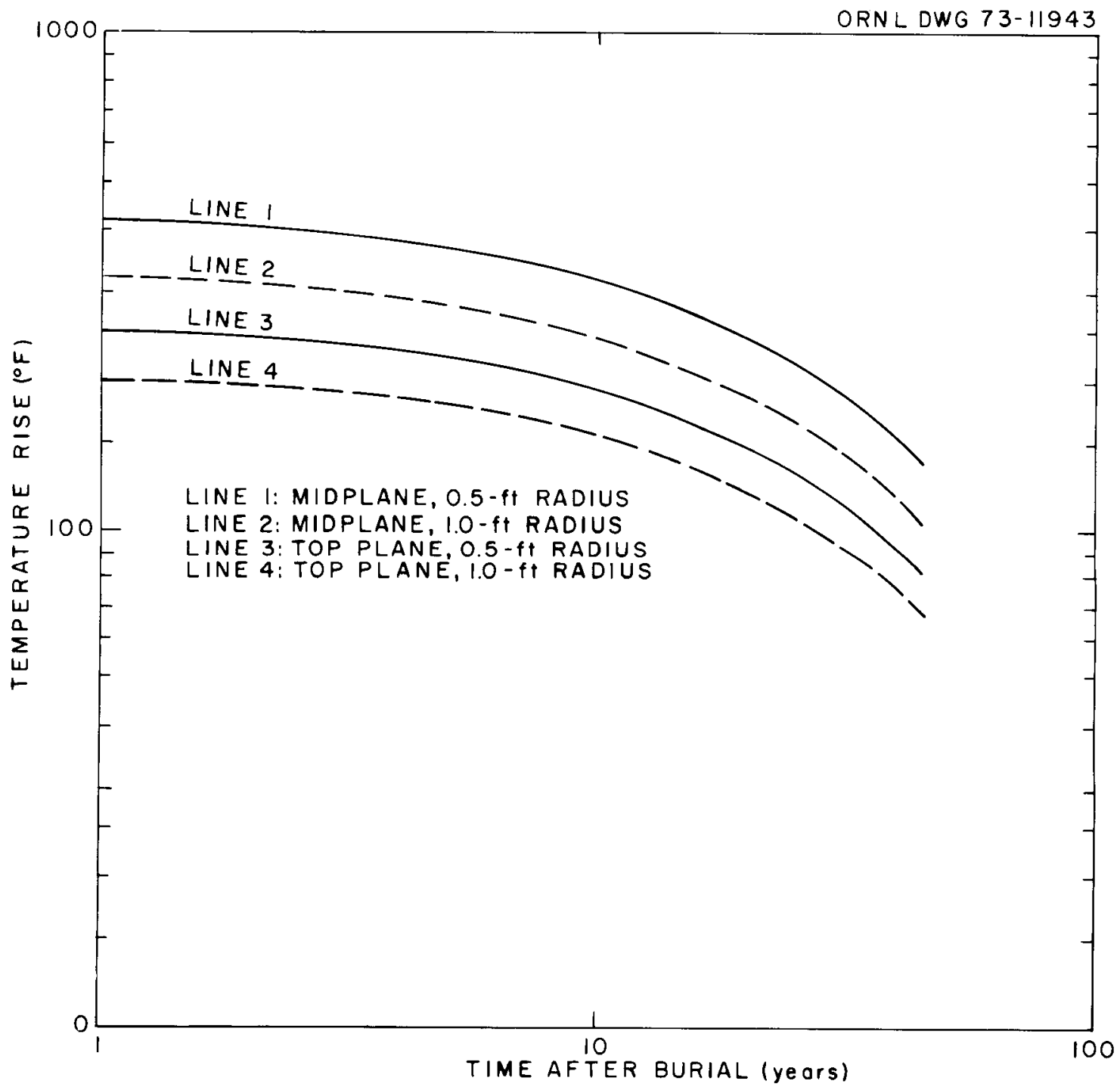

Fig. 13. Temperature rise vs time after burial of an isolated waste package. Conditions: 12-in.-OD by 10-ft-high can; $5 \mathrm{~kW}$ of 10year-old waste at burial. 
14.3. Appendix III: Gamma-Ray Dose Rates and Doses in Salt Around High-Level Waste Packages

Detailed calculations of dose rates and doses in salt surrounding a 6-in. canister (6.065-in. ID, 0.28-in. wall, $8 \mathrm{ft}$ of active length) loaded with PWR ( $\mathrm{UO}_{2}$-fuel) wastes were reported by Blomeke et a1. ${ }^{12}$ More recent calculations by others ${ }^{35}$ for canisters of 6-, 12-, and 24in. ID with $8 \mathrm{ft}$ of active length fully loaded with $\mathrm{UO}_{2}$-fueled PWR highlevel waste of the same power density (relative thermal powers of 1,4 , and 16 in the 6-, 12-, and 24-in. canisters, respectively) indicated that the dose rates and doses in surrounding salt are not strongly dependent on the diameter of the loaded canister because of self-shielding and changing surface areas. Specifically, the relative dose rates at the midplane surfaces were 1, 1.19, and 1.30 for the 6-, 12-, and 24-in. canisters, respectively, when the canisters contained solidified (glass form, $3 \mathrm{~g} / \mathrm{cm}^{3}$ ) 10-year-old waste from a $\mathrm{UO}_{2}$-fueled PWR. The relative values for older wastes were not significantly different from these values.

The gamma doses around a 12-in. canister evaluated from the calculated values of Blomeke et al., ${ }^{35}$ and the ratio values for different canister diameters discussed above are illustrated in Fig. 14. Dose vs time after burial are plotted for several distances from the edge of the canister. The solidified waste assumed in these plots is from $\mathrm{UO}_{2}$ fueled PWRs and is aged 10 years at burial, and the radioactive decay heat at burial is $1.7 \mathrm{~kW}$.

From the information in Fig. 14 and from long decay time calculations of Claiborne, ${ }^{35}$ we estimated that the maximum doses at the surface of a reference 2.25-kW canister (10-year-01d $\mathrm{UO}_{2}$-fuel waste) after 100, 1000, and 10 million years of burial are $2.3 \times 10^{10}, 2.6 \times 10^{10}$, and $3.8 \times 10^{10}$ rads, respectively. The maximum dose rate occurs at the time of emplacement, and this maximum rate at the surface of the 12-in., 2.25-kW canister is $8.8 \times 10^{4} \mathrm{rads} / \mathrm{hr}$. If this same waste had been emplaced 5 years earlier, the maximum dose rate at the surface at emplacement would have been $1.80 \times 10^{5} \mathrm{rads} / \mathrm{hr}$, but the maximum doses accumulated in the salt 


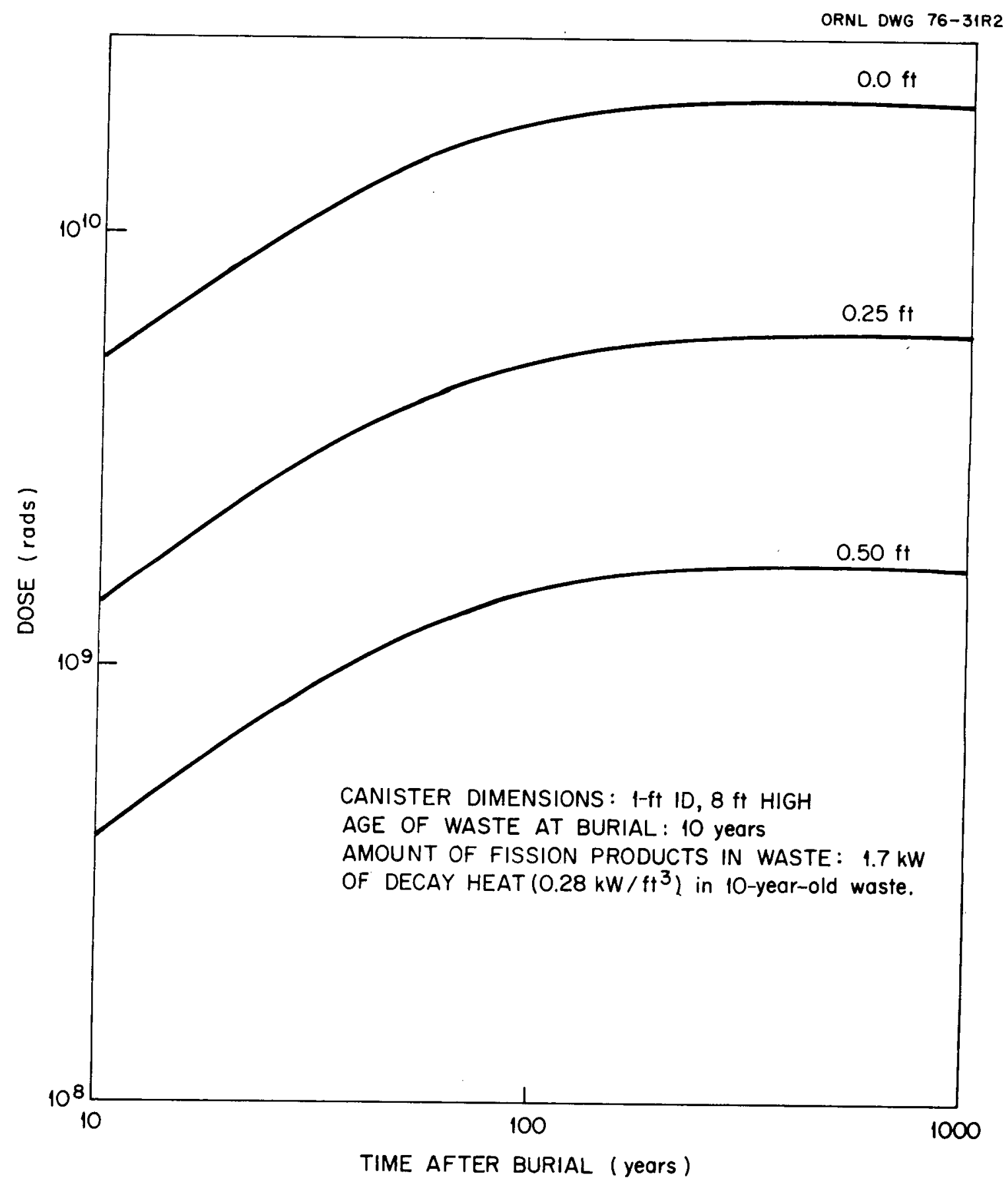

Fig. 14. Gamma-ray dose in salt at several distances from surface of waste canister at midplane vs time after burial. 
would have been increased only $\sim 0.5 \times 10^{10}$ rads above those values for the 10-year-old waste.

As shown in Fig. 14, the dose received by the salt drops off rapidly with increasing distance from the canister; for example, the dose decreases by more than a factor of 10 at a distance of $6 \mathrm{in}$. from the surface of the 12-in. canister.

Waste of the same age from MOX-fueled PWRs would give rise to nearly the same gamma-ray doses and dose rates, al though the radioactive decay heat would exceed the decay heat in waste from $\mathrm{UO}_{2}$-fueled PWRs (see Appendix II). 
14.4. Appendix IV: Drop Calorimeter Measurements of Salt Specimens After Irradiation at $130^{\circ} \mathrm{C}$;

$\gamma$-Exposures 7,8,9,X and $11+12$

14.4.1. Equipment and procedure The calorimeter used in the earlier measurements ${ }^{1}$ was modified to facilitate the dropping and retrieving of the sample container. The method of dropping the sample container is shown in Fig. 15. The tool used in retrieving is shown in Fig. 16. The lowered tool initially contacted the top rim of the container, since the container rests in a tilted position with its top rim against the drop tube. However, rotating the tool caused it to slip past the rim of the container and grip the container. A spring-like gripping action resulted since the seam of the tapered nickel cylinder was left unwelded, and the cylinder was free to expand when it was forced around the container.

A nickel sample container was used instead of the platinum container used in the earlier work in order to achieve the rigidity necessary to withstand the gripping pressure from the tool. The nickel container was fabricated by bending 10-mil nickel sheets to form two cylinders. One end of each was closed by crimping. The seams of the cylinders were left unwelded, and thus, their diameters could be altered by bending so that one cylinder could be fitted tightly into the other. An inner container with closer tolerances was made of a 2-mil-thick platinum sheet to retain fine-particle samples.

The nickel container was not as favorable as the platinum container used in the earlier work from the standpoint that its heat capacity was higher than that of the platinum, and, therefore, higher precision of temperature measurements was required to determine the heat content of the container within a given accuracy. However, temperature measurements could be made with sufficient accuracy, and the use of nickel did not increase the error in the stored energy measurements.

Convection currents in the predrop oven were stifled by adjusting the temperature gradients in such a way that the top was hotter than the bottom. 
ORNL DWG. 75-15044RI

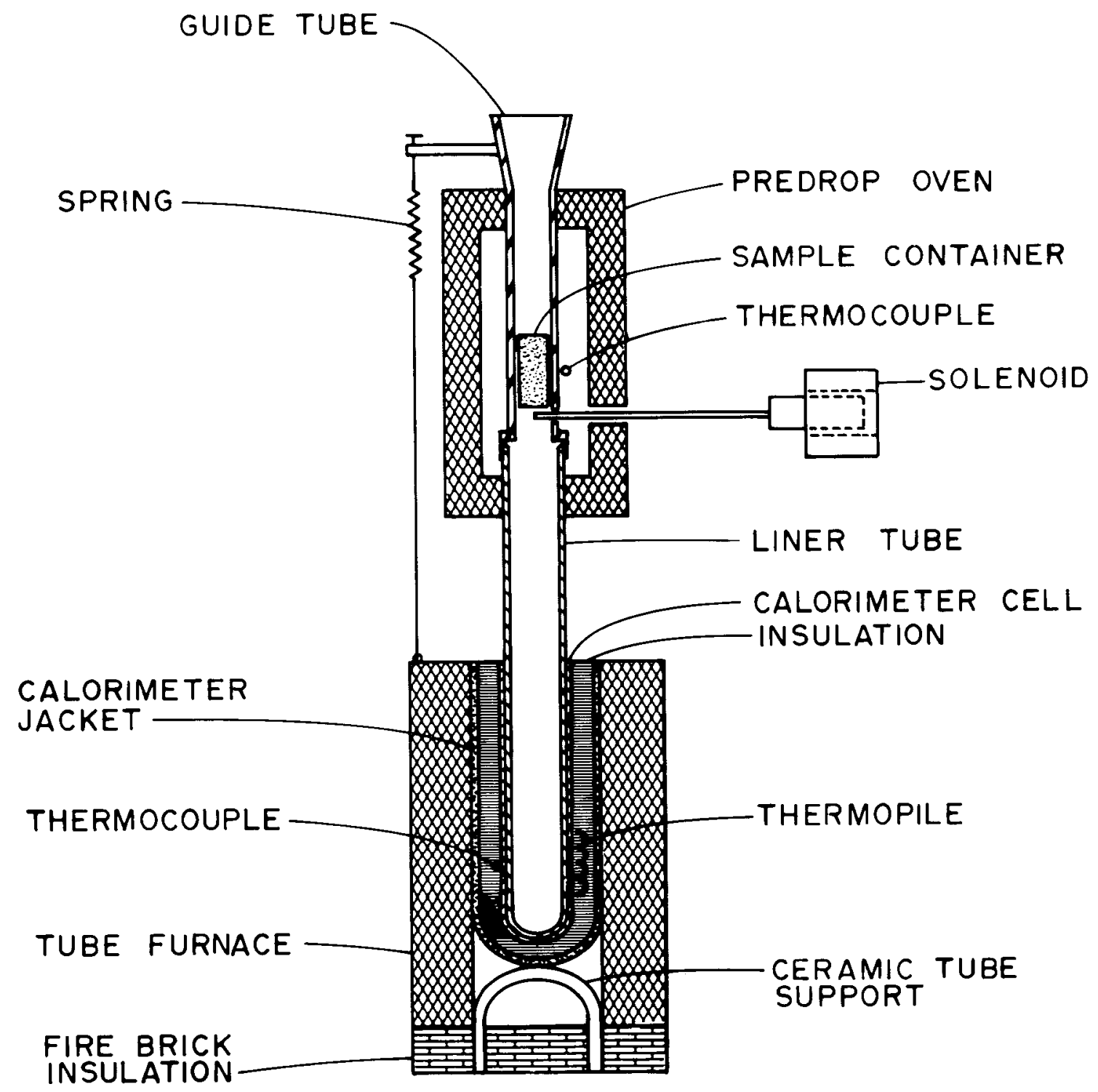

Fig. 15. Schematic drawing of the drop calorimeter. 
ORNL DWG. $75-15043$

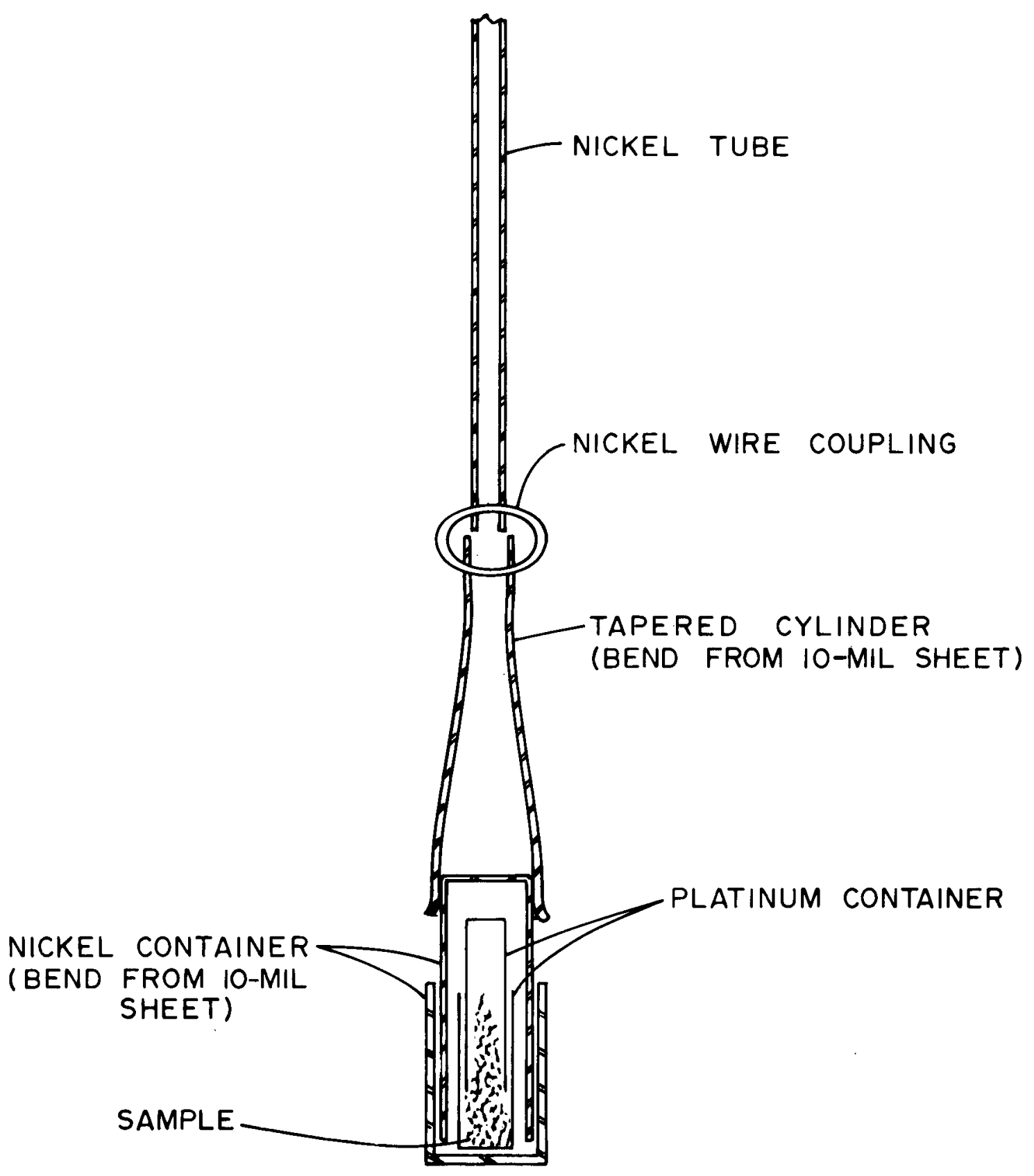

Fig. 16. Schematic showing the method of retrieval. 
14.4.2. Effects from the release of the occluded connate brine Preliminary experiments showed that, for most of the samples from natural deposits, reproducible stored energy measurements could be obtained by crushing to a sufficiently small particle size. With larger particle sizes, there was interference from the rupture of brine occlusions and the vaporization of brine in the calorimeter. Crushing destroyed the larger occlusions that were most susceptible to rupture.

We believe that the particle size required to make brine release effects negligible was determined largely by the mechanical strength of the polycrystalline salt matrix. We found that a finer particle size was required for salt from New Mexico (5,000 to 20,000 particles/gram) than from Lyons, Kansas ( 2500 particles/gram), in order to avoid decrepitation of the salt sample. The properties of the New Mexico salt were not uniform over the core from which we took samples since, in the case of a few samples, it was necessary to crush these samples to a finer particle size $(10,000$ to 20,000 particles/gram) than that which was adequate for most of the samples $(5,000$ to 10,000 particles/gram). In this report, we have listed only the results for which we obtained nearly the same value for more than one particle size (usually for both 5,000- and 10,000-particle/gram sizes in the case of the New Mexico salt).

Measurements were also made on four different dome salt deposits using 5,000- to 20,000-particle/gram sizes. The results were independent of particle size in the case of the Weeks Island and Winfield Mine deposits. However, a dependence on particle size was found with the Grand Saline and Asse deposits, which indicates effects from either residual brine or surface-sorbed moisture.

14.4.3. Surface-sorbed moisture We found that it was necessary to use more stringent drying than in the earlier work. ${ }^{1}$ Probable reasons for this are: (1) the samples were stored longer (several months) prior to measurement, (2) the humidity of the laboratory atmosphere might have been higher (ranging from 40 to $90 \%$ ), and (3) smaller particle sizes were used in the case of the natural deposits, as explained above. The 
samples were dried in the predrop oven (Fig. 15) at a temperature usually in the range of 150 to $185^{\circ} \mathrm{C}$ for usually $\sim 90 \mathrm{~min}$., al though several hours were needed in a few measurements with smaller particle sizes. In most cases, duplicate salt samples were measured using different predrop oven temperatures or different times. This served to test for the adequacy of moisture removal and to check for possible annealing of defects at the predrop oven temperature. Such comparisons showed that there was no defect annealing below $\sim 185^{\circ} \mathrm{C}$. These results agreed with our earlier annealing studies. ${ }^{1}$ [The defect annealing stage in the range of $\sim 105$ to $115^{\circ} \mathrm{C}$ was not observed in the present work because of the higher temperature of irradiation $\left.\left(130^{\circ} \mathrm{C}\right).\right]$

Moisture could not be removed to the required extent from the specimens of bedded salt which were exposed to the highest gamma dose $\left(4.5 \times 10^{10}\right.$ rads $)$. Accordingly, no determinations of stored energy could be made on these specimens. Measurements with such samples would be possible if the samples were crushed, hot-outgassed, and sealed in airtight containers prior to irradiation. In this case, measurements could be made without removing the samples from the containers. ${ }^{27}$ ( $0 f$ course the larger brine occlusions would have been removed during crushing and would not be present during irradiation.)

In all cases crushing was done within 230 min before placing the specimen in the predrop oven. The finer fraction (usually $\sim 20$ to $50 \%$ ) was discarded.

\subsubsection{Accuracy of measurements A method of correction for drift in} the thermopile zero that is based on the calorimeter time constant ${ }^{27}$ resulted in increased sensitivity as compared with the earlier work with salt. ${ }^{1}$ This made it possible to use smaller samples (20 to $40 \mathrm{mg}$ ) and, thus, facilitated crushing and sizing samples from natural deposits. The effects of the sorbed moisture and brine release described above were the dominant factors 1 imiting the accuracy. In order to obtain an estimate of the scatter, duplicate samples were measured by using different predrop oven temperatures or by varying the time in the oven. We assumed that agreement within $\pm 5 \%$ between these measurements indicated that 
moisture adsorption effects were absent. We believe that the scatter between the results reflects the accuracy of the measurements.

The estimated standard error in our reported results for the stored energy in a given sample of salt is $\pm 5 \%$. However, in the case of bedded salt, the results obtained with samples from different parts of a core differed by more than $5 \%$. Presumably, this scatter resulted from nonuniformity of impurity contents or other properties between samples from different locations. Based on the observed scatter, our estimate for the standard error in the reported value for stored energy in a given aggregate sample of Lyons salt which was not sampled representatively is $\sim \pm 10 \%$. Our estimate for the New Mexico salt is $\sim \pm 20 \%$. 
14.5 Appendix V: Results of $\mathrm{H}_{2}$ and $\mathrm{OCT}^{-}$Measurements on Specimens of Harshaw Salt Irradiated at 95 and $126^{\circ} \mathrm{C}$

These measurements employed methods 3 and 5 . The stored energy values that were determined from these results were presented and described in the text (Sects. 6.1.1 and 6.1.3 and Figs. 2 and 3).

Tabulations of the data are presented in Tables 7 and 8 , together with data on the sample weights and solution volumes employed in the measurements. The procedural information is of interest in considering possible reactions between the radiation defects during sample dissolution with concomitant decreases in the amounts of $\mathrm{H}_{2}$ and $\mathrm{HOCl}+\mathrm{OCl}^{-}$that were formed. It can be noted in Table 8 that there were no significant differences between the amounts of $\mathrm{HOCl}+\mathrm{OCl}^{-}$per calorie of stored energy in the dissolved salt, although the amount of stored energy in the samples ranged from 3.2 to $29 \mathrm{cal} / \mathrm{g}$, and the quantity, EW/V, ranged from 0.19 to $1.16 \mathrm{cal} / \mathrm{ml}$. These results then indicated that negligible interaction between defects took place during dissolution in these experiments. The smaller number of results in Table 7 supports this conclusion. 
Table 7. Hydrogen evolved during dissolution of irradiated sodium chloride ${ }^{a}$ (Harshaw salt irradiated at $95^{\circ} \mathrm{C}$ and 10 megarads/hr)

\begin{tabular}{|c|c|c|c|c|c|c|c|}
\hline \multirow[t]{2}{*}{ Sample $\mathrm{e}^{b}$} & \multirow{2}{*}{$\begin{array}{c}\text { Dose } \\
\left(10^{9} \text { rads }\right)\end{array}$} & \multirow{2}{*}{$\begin{array}{l}\text { Stored energy, } E \\
\quad(\mathrm{cal} / \mathrm{g})\end{array}$} & \multirow{2}{*}{$\begin{array}{c}\text { Wt of salt } \\
(\mathrm{mg})\end{array}$} & \multirow{2}{*}{$\begin{array}{c}\text { Solution vol, } V \\
(\mathrm{ml})\end{array}$} & \multirow{2}{*}{$\begin{array}{c}\frac{E W}{V} \\
(\mathrm{cal} / \mathrm{ml})\end{array}$} & \multicolumn{2}{|c|}{ Observed amount of $\mathrm{H}_{2}$} \\
\hline & & & & & & $(\mu \mathrm{mole} / \mathrm{g})$ & ( $\mu \mathrm{mole} / \mathrm{cal})$ \\
\hline$c-2$ & 4.1 & $5.2^{c}$ & 94.5 & 1.3 & 0.38 & 34.4 & 6.6 \\
\hline$c-2$ & 4.1 & $5.2^{c}$ & 88.9 & 1.5 & 0.31 & 28.7 & 5.5 \\
\hline$c-3$ & 10.3 & 12.0 & 130.7 & 1.5 & 1.05 & 57.0 & 4.75 \\
\hline$c-8$ & 47.7 & 29.0 & 11.1 & 1.5 & 0.21 & 139.3 & 4.80 \\
\hline
\end{tabular}

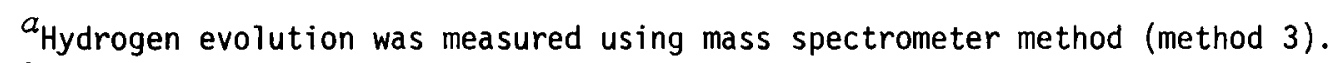

${ }^{b}$ These samples were fully described in ref. 1.

${ }^{c}$ The stored energy was read from the upper curve in Fig. 3. 
Table 8. Amount of $\mathrm{HOCl}+\mathrm{OCl}^{-}$formed during dissolution of irradiated sodium chloride ${ }^{a}$

(Harshaw salt irradiated at 126 or $95^{\circ} \mathrm{C}$ and 10 megarads $/ \mathrm{hr}$ ) $b$

\begin{tabular}{|c|c|c|c|c|c|c|c|}
\hline \multirow[b]{2}{*}{ Sample } & \multirow[b]{2}{*}{$\begin{array}{l}\text { Dose } \\
\left(10^{9} \text { rads }\right)\end{array}$} & \multirow[b]{2}{*}{$\begin{array}{l}\text { Stored energy, E } \\
(\text { cal } / g)\end{array}$} & \multirow[b]{2}{*}{$\begin{array}{l}\text { Wt of } \\
(\mathrm{mg})\end{array}$} & \multirow[b]{2}{*}{$\begin{array}{l}\text { Solution of vol, } \\
\qquad(m])\end{array}$} & \multirow[b]{2}{*}{$\begin{array}{c}\frac{E W}{V} \\
(\mathrm{cal} / \mathrm{ml})\end{array}$} & \multicolumn{2}{|c|}{ Observed amount of $\mathrm{HOCl}+\mathrm{OCl}^{-\mathrm{C}}$} \\
\hline & & & & & & $(\mu \mathrm{mole} / \mathrm{g})$ & $(\mu \mathrm{mole} / \mathrm{cal})$ \\
\hline$c-20$ & 3.2 & $3.2^{d}$ & 119.9 & 2.0 & 0.19 & 19.8 & 5.0 \\
\hline$c-21$ & 7.6 & $8.6^{d}$ & 229.9 & 3.1 & 0.64 & 43.9 & 5.1 \\
\hline$c-21$ & 7.6 & & 93.3 & 2.0 & 0.40 & 41.3 & 4.8 \\
\hline$c-22$ & 13.1 & $13.0^{d}$ & 136.8 & 2.0 & 0.89 & 71 & 5.4 \\
\hline$c-23$ & 19.5 & $16.6^{d}$ & 512.3 & 35.0 & 0.15 & 88 & 5.3 \\
\hline$c-24$ & 26.5 & $163^{e}$ & 131.6 & 2.0 & 1.07 & 83 & 5.1 \\
\hline$c-24$ & 26.5 & & 118.4 & 2.0 & 0.96 & 85 & 5.2 \\
\hline$c-25$ & 27.5 & $16.7^{e}$ & 122.5 & 2.0 & 1.02 & 87 & 5.2 \\
\hline$c-8^{f}$ & 47.7 & 29.0 & 0.0602 & 1.5 & 1.16 & 133 & 4.6 \\
\hline
\end{tabular}

${ }^{a}$ The amount of $\mathrm{OCl}^{-}$was measured using an absorption spectrophotometer (method 5).

${ }^{b}$ All samples were irradiated at $126^{\circ} \mathrm{C}$ except $\mathrm{c}-8$, which was irradiated at $95^{\circ} \mathrm{C}$. Samples are fully described in ref. 1. ${ }^{c}$ The amount of $\mathrm{OCl}^{-}$was measured after dilution and addition of enough $\mathrm{NaOH}$ to increase the $\mathrm{pH}$ to $\sim 9$.

${ }^{d}$ Stored energy ( $E$ ) was read from curve in Fig. 2.

${ }^{e}$ Stored energy (E) was read from dotted line in Fig. 2.

$f_{\text {See Table }} 10$ for $\mathrm{H}_{2}$ measurements on this specimen. 
14.6. Appendix VI: Hydrogen Evolution Measurements on Specimens of Harshaw and Natural Salt Irradiated at $130^{\circ} \mathrm{C}$

The results of the hydrogen evolution measurements, which were obtained by method 4, are shown in Table 9. Method 4 is briefly described in the footnote. ${ }^{9}$ Figure 17 shows a plot of the amount of $\mathrm{H}_{2}$ evolution observed with a given specimen vs the stored energy determined by drop calorimetry.

The amount of $\mathrm{H}_{2}$, which was observed for a given specimen using method 4, was below the amount expected; the difference between the observed and expected values increased with increasing amounts of stored energy in the specimens (Fig. 17). These differences indicated that some interaction between defects, which reduced the yield of $\mathrm{H}_{2}$, was taking place during sample dissolution and that the fraction of the defects which interacted in this way increased as the amount of stored energy in a specimen increased. The fraction of defects that interacted also increased as the number of defects dissolved per unit volume of solution increased, since the ratio of sample weight to solution volume was the same in all cases. No differences of this type were observed in the previous masurements of $\mathrm{H}_{2}$ and $\mathrm{OCl}^{-}$, which were conducted using methods 3 and 5 . However, the values of EW/V, which are representative of the number of defects dissolved per unit volume of solution, in the previous measurements [maxmium $=1.16$ (see Appendix $V$ )] were significantly lower than those in method 4 measurements [1.5 to 5.6 (see Table 10)], and it appeared likely that the method 4 discrepancies could be avoided by using larger volumes of solution and/or smaller samples of salt.

A few experiments were made to verify this idea. The sample weights, solution volumes, and results of these experiments are presented in Table 10. Methods $4 A$ and $4 B$ differed from method 4 and from each other only with respect to the solution volumes and/or sample weights employed in the dissolutions. The results obtained using method $4 \mathrm{~A}$ (150-mg sample with $3 \mathrm{ml}$ of solution) are plotted in Fig. 17. These results appeared to confirm the expected effects of reducing the values of EW/EV 
Table 9. Results of $\mathrm{H}_{2}$ measurements using method $4^{\alpha}$ on specimens of Harshaw and natural salt irradiated at $130^{\circ} \mathrm{C}$

\begin{tabular}{|c|c|c|c|c|c|}
\hline \multirow{2}{*}{ Sample } & \multirow{2}{*}{$\begin{array}{c}\text { Dose } \\
\left(10^{9} \text { rads }\right)\end{array}$} & \multirow{2}{*}{$\begin{array}{l}\text { Stored energy, } E \\
(\text { cal } / g)\end{array}$} & \multirow{2}{*}{$\begin{array}{c}\frac{E W}{V} \\
(\mathrm{cal} / \mathrm{ml})\end{array}$} & \multicolumn{2}{|c|}{ Observed amount of $\mathrm{H}_{2}$} \\
\hline & & & & $(\mu \mathrm{mole} / \mathrm{g})^{b}$ & $(\mu \mathrm{mole} / \mathrm{cal})$ \\
\hline \multicolumn{6}{|l|}{ Harshaw } \\
\hline 9 & 9.78 & 10.2 & 1.5 & 41.9 & 4.11 \\
\hline$x$ & 12.5 & & & 40.5 & \\
\hline $7-8$ & 21.8 & 16 & 2.4 & 58.0 & 3.65 \\
\hline $9-x$ & 22.3 & 16.5 & 2.5 & 69.0 & 4.18 \\
\hline $7-8-9$ & 31.5 & 21 & 3.2 & 69.3 & 3.30 \\
\hline $7-8-9-x$ & 44.0 & 37 & 5.6 & 73.3 & 1.98 \\
\hline \multicolumn{6}{|l|}{ New Mexico } \\
\hline 9 & 9.78 & 13.0 & 2.0 & 39.9 & 3.07 \\
\hline$x$ & 12.5 & 12 & 1.8 & 41.3 & 3.44 \\
\hline $9-x$ & 22.3 & 23.5 & 3.5 & 75.1 & 3.20 \\
\hline $7-8$ & 21.8 & 22.0 & 3.3 & 65.2 & 2.96 \\
\hline $7-8-9$ & 31.5 & 31.0 & 4.7 & 87.4 & 2.82 \\
\hline $7-8-9-x$ & 44.0 & & & 100.3 & \\
\hline $11-12$ & 22.6 & 14.0 & 2.1 & 64.1 & 4.58 \\
\hline 13 & 9.75 & & & 40.4 & \\
\hline $11-12-13$ & 32.4 & & & 77.4 & \\
\hline \multicolumn{6}{|l|}{ Lyons } \\
\hline 9 & 9.78 & 13.3 & 2.0 & 41.3 & 3.11 \\
\hline $7-8-9$ & 31.5 & 33.5 & 5.0 & 90.3 & 2.70 \\
\hline \multicolumn{6}{|c|}{ Weeks Island } \\
\hline 9 & 9.78 & 10.8 & 1.6 & 47.2 & 4.37 \\
\hline \multicolumn{6}{|c|}{ Winfield Mine } \\
\hline 9 & 9.78 & 11.5 & 1.7 & 46.7 & 3.54 \\
\hline
\end{tabular}

$a_{\mathrm{H}_{2}}$ measurements made in ORNL Analytical Chemistry Division by dissolving $20.15 \mathrm{~g}$ of sample in $1 \mathrm{ml}$ of boiled water in a $16-\mathrm{ml}$, rubber stoppered vial, collecting an aliquot of the gas using a syringe and needle, and measuring the amount of $\mathrm{H}_{2}$ in the aliquot using gas chromotography with argon carrier gas.

${ }^{b}$ All analyses were made in duplicate. The listed value is the average of the two results. 
Table 10. Results of $\mathrm{H}_{2}$ measurements using several different ratios of sample weight to solution volume

\begin{tabular}{|c|c|c|c|c|c|c|c|}
\hline \multirow{2}{*}{ Sample } & \multirow{2}{*}{ Method } & \multirow{2}{*}{$\begin{array}{l}\text { Stored energy, } E \\
(\mathrm{ca} l / g)\end{array}$} & \multirow{2}{*}{ Wt of sample, W } & \multirow{2}{*}{$\begin{array}{l}\text { Vol of solution } \\
(\mathrm{m} 1)\end{array}$} & \multirow{2}{*}{$\begin{array}{c}\frac{E W}{V} \\
(\mathrm{cal} / \mathrm{m}\})\end{array}$} & \multicolumn{2}{|c|}{ Observed amount of $\mathrm{H}_{2}$} \\
\hline & & & & & & (umole/g) $)^{a}$ & (umole/cal) \\
\hline \multicolumn{8}{|c|}{ Harshaw } \\
\hline \multirow[t]{3}{*}{9} & $4^{b}$ & 10.2 & 150 & 1 & 1.5 & 41.9 & 4.11 \\
\hline & $4 A$ & 10.2 & 150 & 3 & 0.51 & 48.9 & 4.79 \\
\hline & $4 B$ & 10.2 & 100 & 5 & 0.20 & 41.6 & 4.08 \\
\hline \multicolumn{8}{|c|}{ New Mexico } \\
\hline \multirow[t]{3}{*}{9} & $4^{b}$ & 13.0 & 150 & 1 & 2.0 & 39.9 & 3.07 \\
\hline & $4 A$ & 13.0 & 150 & 3 & 0.65 & 57.3 & 4.41 \\
\hline & $4 B$ & 13.0 & 100 & 5 & 0.26 & 41.0 & 3.15 \\
\hline \multirow[t]{3}{*}{$x$} & $4^{b}$ & 12 & 150 & 1 & 1.8 & 41.3 & 3.44 \\
\hline & $4 A$ & 12 & 150 & 3 & 0.60 & 63.6 & 5.30 \\
\hline & $4 B$ & 12 & 100 & 5 & 0.24 & 45.3 & 3.78 \\
\hline \multirow[t]{3}{*}{$7-8$} & $4^{b}$ & 22 & 150 & 1 & 3.3 & 65.2 & 2.96 \\
\hline & $4 A$ & 22 & 150 & 3 & 1.1 & 97.1 & 4.41 \\
\hline & $4 B$ & 22 & 100 & 5 & 0.44 & 81.3 & 3.70 \\
\hline \multirow[t]{3}{*}{9} & $4^{b}$ & 10.8 & 150 & 1 & 1.6 & 47.2 & 4.37 \\
\hline & $4 A$ & 10.8 & 150 & 3 & 0.54 & 49.9 & 4.62 \\
\hline & $4 B$ & 10.8 & 100 & 5 & 0.22 & 48.2 & 4.46 \\
\hline
\end{tabular}

$a_{\text {All }}$ analyses were made in duplicate. The listed value is the average of the two results.

${ }^{b}$ The results for these samples were presented in Table 9. 


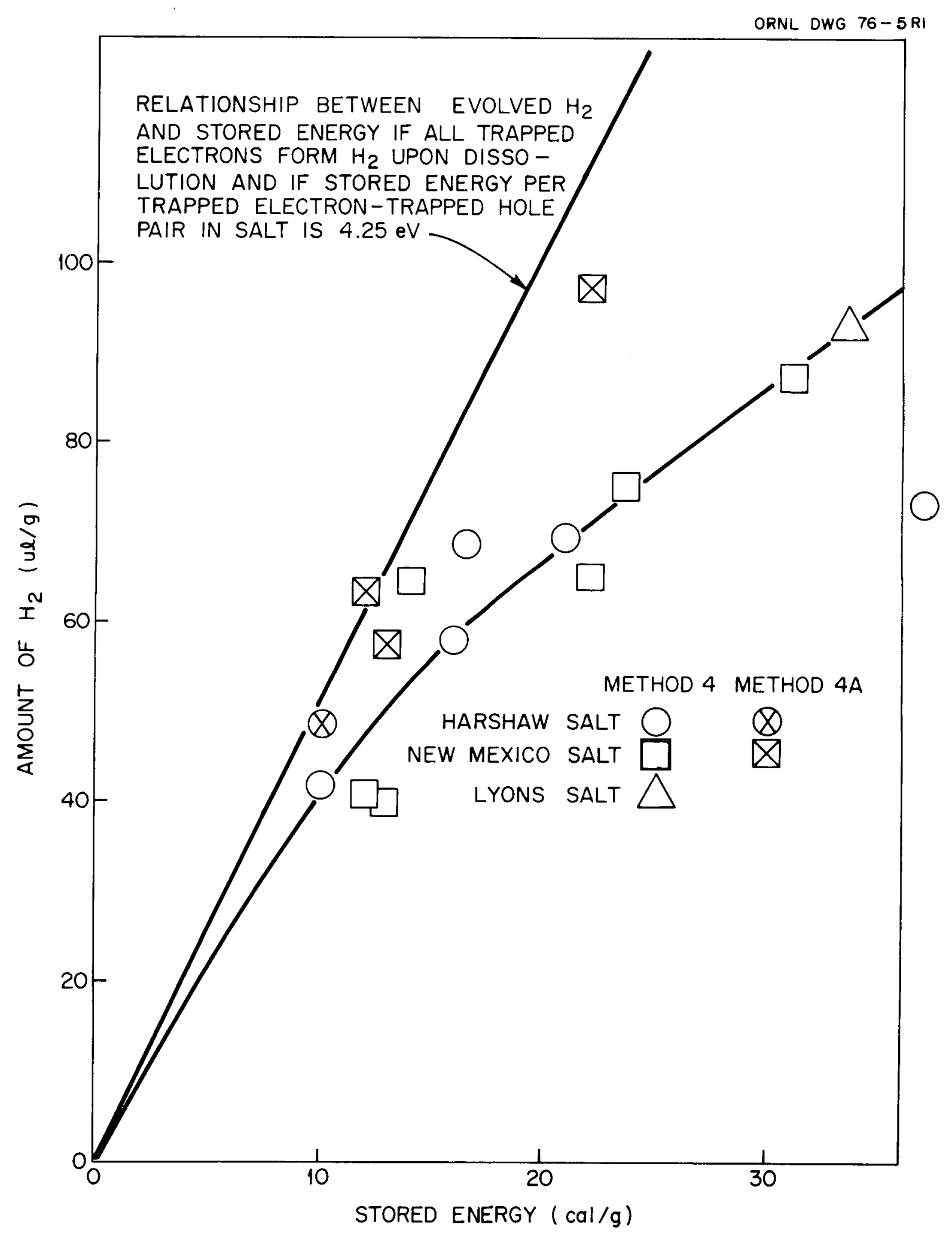

Fig. 17. $\mathrm{H}_{2}$ evolved upon dissolving salt irradiated in HFIR spent fuel elements at $130^{\circ} \mathrm{C}$ vs stored energy in salt. 
to the range of values employed in the method 3 and 5 measurements. However, upon increasing the solution volume still further and, at the same time, by reducing the sample weight (100-mg sample with $5 \mathrm{ml}$ of solution, method $4 B$ ), the amounts of $\mathrm{H}_{2}$ that were observed were apparently less than those with method $4 \mathrm{~A}$ (although higher than those with method 4).

Additional experimental measurements would be required to establish an explanation for the difference between the results of methods $4 A$ and 4B. We did not pursue these additional measurements since we did not require the $\mathrm{H}_{2}$ evolution data to establish the stored energies in our $130^{\circ} \mathrm{C}$ irradiated specimens. We did use method 4 results to help establish the stored energy in specimens which were irradiated at a temperature range of 30 to $50^{\circ} \mathrm{C}$ (Sect. 6.2). However, the stored energy in these specimens was $<5 \mathrm{cal} / \mathrm{g}$, and, accordingly, we could assume that the amounts of $\mathrm{H}_{2}$ which were observed corresponded to the amounts of stored energy in the specimen within $220 \%$ (see Fig. 17). 
14.7. Appendix VII: Results of Measurements of Postirradiation Thermally Activated Annealing of Stored Energy

Thermally activated annealing characteristics were investigated by exposing portions of some of the irradiated samples to elevated temperatures prior to measuring the stored energy. This work was presented and discussed in a previous report. ${ }^{1}$ Most of this previous data presentation is reviewed in this section.

The Harshaw salt that had been irradiated at $95^{\circ} \mathrm{C}$ showed rapid annealing to a maximum value of 2 to $3 \mathrm{cal} / \mathrm{g}$ in the temperature range of 115 to $120^{\circ} \mathrm{C}$. The remainder annealed (at measurable rates) only at temperatures above $\sim 180^{\circ} \mathrm{C}$. Most of our quantitative measurements dealt with the higher temperature stage of the annealing. Specimens that had been irradiated at temperatures $\geq 126^{\circ} \mathrm{C}$ exhibited only the higher temperature stage.

14.7.1. The effects of time at a given temperature on the amount of annealing - kinetic order of the annealing process The results of experiments conducted to determine the kinetic order of the thermally activated annealing process are presented in Figs. 18 and 19. The annealing temperature for the experiments summarized in Fig. 18 ranged from 228 to $233^{\circ} \mathrm{C}$. We normalized the experimental data to $228^{\circ} \mathrm{C}$ in order to evaluate the effects of time without interference from the effects due to differences in temperature, assuming that the annealing reaction was zero order and the activation energy was $39 \mathrm{kcal} / \mathrm{mole}$. The plots of the observed as well as the plots of the normalized data show that the annealing process was zero order in these experiments. The basis for the assumption of the $39-\mathrm{kcal} / \mathrm{mole}$ activation energy is presented in the next section.

The results of other experiments that were made to further test for the existence of zero-order kinetics are plotted in Fig. 19. Samples of both Harshaw and Lyons salt irradiated at $160^{\circ} \mathrm{C}$ were studied. Again, the data were temperature-normalized, where appropriate, assuming zeroorder kinetics and an activation energy of $39 \mathrm{kcal} / \mathrm{mole}$. The normalized 


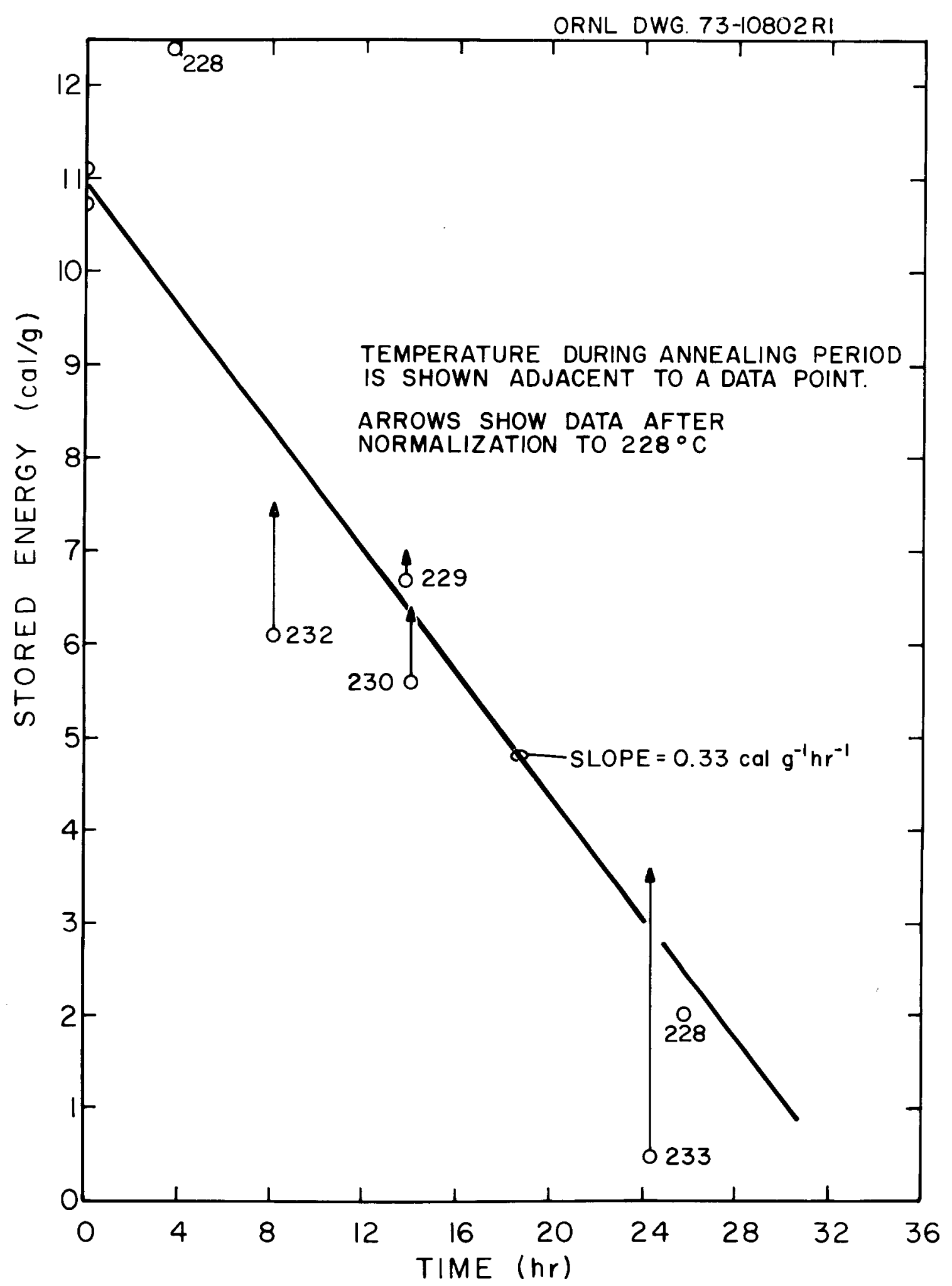

Fig. 18. The effects of heating time at $2230^{\circ} \mathrm{C}$ on the amount of annealing of stored energy in Harshaw salt irradiated at $95^{\circ} \mathrm{C}$. 
ORNL DWG. 73-10803RI

TIME AT TEMPERATURE ( $h r)$, SCALE B

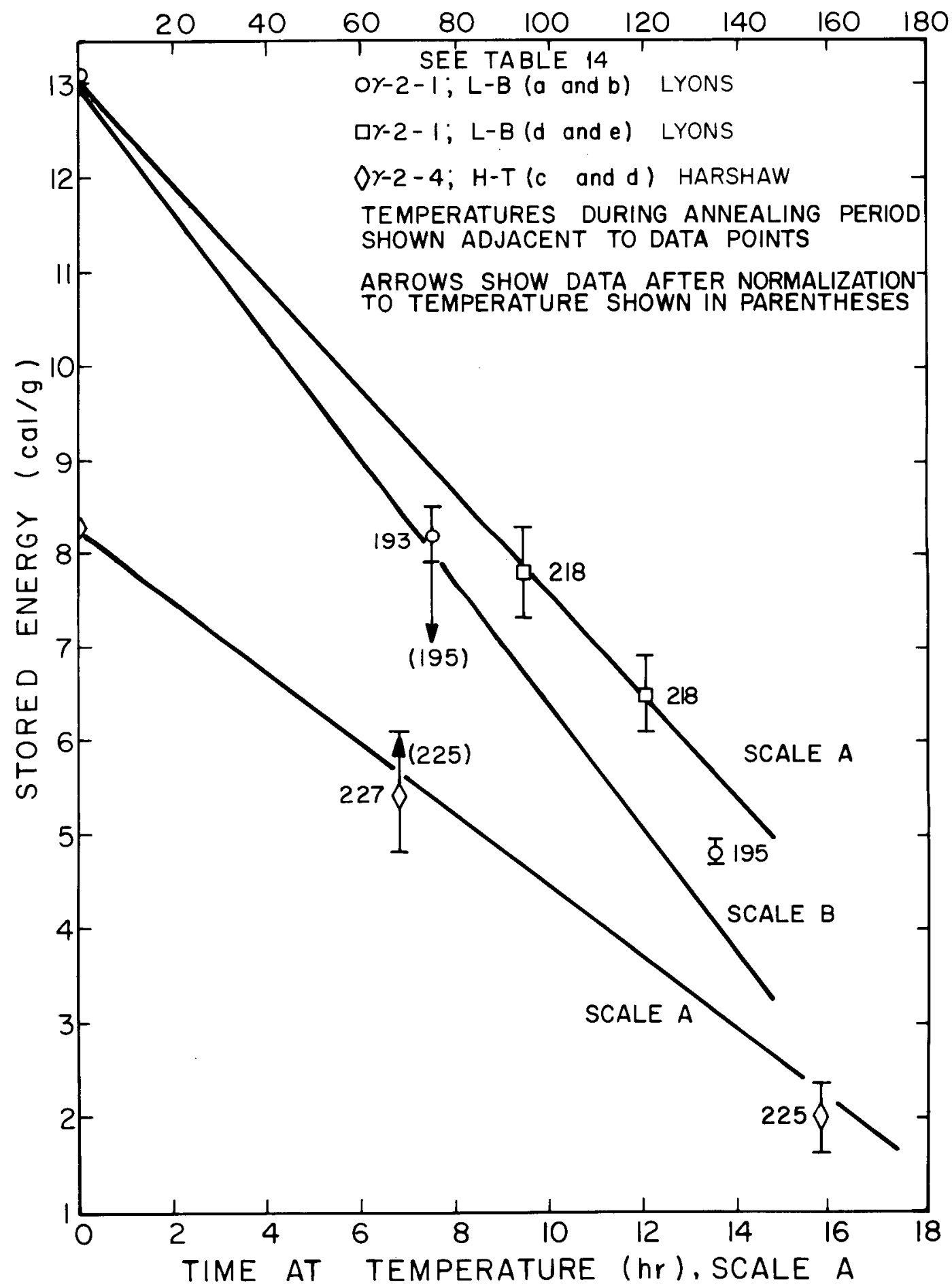

Fig. 19. The effects of time at indicated temperature on the amount of annealing of stored energy in Harshaw and Lyons salt irradiated at $160^{\circ} \mathrm{C}$. 
values are shown by arrows, and the normalization temperatures are given in parentheses. The data, as plotted in Fig. 19, confirm the occurrence of zero-order kinetics for the sample materials, radiation exposure conditions, and annealing conditions that were tested.

14.7.2. The effects of temperature on the amounts of annealing activation energy for the annealing process Test conditions and results for experiments aimed at establishing the effects of temperature on the rates of thermally activated annealing are presented in Table 11. In these experiments, the measurements of stored energy were conducted by the standard method using a preheating temperature of $125^{\circ} \mathrm{C} .1$

The zero-order rate constant values which were calculated from the data are plotted vs the reciprocal temperature in Fig. 20 . The plots show that the rate constant at a given temperature may depend on the radiation exposure history of the specimen and, possibly, on the type of salt (i.e., Harshaw synthetic crystal or Lyons salt).

The indicated activation energy is $9.8 \mathrm{kcal} / \mathrm{mole}$ and is the same for all types of salt.

The lines through the data obtained with a given irradiated specimen were drawn using the following criteria:

1. The slopes should be equal.

2. Lines through the data obtained with specimen portions from a given irradiated specimen should give reasonably good "eyebal1" fits to the data.

3. Extrapolations of the lines should pass near zero-order rate constant values for the thermal annealing of Lyons salt (at $2158^{\circ} \mathrm{C}$ ) that were inferred from correlations of the stored energy data for salt irradiated in Project Salt Vault (Sect. 6.1.9) and for salt irradiated in our laboratory experiments in the temperature range of 160 to $173^{\circ} \mathrm{C}$ (Sect. 6.3). This criterion was best satisfied for the Lyons salt by the lower line in Fig. 20 . 
Table 11. Effects of temperature and time on the thermal annealing of Harshaw and Lyons salt

\begin{tabular}{|c|c|c|c|c|c|}
\hline \multirow[b]{2}{*}{$\begin{array}{l}\text { Sample Ref. No. } \\
\text { and description }\end{array}$} & \multirow{2}{*}{$\begin{array}{l}\text { Initial } \\
\text { stored } \\
\text { energy } \\
(\text { cal } / g)\end{array}$} & \multicolumn{2}{|c|}{ Annealing treatment } & \multirow[b]{2}{*}{$\begin{array}{l}\text { Decrease in } \\
\text { stored energy } \\
(\mathrm{ca}) / \mathrm{g})\end{array}$} & \multirow{2}{*}{$\begin{array}{l}\text { Zero-order } \\
\text { rate } \\
\text { constant } \\
\left.\text { (cal } \mathrm{g}^{-1} \mathrm{hr}^{-1}\right)\end{array}$} \\
\hline & & $\begin{array}{l}\text { Temperature } \\
\left({ }^{\circ} \mathrm{C}\right)\end{array}$ & $\begin{array}{l}\text { Time } \\
(\mathrm{hr})\end{array}$ & & \\
\hline
\end{tabular}

$\gamma-2-4$; Harshaw
(f)
$8.5 \pm 0.1 \quad 185.0$
278.3
$5.7 \pm 0.3(2)$
0.020
(c)
225.2
15.8
$6.3 \pm 0.4$ (2)
0.40
(d)
227.4
6.8
$2.9 \pm 0.6$ (2)
0.42

$\gamma-2-1$; Lyons
(a)
$13.1 \pm 0.3$
192.7
70.5
$4.9 \pm 0.3(2)$
0.070
(b)
195.2
134.3
$8.3 \pm 0.1$ (2)
0.062
(c)
212.5
4.8
$6.6 \pm 0.6(2)$
1.4
(d)
217.6
9.4
$5.3 \pm 0.5(2)$
0.56
(e)
218.3
12.0
$6.6 \pm 0.4$ (2)
0.55
(f)
226.2
5.65
$6.6 \pm 0.9$ (2)
1.2

$\gamma-1-1$; Lyons
(i)
$7.5 \pm 0.2 \quad 220.0$
$47.8 \quad 4.9$
(1)
0.102
(a)
238.8
2.4
$3.8 \pm 0.2(2)$
1.6
(e)
244.8
2.8
2.2
0.79
(d)
258.4
3.6
$4.2 \pm 0.5$ (2)
1.2
(c)
262.6
1.0
$4.2 \pm 0.6(2)$
4.2

$\gamma-6-2$; Harshaw

(b)

$$
7.4 \pm 0.4 \quad 228.9
$$

4.5

$4.7 \pm 0.8$ (2)

1.05

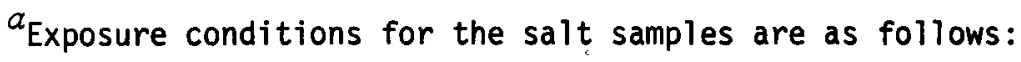

\begin{tabular}{cllcc}
\cline { 3 - 5 } & Salt & $\begin{array}{c}\text { Temp } \\
\left({ }^{\circ} \mathrm{C}\right)\end{array}$ & $\begin{array}{c}\text { Exposure conditions } \\
\text { (megarads } / \mathrm{hr})\end{array}$ & $\begin{array}{c}\text { Dose } \\
\left(10^{9}\right.\end{array}$ \\
\hline$\gamma-2-4$ & Harshaw & 160 & 61 & 13 \\
$\gamma-6-2$ & Harshaw & 144 & 40 & 9.8 \\
$\gamma-2-1$ & Lyons & 160 & 61 & 13 \\
$\gamma-1-1$ & Lyons & 160 & 36 & 7.6
\end{tabular}

${ }^{b}$ The number of measurements on the annealed sample is shown in parentheses. The spread of the results of two measurements is shown as a plus-minus value. 


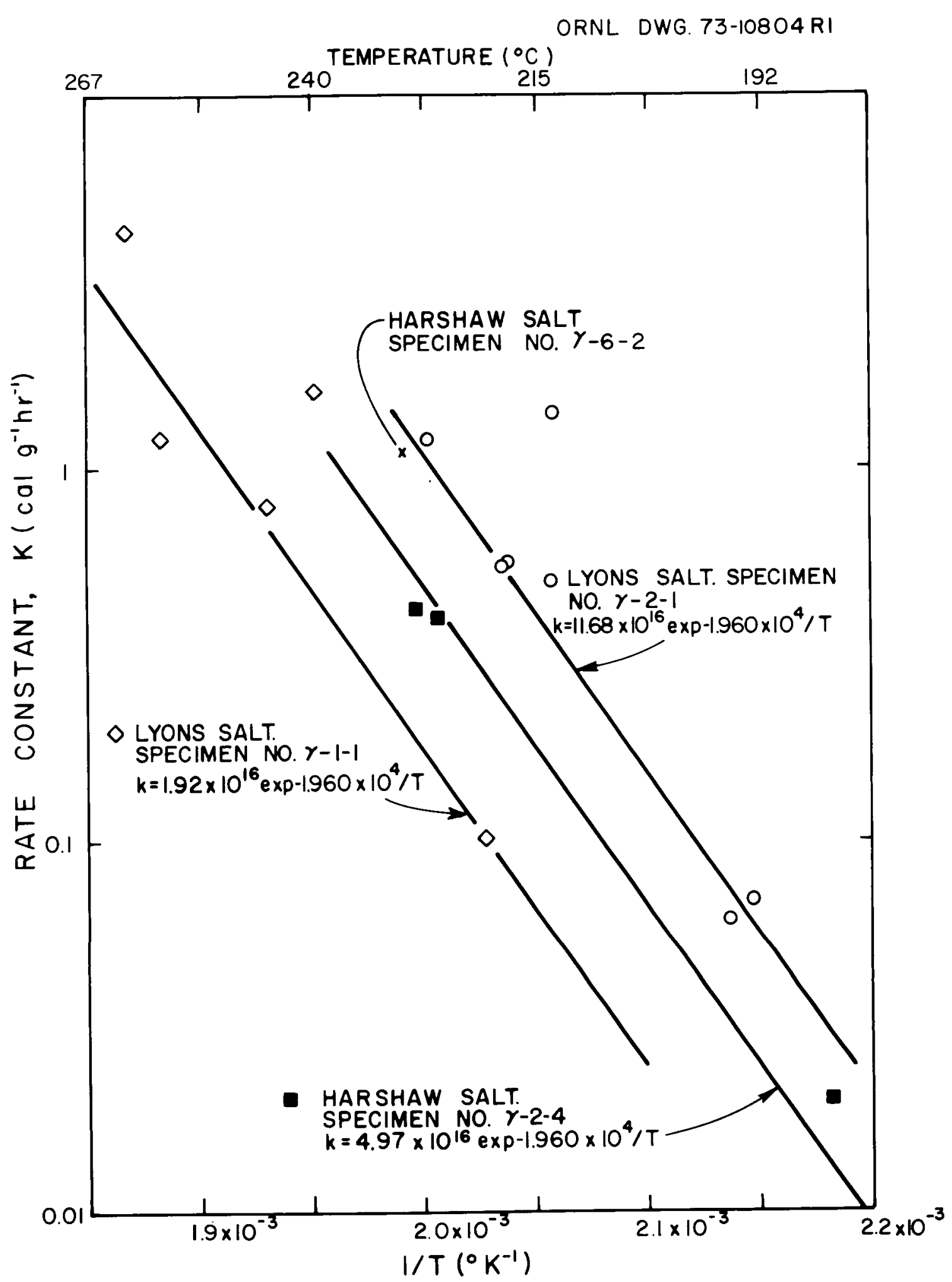

Fig. 20. Zero-order thermal annealing constants as a function of annealing temperature for Harshaw and Lyons salt. 
With respect to correlations between our other postirradiation annealing data and those in Fig. 20, it can be noted that the value of $0.33 \mathrm{cal} \mathrm{g}^{-1} \mathrm{hr}^{-1}$ at a temperature of $228^{\circ} \mathrm{C}$ for the Harshaw salt data in Fig. 18 falls very close to the line representing the Harshaw salt data in Fig. 20. Since the specimens represented in Fig. 18 were irradiated at 10 megarads $/ \mathrm{hr}$ and at a temperature of $95^{\circ} \mathrm{C}$, this agreement indicates that changing the irradiation conditions for Harshaw salt did not appreciably affect the second-stage thermal annealing. 


\subsection{Appendix VIII: Loss of Water from Bedded} Salt Specimens During Gamma Irradiation ${ }^{36}$

Several $\frac{1}{2}-i n$. cube specimens of bedded salt from the Lyons mine and one sample of Harshaw salt, which were irradiated in previously reported ${ }^{1}$ HFIR-gamma exposures 2 and 3 , were examined for changes in weight during exposure. It was known that bedded salt from the Lyons mine contained $\leq 0.25$ wt \% water, which was held in small brine cavities within crystals and on crystal boundaries. ${ }^{34}$ It was expected that some of the water would be lost during the HFIR-gamma irradiations due to the thermalgradient-induced migration of brine cavities and/or the expulsion of brine or steam along crystal boundaries. Table 12 provides information on the specimens and shows the results of weight measurements. The surfaces of the irradiated specimens were examined for deposits which would result from evaporation of brine at a surface, and none were detected.

Pertinent information concerning the sample identification symbols and exposure conditions for the tests on Lyons salt is given in refs. 1 and 36. The B sample was located at the centerline of the HFIR spent fuel element. The $B_{m}$ and $B_{u}$ samples were located at 2-3/4 and 6 in., respectively, above the centerline. All specimens were in contact with aluminum conductors on two opposite faces. The other sides were in contact with thick layers of gas (helium) and, thus, were effectively insulated. Accordingly, the highest temperature was at the midplane of the specimen.

The listed values for migration distance are those values calculated using Fig. 6.4 of ref. 34 and apply to brine-filled cavities within a crystal. These values move up a temperature gradient. Cavities having both a gas and a liquid phase would move down a temperature gradient, and the rate of movement would exceed that of brine-filled cavities. ${ }^{34}$

The results indicated that a significant fraction of the original water was lost from the Lyons specimens during HFIR-gamma irradiation. The insignificant loss of weight observed for the Harshaw specimen supported the assumption that the weight loss of the Lyons specimens 
Table 12. Change in specimen weight during radiation exposure with exposure conditions, calculated brine migration distances, and observed weight changes

\begin{tabular}{|c|c|c|c|c|c|c|}
\hline $\begin{array}{l}\text { Sample } \\
\text { identification }\end{array}$ & $\begin{array}{c}\text { Average dose } \\
\text { rate } \\
\left(10^{7} \text { rads } / \mathrm{hr}\right)\end{array}$ & $\begin{array}{c}\text { Average temp } \\
\left({ }^{\circ} \mathrm{C}\right)\end{array}$ & $\begin{array}{c}\text { Average } \\
\text { temp gradient } \\
\left({ }^{\circ} \mathrm{C} / \mathrm{cm}\right)\end{array}$ & $\begin{array}{l}\text { Calculated } \\
\text { migration } \\
\text { distance } \\
(\mathrm{cm})\end{array}$ & $\begin{array}{r}\text { Obs } \\
\text { weigh } \\
(\mathrm{mg})\end{array}$ & $\frac{g e}{(\%)}$ \\
\hline$\gamma-2-5 ; L_{2}-B_{m}$ & 6.0 & 160 & 3.4 & 0.21 & -6.1 & 0.16 \\
\hline$\gamma-2-6 ; L-B_{u}$ & 3.4 & 160 & 3.8 & 0.24 & -22.4 & 0.22 \\
\hline$\gamma-3-7 ; L-B_{u}$ & 3.7 & 173 & 4.1 & 0.32 & -17.2 & 0.15 \\
\hline$\gamma-3-3,4 ; H-B$ & 6.6 & 173 & 3.7 & 0.29 & -0.6 & 0.01 \\
\hline
\end{tabular}

$a_{L}$ and $L_{2}$ indicate Lyons salt. $H$ indicates Harshaw salt. See refs. 1 and 36 for full description of specimens and irradiation conditions. 
resulted from water loss; the Harshaw salt had no brine inclusions. The absence of deposits on the surfaces of the irradiated Lyons specimens and the possibility that brine migration distances were less than sample thicknesses indicate that the water was lost as vapor, which diffused out along crystal boundaries. 


\subsection{Appendix IX: Gases in Unirradiated and} Irradiated Specimens of Bedded Salt $t^{36}$

A mixture of gases and water were extracted from several samples of Lyons bedded salt, and quantitative analyses were made of the molecular constituents in the off-gas (Table 13). These data were obtained using a crystal-crusher device that was attached to a mass spectrometer through a gas handling system.* The sample was placed within the metal crystal crusher, outgassed at about $100^{\circ} \mathrm{C}$, and then crushed by hammering on the crystal through a metal rod which was bellows-sealed into the crusher. The released water was trapped at liquid nitrogen temperature and was subsequently weighed. The gases were analyzed in the mass spectrometer making use of a known amount of an Ne tracer, which was mixed with the gases within the gas handling system. Most of the salt particles were less than $0.5 \mathrm{~mm}$ after crushing. A few larger particles had dimensions ranging up to a maximum of $\sim 2.8 \mathrm{~mm}$.

The PSV-2 sample consisted of salt that had been irradiated in Project Salt Vault. ${ }^{1}$ The maximum temperature attained in the specimen was estimated to be 150 to $155^{\circ} \mathrm{C}$. Brine migration took place both during and following irradiation exposure. The migration following irradiation occurred because the salt remained at high temperature for an appreciable period after electrical and radiation heating was terminated. Cooling of the brine cavities must have produced gas-vapor phases, and the resulting two-phase droplets very likely migrated rapidly down a temperature gradient toward the edge of the hole for several days during which air was passed through the hole. ${ }^{1}$

The $\gamma-2-5 ; L_{2}-B_{m}$ specimen was described previously. ${ }^{1},{ }^{\dagger}$ Brine droplet migration in this sample took place only during irradiation. The unirradiated specimen, $L$, was a sample of the Lyons salt used in the irradiation experiments.

*Analytical work performed by J. R. Walton of the ORNL Analytical Chemistry Division.

${ }^{\dagger}$ See Appendix VIII. 
Table 13. Gases in irradiated and unirradiated samples of Lyons salt with calculated values of $\mathrm{G}-\mathrm{H}_{2}$

\begin{tabular}{|c|c|c|c|c|c|c|c|}
\hline \multirow[b]{2}{*}{ Salt sample ${ }^{a}$} & \multirow[b]{2}{*}{$\begin{array}{l}\text { Weight } \\
(g)\end{array}$} & \multirow[b]{2}{*}{$\begin{array}{l}\text { Gamma dose } \\
\text { (rads) }\end{array}$} & \multirow{2}{*}{ (No. molecules/100 eV) } & \multicolumn{4}{|c|}{ Quantity of gas } \\
\hline & & & & $\begin{array}{l}\mathrm{H}_{2} \mathrm{O} \\
(\mathrm{mg})\end{array}$ & $\begin{array}{c}\mathrm{H}_{2} \\
\left(\mathrm{~cm}^{3}\right)\end{array}$ & $\begin{array}{c}\mathrm{N}_{2}+\mathrm{CO} \\
\left(\mathrm{cm}^{3}\right)\end{array}$ & $\begin{array}{l}0_{2} \\
\left(\mathrm{~cm}^{3}\right)\end{array}$ \\
\hline PSV-2 & 2.403 & $5 \times 10^{8}$ & 0.26 & 0.8 & $2.19 \times 10^{-3}$ & $4.53 \times 10^{-4}$ & $1.71 \times 10^{-4}$ \\
\hline$\gamma-2-5 ; L_{2}-B_{m}$ & 2.524 & $1.3 \times 10^{10}$ & 0.016 & 2.0 & $9.9 \times 10^{-3}$ & $2.02 \times 10^{-4}$ & $2.17 \times 10^{-3}$ \\
\hline$L$ & 2.224 & 0 & 0 & 0.8 & 0 & $8.9 \times 10^{-5}$ & $1.3 \times 10^{-5}$ \\
\hline
\end{tabular}

$a_{\mathrm{L}}$ and $\mathrm{L}_{2}$ indicate Lyons salt. PSV indicates salt irradiated in Project Salt Vault. See Refs. 1 and 36 for full description of specimens and irradiation conditions. 
The amount of $\mathrm{H}_{2}$ found with the PSV-2 and $\gamma-2-5$ specimens corresponds to 0.13 and $0.22 \mathrm{M}$, respectively, within the brine that remained in the salt. The low value of $\mathrm{G}-\mathrm{H}_{2}$ for $\gamma-2-5$ clearly indicated that the amount of $\mathrm{H}_{2}$ in this sample was near a limiting value. A previously reported analysis ${ }^{34}$ based on known radiation chemistry led to the prediction that the steady-state amount of $\mathrm{H}_{2}$ would exceed $0.05 \mathrm{M}$, but the actual value could not be predicted because of the lack of information on rate constants for pertinent reactions at elevated temperatures. The available experimental values indicate that the estimates were approximately correct.

The ratio of $\mathrm{O}_{2}$ to $\mathrm{H}_{2}$ in specimen $\gamma-2-5$ was somewhat less than 0.5 , and this indicated that other oxidized species such as $\mathrm{ClO}_{3}{ }^{-}$were radiolysis products. In specimen PSV-2, the ratio of $\mathrm{O}_{2}$ to $\mathrm{H}_{2}$ was very much less than 0.5. This behavior may have been associated with the migration of brine after termination of irradiation and the concomitant dissolution of irradiated salt within brine droplets. As described elsewhere, ${ }^{2}$ dissolution of irradiated salt, subsequent to irradiation, produces $\mathrm{H}_{2}$ but very little $\mathrm{O}_{2}$. Presumably, $\mathrm{H}_{2} \mathrm{O}_{2}$ and/or $\mathrm{ClO}_{3}{ }^{-}$are the oxidized species that balance the $\mathrm{H}_{2}$.

The amounts of air, indicated by the amounts of $\mathrm{N}_{2}+\mathrm{CO}$, exceed those present in the gas bubbles within the brine cavities. ${ }^{37}$ Accordingly, most of the air must have been trapped on crystal boundaries. 
14.10. Appendix X: Procedure for Estimating Mechanical Energy Released Upon The Abrupt Release of Stored Energy in Salt

The symbols used in this appendix are explained in the following table:

Symbol

E

d

W

C

T

P

$\Delta V / V$

$\alpha$

K

V

$p^{\prime}$

$\Delta V^{\prime} / \mathrm{V}$

$\beta$
Definition and unit

Stored energy, cal/g

Density, $\mathrm{g} / \mathrm{cm}^{3}$

Weight of sample, $g$

Heat capacity, $c a 1 / g-{ }^{\circ} \mathrm{C}$

Temperature, ${ }^{\circ} \mathrm{C}$

Overburden pressure on

salt, atm

Equals $\alpha \Delta T$

Coefficient cubical

thermal expansion, ${ }^{\circ} \mathrm{C}^{-1}$

Converts atm- $\mathrm{cm}^{3}$ to cal, $\mathrm{cal} / \mathrm{atm}-\mathrm{cm}^{3}$

Volume, $\mathrm{cm}^{3}$

Average pressure required to prevent expansion of salt by amount, $\mathrm{P}^{\prime}=\mathrm{V}^{\prime} / 2 V^{\prime} \mathrm{B}$

Thermal expansion of salt that would occur without pressure restraint and is numerically equal to $\alpha \Delta T$

Compressibility, $\mathrm{atm}^{-1}$
2.15

136

0.0242

Assumed value

0.22

$1.2 \times 10^{-4}$

Case 1

Case 2 
14.10.1. General Procedure It is assumed that all stored energy is dissipated in raising the temperature of the salt which contains the stored energy and in doing pressure-volume work. In Case 1 , the thermal expansion of the salt takes place against the overburden pressure on the salt. In Case 2, the temperature rise caused by the release of stored energy is so rapid that the surrounding salt does not move; accordingly, the temperature rise produces a local increase in pressure the amount of which can be calculated from the compressibility of the salt and the thermal expansion that would occur without any overpressure.

The estimated amounts of mechanical energy released from the waste package and salt are then compared to the heat of detonation of TNT. For heavily confined charges of TNT, the reported heat of detonation is $4.9 \times 10^{5} \mathrm{cal} / 1 \mathrm{~b} .^{38}$

14.10.2. Case 1 For this case, the energy relationship per cubic centimeter of salt is:

$$
E d=C \Delta T d+\frac{P \Delta V}{V} K \text {, }
$$

but

$$
\Delta T=\frac{\Delta V}{V a}
$$

Substituting Eq. (2) in Eq. (1) and rearranging:

$$
E d=\frac{C d}{\alpha} \frac{\Delta V}{V}+\frac{P \Delta V}{V} K \text {. }
$$

Solving for $\frac{P \Delta V}{V} K$,

$$
\frac{P \Delta V}{V} K=\frac{E d}{\frac{C d}{P Q K}+1}
$$


Introducing values for $\frac{C d}{P \alpha K}$,

$$
\frac{C d}{P \alpha K}=\frac{(0.22)(2.15)}{(136)\left(1.2 \times 10^{-4}\right)\left(2.42 \times 10^{-2}\right)}=1.2 \times 10^{3} .
$$

We have,

$$
\frac{P \Delta V}{V} K=8.3 \times 10^{-4} \mathrm{Ed}, \frac{\mathrm{Cal}}{\mathrm{cm}^{3}}
$$

that is, $0.083 \%$ of the energy released is converted to mechanical work.

14.10.3 Case 2 The energy relationship in this case is analogous to that for Case 1,

$$
E d=C \Delta T d+\frac{P^{\prime} \Delta V^{\prime} K}{V} \text {. }
$$

Solving Eq. (6) for $\frac{P^{\prime} \Delta V^{\prime} K}{V}$,

$$
\frac{P^{\prime} \Delta V^{\prime} K}{V}=\frac{E d}{\frac{C d}{\alpha P^{\prime} K}+1}
$$

To solve for the value of $\mathrm{P}^{\prime}$ in Eq. (7), first let

$$
\Delta T \cong \frac{E}{C} \text {. }
$$

(It can be shown that this approximation is valid within $5 \%$ at $E=60$ $\mathrm{cal} / \mathrm{g}$ and $<5 \%$ at smaller values of $E$.)

Since

$$
P^{\prime}=\frac{1}{2} \frac{\Delta V^{\prime}}{V \beta}
$$


and

$$
\frac{\Delta V^{\prime}}{V}=\alpha \Delta T \cong \frac{\alpha E}{C}
$$

then

$$
P^{\prime} \cong \frac{1}{2} \frac{\alpha E}{C \beta}
$$

Substituting Eq. (11) in Eq. (7) yields Eq. (12):

$$
p^{\prime} \frac{\Delta V^{\prime}}{V} K=\frac{E d}{\frac{2 C^{2} d \beta}{\alpha^{2} K E}+1} .
$$

Now, evaluating

$$
\frac{2 C^{2} d B}{\alpha^{2} K E}=\frac{(2)(0.22)^{2}(2.15)\left(4 \times 10^{-6}\right)}{\left(1.2 \times 10^{-4}\right)^{2}(0.0242) E}=2.38 \times 10^{3} / E \text {, }
$$

and substituting Eq. (13) in Eq. (12) and rearranging we have:

$$
\frac{P^{\prime} \frac{\Delta V^{\prime}}{V} K}{E d}=4.19 \times 10^{-4} \mathrm{E} .
$$

The term on the left side of Eq. (14) represents the fractional amount of the stored energy release that is converted to mechanical work. Equation (14) shows that the value of this fraction depends upon the value of $E$. If $E$ equals $60 \mathrm{cal} / \mathrm{g}$, then $2.5 \%$ of the released energy appears as mechanical energy. If $E$ equals $10 \mathrm{cal} / \mathrm{g}$, then $0.4 \%$ appears as mechanical energy, approximately 5 times that found for Case 1 for all values of $E$. 


\section{REFERENCES}

1. G. H. Jenks and C. D. Bopp, Storage and Release of Radiation Energy in Salt in Radioactive Waste Repositories, ORNL/TM-4449 (January 1974).

2. G. H. Jenks, E. Sonder, C. D. Bopp, J. R. Walton, and S. Lindenbaum, "Reaction Products and Stored Energy Released from Irradiated $\mathrm{NaCl}$ by Dissolution and by Heating," J. Phys. Chem. 79 , 871 (1975).

3. T. F. Lomenick, personal communication, July 1974.

4. E. Sonder and W. A. Sibley, "Defect Creation by Radiation in Polar Crystals," pp. 201-290 in Point Defects in Solids, ed. by J. H. Crawford and A. Slifkin, Plenum Press, London, 1971.

5. C. D. Clark and J. H. Crawford, "The Interaction of Colour Centres and Dislocations," Adv. Phys. 22, 117-205 (1973).

6. L. W. Hobbs, A. E. Hughes, and D. Pooley, "A Study of Interstitial Clusters in Irradiated Alkali Halides Using Direct Electron Microscopy," Proc. R. Soc. London, Ser. A 332, 167-85 (1973).

7. S. V. Pappu and K. A. McCarthy, "On the Colloidal Centers in Irradiated Sodium Chloride Crystals," J. Phys. Chem. Solids 32, 1287 (1971).

8. W. G. Burns and T. F. Williams, "Chemical Effects Associated with 'Colour Centres' in Alkali Halides," Nature 175, 1043 (1955).

9. K. Przibram and J. E. Caffyn, Irradiation Colours and Luminescence, pp. 148-52, Pergamon, London, 1956.

10. E. Sonder and S. Lindenbaum, "Stored Energy in Irradiated $\mathrm{NaCl}, "$ p. 17 in Solid State Div. Annu. Prog. Rep. for Period Ending Dec. 31, 1971, ORNL-4779 (April 1972).

11. E. Sonder, personal communication, June 1975.

12. J. 0. Blomeke et al., An Analysis of Energy Storage and Its Effects in the Proposed National Radioactive Waste Repository, ORNL/TM-3404 (June 1971).

13. H. Kubota, Waste Treatment and Disposal Q. Prog. Rep., Feb. through Apr. 1963, ORNL/TM-603 (December 1963), p. 91. 
14. L. M. Epstein, Formation of Chemically Free Halogen by Radiolysis of Solid Potassium Chloride, WERL-0100 (June 1962).

15. A. B. Scott, W. A. Smith and M. A. Thompson, "Alkali Halides Colored by Colloidal Metal," J. Phys. Chem. 57, 756 (1953).

16. Frederick Seitz, "Color Centers in Alkali Halide Crystals, II," Rev. Mod. Phys. 26, 7-94 (1954).

17. F. Augu110-Lopez and P. W. Levy, "Effects of Gamma-ray Irradiation on the Mechanical Properties of $\mathrm{NaCl}$ Single Crystals," Proc. Br. Ceram. Soc., Point Defects, No. 1 (July 1964).

18. Hermann Borchert and R. 0. Muir, pp. 237-80 in Salt Deposits, the Origin, Metamorphism and Deformation of Evaporites, Van Nostrand, 1964.

19. B. D. Gunther and F. L. Parker, The Physical Properties of Rock Salt as Influenced by Gamma Rays, ORNL-3027 (March 1961).

20. T. G. Godfrey and S. H. Jury, "Rock Property Measurements," p. 45 in Geologic Disposal Evaluation Program, Semiannu. Rep. for Period Ending Mar. 31, 1975, ORNL-5052 (JuTy 1975).

21. A. S. Nowick, "Effect of Plastic Deformation on the $\gamma$-Ray Coloration of NaCl Crysta1s," Phys. Rev. 111, 16 (1958).

22. G. Dreschhoff and E. J. Zeller, Determination of Energy Storage in Irradiated Salt and Synthetic Waste Products, prepared by University of Kansas Center for Research, Inc., for Union Carbide Corporation, Nuclear Division, Oak Ridge National Laboratory, ORNL/SUB-3484/5 (July 1, 1973).

23. D. J. Elliott and P. D. Townsend, "Defect Formation and Sputtering of Alkali Halides with Low Energy Irradiation," Phil. Mag. 23, 249 (1971).

24. H. Tokutaka, M. Prutton, et al., "The (100) Surfaces of Alkali Halides II," Surf. Sci. 21, 233 (1970).

25. R. I. Didyk, Yu. V. Karavan, Z. V. Stasyuk, and N. A. Tsal', "MassSpectrometric Investigation of the Radiolysis of $\mathrm{NaCl}$ Crystals," Sov. Phys.-Solid State 12, 2951 (1971).

26. R. N. Compton et al., Health Physics Div. Annu. Prog. Rep. for Period Ending July 31, 1972, ORNL-4811 (September 1972), p. 33. 
27. F. W. Roberts, G. H. Jenks, and C. D. Bopp, Radiation Effects in Solidified High-Level Wastes. Part I, Stored Energy, BNWL-1944 (January 1976).

28. R. D. Cheverton and W. D. Turner, Thermal Analysis of the National Radioactive Waste Repository: Progress Through March 1972, ORNL-4789 (September 1972).

29. R. D. Cheverton, ORNL, personal communication, November 1973.

30. J. 0. Blomeke, C. W. Kee, and J. P. Nichols, Projections of Radioactive Wastes to Be Generated by the U.S. Nuclear Power Industry, ORNL/TM-3964 (February 1974).

31. J. 0. Blomeke and C. W. Kee, "Projections of Wastes to Be Generated," pp. 96-117 in Proceedings of the International Symposium on the Management of Wastes from the LWR Fue1 Cycle, CONF-76-0701, October 1976.

32. A. P. Hoskins and J. R. Berreth, Heat Transfer Considerations in the Canister Storage of High-Level Solidified Wastes, ICP-1090 (Apri1 1976).

33. J. 0. Blomeke, personal communication, June 1976.

34. G. H. Jenks, Radiolysis and Hydrolysis in Salt-Mine Brines, ORNL/TM-3717 (March 1972).

35. H. C. Claiborne, personal communication, July 1974.

36. C. D. Scott et al., Chemical Development Section B Semiannual Prog.

Rep. March 1, 1973 to August 31, 1973, Part 1, ORNL/TM-4370

(February 1974), pp. 339-344.

37. A. L. Boch et a7., Radioactive Waste Repository Project: Prog. Rep. for Period Ending Sept. 30, 1972, ORNL-4824 (December 1972), pp. 216-18.

38. Donald L. Ornellas, The Heat and Products of Detonation of Cyclotetramethylene Tetranitramine (HMX), 2,4,6-Trinitrotoluene (TNT), Nitromethane (NM), and Bis-Formal (FEFO), UCRL-7074 preprint, CONF-670904-4 (May 22, 1967). 
$\vartheta$

$\theta$

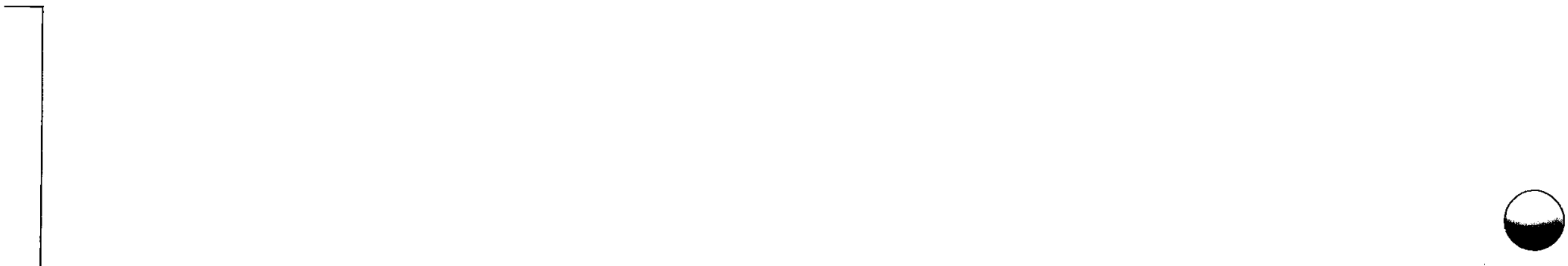


ORNL-5058

Distribution Category UC-70

INTERNAL DISTRIBUTION

1. C. F. Baes

2. J. 0. Blomeke

3. A. L. Boch

4. C. D. Bopp

5. R. E. Brooksbank

6. W. D. Burch

7. H. C. Claiborne

8. F. L. Culler, Jr.

9. L. R. Dole

10. D. E. Ferguson

11. E. L. Gaden, Jr. (consultant)

12. R. W. Glass

13. W. A. Goldsmith

14. R. F. Hibbs

15. J. R. Hightower

16. C. H. Ice (consultant)

17-46. G. H. Jenks

47. R. E. Leuze

48. T. F. Lomenick

49. R. S. Lowrie

50. A. P. Mal inauskas

51. L. L. McCauley
52. W. C. McClain

53. L. E. McNeese

54. J. M. Morrison

55. E. Newman

56. H. Postma

57. A. S. Quist

58. R. B. Richards (consultant)

59. H. N. Rosenberg

60. J. E. Russell

61. C. D. Scott

62. E. Sonder

63. I. L. Thomas

64. D. B. Trauger

65. R. F. Walters (consultant)

66. R. G. Wymer

67. C. D. Zerby

68. $Y-12$ Records

69-128. OWI Records

129-130. Central Research Library

131. Document Reference Section

132. ORNL Patent Section

133-134. Laboratory Records Department

135. Laboratory Records - ORNL R.C.

EXTERNAL DISTRIBUTION

ARGONNE NATIONAL LABORATORY, 9700 South Cass Avenue, Argonne, IL 60439

136. A. M. Friedman

137. L. J. Jardine

ASSOCIATED UNIVERSITIES, INC., Brookhaven National Laboratory, Upton, NY 11973

138. M. B7ume

139. P. W. Levy

BATTELLE PACIFIC NORTHWEST LABORATORIES, P.O. Box 999, Richland, WA 99352

140. J. E. Mende]

141. R. J. Serne 
CORNELL UNIVERSITY, Department of Physics, Clark Ha11, Ithaca, NY 14835

142. R. 0. Poht

GEOLOGIC SOCIETY OF AMERICA, INC., 3300 Penrose Place, Boulder, CO 80301

143. Dr. John C. Frye, Executive Director

OAK RIDGE ASSOCIATED UNIVERSITIES, Institute for Energy Analysis, P.0. Box 117, Oak Ridge, TN 37830

144. A. M. Weinberg

PARSONS BRINCKERHOFF QUADE \& DOUGLAS, INC., One Penn Plaza, 250 west 34 th Street, New York, NY 10001

145. Thomas Hoover

PENNSYLVANIA STATE UNIVERSITY, Materials Research Laboratory, University Park, PA 16802

146. J. V. Biggers

147. D. M. Roy

RE/SPEC Inc., P.0. Box 725, Rapid City, SD 57701

148. P. F. Gnirk

SANDIA LABORATORIES, P.0. Box 5800, ATbuquerque, NM 87115

149. L. R. Hill

150. R. C. Lincoln

151. A. R. Sattler

152. W. D. Weart

STANFORD UNIVERSITY, Department of Geology, Stanford, CA 94305

153. Konrad B. Krauskopf

TRW, One Space Park, Building R-4/1098, Redondo Beach, CA 90278

154. Linda Friedman

UNITED STATES GEOLOGICAL SURVEY, National Center, Mai1 Stop 959, Reston, VA 22092

155. D. B. Stewart

UNIVERSITY OF ARIZONA, Department of Hydrology and Water Resources, Tucson, AZ 85721

156. Stanley N. Davis 
UNIVERSITY OF CALIFORNIA, Lawrence Livermore Laboratory, P.0. Box 808, Livermore, CA 94550

157. H. C. Heard

UNIVERSITY OF CALIFORNIA, Los Alamos Scientific Laboratory, P.0. Box 1663, Los Alamos, NM 87545

158. K. E. Apt

UNIVERSITY OF ILLINOIS, Department of Geology, 254 Natural History Building, Urbana-Champaign, IL 61801

159. Fred A. Donath

UNIVERSITY OF KANSAS, Department of Geology, Lawrence, KS 66045

160. S. Lindenbaum

UNIVERSITY OF NEW MEXICO, College of Engineering, Bureau of Engineering Research, Albuquerque, NM 87101

161. D. G. Brookins

UNIVERSITY OF NORTH CAROLINA AT CHAPEL HILL, Department of Physics, Chapel Hill, NC 27514

162. James H. Crawford

UNIVERSITY OF PITTSBURGH, Pittsburgh, PA 15260

163. B. L. Cohen

UNIVERSITY OF TEXAS AT AUSTIN, College of Engineering, Austin, TX 78712

164. Earnest F. Gloyna

ERDA, Division of Waste Management, Oak Ridge Operations, P.0. Box E, Oak Ridge, TN 37830

165-194. J. J. Schreiber

ERDA, Research and Technical Support Division, Oak Ridge Operations, P.0. Box E, Oak Ridge, TN 37830

195-198. J. A. Lenhard

CNEN-CSN CASACCIA, Laboratorio Rifitui Radioattivi, c.p. 2400, 00100 Rome, Italy

199. Willy Bocola 


\author{
OECD-NEA, 38, Boulevard Suchet, 75016, Paris, France \\ 200. Ferruccio Gera \\ 201-482. For distribution as shown in TID-4500 Distribution Category \\ UC-70 - Nuclear Waste Management
}

